\title{
FINAL REPORT: TEST PROGRAM TO DETERMINE THE FEASIBILITY OF PRODUCING METHANE FROM UNMINABLE COALBEDS
}

By

Intercomp Resource Development and Engineering, Inc. Houston, Texas

April 1979

Work Performed Under Contract No. AC21-78MC08352

For

U. S. Department of Energy

Office of Fossil Energy

Morgantown Energy Technology Center

Morgantown, West Virginia

TECHNICAL INFORMATION CENTER OFFICE OF SCIENTIFIC AND TECHNICAL INFORMATION UNITED STATES DEPARTMENT OF ENERGY 


\section{DISCLAIMER}

This report was prepared as an account of work sponsored by an agency of the United States Government. Neither the United States Government nor any agency Thereof, nor any of their employees, makes any warranty, express or implied, or assumes any legal liability or responsibility for the accuracy, completeness, or usefulness of any information, apparatus, product, or process disclosed, or represents that its use would not infringe privately owned rights. Reference herein to any specific commercial product, process, or service by trade name, trademark, manufacturer, or otherwise does not necessarily constitute or imply its endorsement, recommendation, or favoring by the United States Government or any agency thereof. The views and opinions of authors expressed herein do not necessarily state or reflect those of the United States Government or any agency thereof. 


\section{DISCLAIMER}

Portions of this document may be illegible in electronic image products. Images are produced from the best available original document. 


\title{
DISCLAIMER
}

\begin{abstract}
This report was prepared as an account of work sponsored by an agency of the United States Government. Neither the United States Government nor any agency thereof, nor any of their employees, makes any warranty, express or implied, or assumes any legal liability or responsibility for the accuracy, completeness, or usefulness of any information, apparatus, product, or process disclosed, or represents that its use would not infringe privately owned rights. Reference herein to any specific commercial product, process, or service by trade name, trademark, manufacturer, or otherwise does not necessarily constitute or imply its endorsement, recommendation, or favoring by the United States Government or any agency thereof. The views and opinions of authors expressed herein do not nccessarily state or reflect those of the United States Government or any agency thereof.
\end{abstract}

This report has been reproduced directly from the best available copy.

Available from the National Technical Information Service, U. S. Department of Commerce, Springfield, Virginia 22161.

Price: Printed Copy A09

Microfiche A01

Codes are used for pricing all publications. The code is determined by the number of pages in the publication. Information pertaining to the pricing codes can be found in the current issues of the following publications, which are generally available in most libraries: Energy Research Abstracts (ERA); Government Reports Announcements and Index (GRA and I); Scientific and Technical Abstract Reports (STAR); and publication NTIS-PR-360 available from NTIS at the above address. 


\title{
FINAL REPORT: TEST PROGRAM TO DETERMINE THE FEASIBILITY OF PRODUCING METHANE FROM UNMINABLE COALBEDS
}

\author{
By \\ Intercomp Resource Development and Engineering, Inc. \\ 1201 Dairy Ashford, Suite 200 \\ Houston, Texas 77079
}

April 1979

Work Performed Under Contract No.: EW-78-C-21-8352

\author{
For \\ U. S. Department of Energy \\ Office of Fossil Energy \\ Morgantown Energy Technology Center \\ P. O. Bux 880 \\ Morgantown, West Virginia 26505
}




\section{THIS PAGE}

WAS INTENTIONALLY

LEFT BLANK 


\section{EXECUTIVE SUMMARY}

A simulation model was used to develop a comprehensive test program to characterize the potential of methane production from "unminable" coalbeds in the United States. The study identified the parameters that are most important to the production of methane from coal; these independent variables are:
1. Coalbed Thickness,
2. Coalbed Permeability,
3. Initial pressure,
4. Initial Gas content,
5. Relative Permeability,
6. Hydraulic Fracture Length, and
7. Hydraulic Fracture Conductivity.

The range of values over which each independent variable may vary was estimated together with the frequency distribution within the range. A sensitivity study was made which varied the independent variables over their ranges and calculated a characterization parameter, $\phi$. The definition of $\phi$ is the cumulative discounted gas production for ten years at a discount rate of $15 \%$ per year.

Next, the methods of measurement and sequence of tests were established together with costs of the various tests. These were then connected sequentially into test modules. Each test module has an array of the independent variables which are determined and an associated measurement error.

A regression equation was then calculated for each module which quantified the ability of that module to predict the production characterization parameter, $\phi$. The module which included 
determination of all the independent variables was, of course, the best predictor of $\phi$. By calculating the standard deviation of the distribution of $\phi$ as a function of number of observations for each module the rate of change of standard deviation with increased observation, i.e. dollars expended, was plotted. The. result is that at least twenty-five observations of the most precise module was necessary to adequately describe the distribution of the production characterization parameter, $\phi$.

Further, since the distributions and ranges of the independent variables were estimated, an additional number of tests is necessary to independently describe these distributions. Finally, since none of the measurements are perfect, additional independent measurements are necessary to quantify the measurem ment error. Since these requirements are about the individual variables themselves and not the gas deliverability itself, a less expensive survey type test module will suffice for these measurements. These require a total of sixty survey type test modules with specific spatial considerations as to location of those sixty modules.

This program defines the tests that need to be made. These tests need not be new tests. If data exists from previous testing either by government or the private sectur, which fulfills the requirements of a test, that test need not be run. While it is thought that not a great deal of tests can be eliminated in this manner, information has been requested that wili better define this for the final test program.

These tests will require a total budget of between $\$ 2.7$ and $\$ 4.3$ million depending on the support that can be obtained from private industry. The difference in the two budget figures is basically the cost of drilling new wells for the production tests and finding existing wells that could be used but were drilled for other purposes. 
Since limited funds are available for testing in 1978, the most prudent tèsting program is to run fifteen survey type modules and one complete production test. Twelve of these survey modules are to be taken in areas where there is essentially no data. Three are oriented to validate the testing procedure and quantify the measurement errors. The production test will validate the test procedure and give opportunity for modification before setting out to do twenty-five such tests. Costs of this limited program are estimated to be between $\$ 300,000$ and $\$ 400,000$. 


\section{ACKNOWLEDGEMENT}

INTERCOMP wishes to thank Mr. Michael smith and william Redmond of Resource Analysts for the statistical analysis contained in this report. 
II. CONCEPTUAL MODEL AND MATHEMATICAL SIMULATION

A. Conceptual Model

B. Mathematical simulation

C. Simulator output and

Characterization

III. DETERMINATION OF IMPORTANT PARAMETERS

AND THEIR SENSITIVITY

A. Determination of Independent

Variables

B. Discussion of Independent Variables

1. Gas content

2. Initial Pressure

3. Permeability

4. Relative Permeability

5. Fracture Length

6. Fracture Conductivity

C. Sensitivity Analysis

1. Assumptions

2. Sampling the Independent Variables

IV. DEVELOPMENT OF TESTING AND TEST MODULES

A. Possible Tests and Measurements 21

B. Testing Philosophy 
IV. DEVELOPMENT OF TESTING AND TEST MODULES - Continued

C. Test Modules 24

1. Module I-I 24

2. Module II-1 26

3. Module II-2 28

4. Module $I I=3 \quad 28$

5. Module III-1 . - 29

6. Module III-2 30

7. Module III-3 30

8. Module III-4 30

9. Module IV-1 30

10. Module V-I 30

V. MATHEMATICAL REPRESENTATION OF
SIMULATION RFITITS

A. Distribution of Independent
Variables

B. Potential Sources of Uncertainty 36

C. Regression Equation Development 38

D. Data Source and Treatment. 39

1. Source 39

2. Data Treatment 39

3. Other Data Treatment 41

E. Determination of Regression. 41

F. Measurement Error Simulation 47

G. Test Program Simulation 50 
VI. TEST PROGRAM DEVELOPMENT · 53

A. Priorities . 53

B. Testing Options. 53

1. Survey of Resource Base 54

2. Range and Distribution of Independent Variables Quality and Quantity Considerations

3. Assessment of Measurement Errors

4. Validation of the Simulation 55

C. Recommended Test Program 56

D. Estimated Costs $\quad .58$

E. 1978 Test Program 59

1. Specific Program 59

2. Costs 60

3. Flexible Budgeting 60

REFERENCES 61

FIGURES

APPENDIX 81 
Page

INTRODUCTION

94

CLASSIFICATION OF DEEP GASSY COAL AREAS

96

MAJOR COAL AREAS

1. Northern Appalachians

2. Middle Appalachians

3. Luwer Apualdclitalis and for Warrior Baoin 1 ?

4. Illinois Basin

106

5. Arkoma Basin I09

6. Raton Basin 112

7. San Juan Basin 113

8. Uinta Basin and Wasatch Plateau 114

9. Uinta-Piceance Basin 117

10. Green River--Sand Wash … . . 119

11. Green River-Washakie, Great Divide and 121 Rock Springs

12. Hanna Basin and Rock Creek Field 123

13. Wind River Basin 124

14. Jackson Hole Coal Field 125

15. Powder River Basin $\quad \therefore \quad 127$

16. Big llorn Basin 128

17. Black Mesa 129

18. Nuclu-Naurita 130

19. North Park and South Park 131

20. Henry Mountains . . . . 132

21. Kaiparowits Basin 133

22. Bellingham, Cokedale--Hamiltion $\cdots$

23. Additional Areas . . . . 135

SITE IDENTIFICATION 136 
TABLE OF CONTENTS, continued

\section{Page}

FIGURES

139

$\therefore 4 . \because \ldots . \div$ 
$\underline{\text { Page }}$

I. INTRODUCTION 150

II. TEST SITE ANALYSIS 151

A. Test site A - Sublette

county, wyoming 151

1. Location and Geology . 151

2. Tests and Resulto 13i

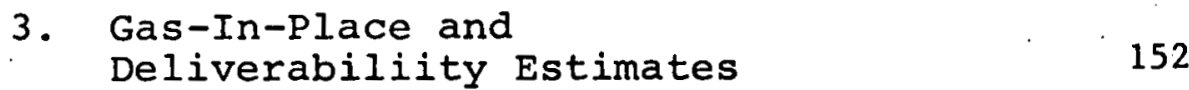

4. Comments 152

$\begin{array}{ll}\text { B. Test Site B - Confidential } & 153 \\ \text { Location } & \end{array}$

1. Location 153

2. Tests Run and Results 153

3. Gas-In-Place and
Deliverability

4. Comments 155

$\begin{array}{ll}\text { C. Test site C - Pittsburg county, } & 155 \\ \text { oklahoma } & \end{array}$

1. Location and Geology 156

2. Tests and Results 156

3. Gas-In-Place and
Deliverability Estimates

4. Comments 157

ע. Test site D - R1u Blancu Cunily, 157

1. Site Location and Geology 158

2. Tests Run and Results 158

$\begin{array}{ll}\text { 3. Gas-In-Place and } & 158 \\ \text { Deliverability Estimates } & \end{array}$

4. Comments 159 
TABLE OF CONTENTS - Continued

Page

II. TEST SITE ANALYSIS - Continued

E. Test site E - Clay county, Illinois

1. Location and Geology

159

2. Tests and Results

159

3. Gas-In-Place and

Deliverability Estimates

160

4. Comments

160

F. Data From Other Locations

161

III. TEST PROCEDURES

A. Gas content Tests

162

B. Drill-Stem Tests

163

c. Other Tests

163

IV. PARAMETER DISTRIBUTIONS

164

A. Gas content

164

B. Pressure

164

c. Permeability

165

D. Other Parameters

165

V. CONCLUSIONS AND RECOMMENDATIONS

166

TABLES

167

FIGURES

173 
I. INTRODUCTION

This report presents the results of a study to develop an engineering program to test, evaluate, and characterize coal as a potential source of methane gas production. The impetus of this study is to utilize known. technologies in developing a testing procedure to obtain a significant data base of the parameters quantifying the potential methane gas production from coalbeds located throughout the United States. The eventual benefit derived from this study is the characterization of the vast and varied coal deposits as to productive potential, and coupling this characterization with econonmic considerations which will provide viable assessment in the feasible exploitation of this resource.

The technical aspects and testing designs will be dealt with in detail in separate sections of this report, but an effort to present a perspective overview of the engineering approach will be discussed in the following paragraphs.

Historically, methane gas production from coal has focused on the removal of this highly dangerous explosive gas from seams being mined for the coal. With today's demand and price of gas, production of this methane gas from coal has become an attractive prospect in the search for future energy needs. Based on current knowledge and sophisticated engineering technologies, previous investigations conclude that trillions of cubic feet of gas can be recovered at today's gas prices. This assessment of feasible gas production is encouraging, but verification and definition remain to be factualized through field development and production of this resource.

Since actual production data is essentially nonexistent and such data would take many years to obtain, a reservoir 
simulation model was developed to represent the process of gas production from coal. A description of this simulation model and its development is presented later in this report. In lieu of actual data, simulation models are a prime investigative tool throughout the various engineering disciplines. This particular simulation model is quite similar to those used in the oil and gas industry and should be valuable in assessing gas production from coal. As actual data becomes available, assessment of the results can be incorporated as enhanced validation of the simulation model. This feature of the data base development is absolutely necessary.

The engineering problem to which this study addresses itself can now be defined in terms of expressing the feasibility of methane gas production as a function relating the parameters which quantify gas production and the testing procedures necessitated to define these parameters. To relate these parameters, the previously mentioned simulation model was used to model a coal reservoir, the reservoir parameters are input to the model and production performance calculated. Since coals and completion practices vary, parameters were varied over a range of expected values and modeled production profiles obtained. Over 500 separate reservoir descriptions were modeled. From these model runs, each gas production profile was obtained for a ten year period. To relate this gas production to the modeled parameters, a production characterization factor was developed and called Phi, $\phi$. The characterization parameter, $\phi$, is defined as the cumulative average discounted production for a ten year period. The discount factor chosen was $15 \%$ per year. By assigning a gas price and including development costs, $\phi$ can be quickly converted to an economic indicator of the coal production scheme.

To correlate $\phi$ with reservoir parameters, engineering and statistical methods were applied. Sensitivity model runs were used to delineate the parameters which were major contributors in determining the magnitude of $\phi$. These parameters 
were evaluated using statistical methods, and a linear correlation was developed relating the $\log$ of $\phi$ to the $\log$ of the parameters. Good agreement was acknowledged between the values calculated for $\phi$ with the correlation functions and the $\phi$ calculated from the model. This agreement in results, expressed statistically within some degree of error, verified the correlation expression as a valid tool in determining the value of $\phi$ as a function of the significant reservoir parameters. This correlation now enables the quick assessment of $\phi$ for any reservoir once its descriptive parameters can be obtained.

To obtain the parameters by which the gas production can be characterized, tests on the coal must be made. Since the type, number, accuracy, application, and costs of tests vary; a set of test schemes or modules were developed. A discussion of these test modules are presented in detail later in this report. The test modules were evaluated through statistical methods relating budgetary constraints and degree of assessment in determining $\phi$. While the cost effectiveness of alternative tests can be related, the value to be assigned to relate cost versus accuracy is as yet arbitrary. Through actual field tests, the level of accuracy and the associated costs may be determined.

In all, a rather extensive statistical investigation is made relating 1) the relative importance of a parameter on determining $\phi$, 2) the relative effectiveness of various test modules in determining the various parameters and 3) the number of observations of each test module that must be made to establish an acceptable description of the population of coals which are being sampled.

This engineering approach in evaluating coal lends itself to a continual assessment and enhancement in characterizing the productive potential of methane gas from coal. Through extensive testing, the many and various coal beds can be characterized. Through production, validation of the predictive model will result in a higher degree of reservoir assessment. With time and 
effort, all levels of evaluation will be enhanced by the additional accumulation of data. While a considerable effort has been made to assess the factors in the determination of attaining a level of confidence in a reservoir's productive capacity as characterized by $\phi$, it still remains that $\phi$ was developed from simulating models of coal reservoirs as they are thought to exist. The simulation model, therefore, is the base level of accuracy on which all other assessment relies. At some point in time, a degree of confidence can be attributed to this means of analysis and a total assessment in coal characterization will be achieved. 
II. CONCEPTUAL MODEL AND MATHEMATICAL SIMULATION

\section{A. Conceptual Model}

It is weil accepted that methane is adsorbed onto the internal surface of coal particles. This phenomenon has been demonstrated in the laboratory for many coals throughout the world. This adsorbed gas is a quantity of gas that exists in equilibrium between an external pressure and the internal packing of methane molecules on the coal surfaces. These equilibrium points are described by an equilibrium sorbtion isotherm. Figure 1 is a laboratory determined equilibrium isotherm for several samples of coals in the United States. The concept of methane sorbtion in U.S. coals is best documented in Joubert et al $(1),(2),(3)$, $\mathrm{Kim}^{(4)}$, and Kissell et al ${ }^{(5)}$.

The first assumption of the conceptual model is that the virgin coal exists with a gas content that is in equilibrium with its existing external pressure.

The second assumption of the conceptual model is that there exist some natural flow paths or permeability through the coal. These flow paths are physically natural fractures or cleat in the coal. It is this system of natural fractures that givcs the coal its character of "friable" or "blocky". close spaced fracture systems yield friable coals and wide spaced systems result in blocky coals. McCullough, et al (6), illustrate the apparent universal nature of cleat in bituminous coals of the U.S.

These fractures create a finite amount of porosity as well as permeability. The porosity of the coalbed is small in comparison to conventional reservoir rocks with values in the one to four percent range. Contained in this porosity are the formation fluids. The pressure at which the fluids exist is the 
pressure external to the coal particles that determines the point on the equilibrium isotherm at which the virgin coal exists. These concepts have been verified in laboratory studies by Tabor et al. (7)

In addition to the magnitude of the porosity and its pressure, the composition of the fluids in the porosity is important to the system. It is generally accepted that during the coalification process, gases of differing composition are evolved from the coal itself. These gases migrate away from their places of origin over geologic time either by solution in inherent water or by gravity forces. If there exists a trap such that gas cannot migrate by gravity, the fracture porosity may contain a significant amount of "free" gas that is stored under compression just as in conventional reservoirs. On the other hand, there may be a free gas path to an outcrop such that coal at depth exists at a very low pressure and an insignificant amount of gas can be stored by either adsorption or compression. Geochemical considerations tend to verify these concepts at least in some parts of the world. (8)

It follows that the coal exists at initial conditions discussed above that can be described as equilibrium. If the equilibrium is broken by any means, the systeil will attempt to find a new equilibrium condition. Physically the equilibrium can be broken by drilling and producing a well, driving a mine entry, etc. In all the cases of economic interest the equilibrium is broken by reducing the pressure in the fracture systell at a point such as a well or over an area such as mine advancement.

When the pressure is lowered, the fluids in the fracture system begin to move toward the point of low pressure. In addition, the coal that contained adsorbed gas in equilibrium with initial pressure will begin to desorb gas in an attempt to come into equilibrium with the new reduced pressure. 
It has been demonstrated that the flow through the fracture system is described by Darcy flow very similar to conventional gas and water reservoir flow. Further, the flow through the solid coal particle is by the much slower process of diffusion as gas is evolved in an attempt to reach equilibrium with a new reduced pressure and is described by Fick's Law.

It then follows that gas migrates from the internal surfaces of the coal to a fracture surface by diffusion in response to a concentration gradient and from there through the fracture system by Darcy flow to the well or point of lowest pressure.

\section{B. Mathematical Simulation}

In order to calculate quantitatively the flow described by the foregoing concepts, the mechanisms must be reduced to mathematical expressions. The mathematical expression for diffusion of gases through a microporous medium is given by Fick's Law. Physically, the coal particles are surrounded by fracture planes or surfaces. Assuming that these particles can be represented by spheres of equal radii, the expression for the mass balance is

$$
\frac{D}{r^{2}} \frac{\partial}{\partial r}\left(r^{2} \frac{\partial C}{\partial r}\right)=\frac{\partial C}{\partial t} \cdot . \cdot \cdot \cdot \cdot \cdot \cdot \cdot \cdot \cdot \cdot \text {. }
$$

where: $D=$ diffusion coefficient of the material,

$r=$ radial distance from the coal particle center, and

$\mathrm{C}=$ concentration of methane.

The flow of gas and water in the fracture system is described by Darcy's Law and when combined with the continuity equation gives the following equations:

$$
\begin{aligned}
& \nabla \cdot\left[\frac{\rho_{w} k^{k w}}{\mu_{w}}\left(\nabla p_{w}-\rho_{w} g \Delta h\right)\right]-q_{w v}=\frac{\partial}{\partial t}\left(\phi \rho_{w} s_{w}\right) \cdot \ldots \\
& \nabla \cdot\left[\frac{\rho g^{k k} r g}{\mu_{g}}\left(\nabla p_{g}-\rho_{g} g \Delta h\right)\right]-q_{g v}=\frac{\partial}{\partial t}\left(\phi \rho_{g} s_{g}\right)
\end{aligned}
$$


These equations include the concepts of relative permeability and capiliary pressure which yield the two additional equations :

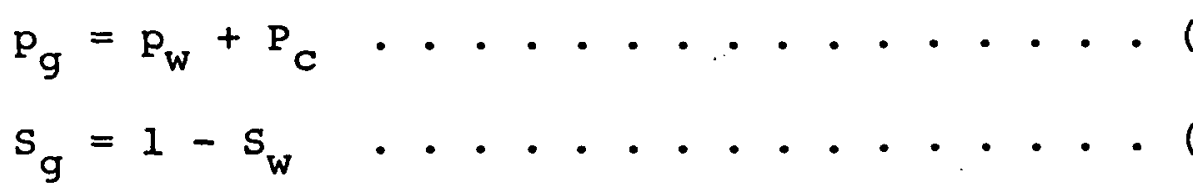

For this discussion let it suffice to say that there are five equations and five unknowns as the calculation proceeds through time. These unknowns are gas pressure, gas saturation, water pressure, water saturation, and adsorbed gas concentrations that are determined at time $t$.

Solution of the equations on validation of the model is beyond the scope of this discussion and is the subject of a separate document. Let it suffice'to say that the finite difference approximations and solution methods introduce errors that are insignificant in relation to the precision with which the basic input parameters can be specified.

The only constraints on the simulator are that the basic assumptions are not violated. These are few and very simple. First, there is Darcy flow in the fractures. This assumption is valid as long as the fracture spacing is small in relation to the gria size. For the case of coal where cleat spacing is at most on the order of inches, this assumption appears to be valid. Second, it is assumed that the desorbtion can be represented by a diffusion calculation from uniform spheres. By analyzing laboratory tests, it has been found that this is a very good approximation, particularly after the first. few seconds of desorbtion. The simulator does assume that the sorbtion coefficient, $D$, is a constant. There is one laboratory test that indicates $D$ is slightly pressure dependent. By taking $D$ over the entire pressure range as is done in direct measurement of gas content, any errors introduced by using a constant $D$ are minimized. 
The assumption that the diffusion geometry is spherical is valid in that nearly the same solution will be found if the coal particles are assumed to be cubic or parallelepiped.

\section{Simulator Output and Characterization}

The simulator input includes values of all the parameters discussed earlier. These include dimensions and geometry of the coal seam, the sorbtion coefficient and fracture spacing, coal permeability and porosity, fluid properties as functions of pressure, and relative permeabilities and capillary pressures as functions of saturation. Further input includes data on the boundary conditions. Boundary conditions are determined by the operation mechanism of the system. Possible boundary conditions include producing a constant rate from a point and calculating pressures, or establishing a constant pressure boundary condition and calculating varying production rates.

For the purposes of this study it was assumed that a well was drilled at the center of an infinite acting reservoir and the pressure was lowered to atmospheric and the rate of flow was calculated as a function of time. This is the most optimistic operating condition because it assumes that the mechanical water removal equipment can remove water faster than the reservoir can produce it. This is in general a valid assumption, but does not account for operating problems such as pump downtime, freezing weather, etc.

In general, the output of the simulator is a schedule of deliverability as a function of time. A typical deliverability is shown graphically on Figure 2. For the purposes of this study, it was necessary to establish a single number to characterize the simulator. It was arbitrarily agreed among the parties to use a value calied Phi, " $\phi$ " which is defined as the cumulative production at the end of ten years discounted at the rate of $15 \%$ per year. Figure 3 graphically illustrates the value of $\phi$ in relation to the actual deliverability. This gives $\phi$ the 
units of MCf, and the parameter when multiplied by an appropriate gas price gives the present value of the revenue from that deliverability schedule.

This parameter will change value when the basic input variables vary over their ranges of expected values. As the basic variables become better established by measurement during the test program, the variation of $\phi$ will get smaller and smaller, and if the well were produced ten years, the value of $\phi$ would have almost zero variation.

This definition of the parameter $\phi$ makes it possible to distinguish between deliverability schedules having equal production but different distributions of rates with time. In general, the value of $\phi$ gets larger with higher production rates. It is important to note that this study is devoted to learning about the distribution of $\phi$ and not trying to maximize $\phi$. The value of $\phi$ is of no importance to the test program design, only the variance of the mean of the distribution of $\phi$ and the variance of the variance of the distribution of $\phi$ is of importance to this study.

During the actual simulations discussed in the following sections, $\phi$ was calculated for one-fourth of a total well. This was done to take advantage of symmetry about the weIl in order to conserve computer time. The actual value for a total well should be four times the values shown hereafter in this report for $\phi$. The justification for this treatment is that the actual value of $\phi$ has little significance for the development of the test program. The important thing to know for test program design is the variability of $\phi$ which is the same regardless of whether $\phi$ is determined for a total well or only a $90^{\circ}$ segment of the reservuir. 


\title{
III. DETERMINATION OF IMPORTANT PARAMETERS \\ AND THEIR SENSITIVITY
}

A. Determination of Independent Variables

The variables that affect the production of methane from coal are all accounted for in the simulator. To determine those which have the most effect on the value of $\phi$ a brief sensitivity study was done. The variables that affect the value of $\phi$ are all listed in Table 1. Each variable was changed over a range of values with all others held fixed. The results of this brief study was that there are seven variables that affect the calculation of $\phi$ more than the others. These are thickness, gas content, pressure, permeability, relative permeability, fracture length and fracture conductivity.

\section{TABLE 1}

VARIABLES NEEDED TO COMPUTE $\phi$

\author{
1. Thickness \\ 2. Permeability \\ 3. Pressure \\ 4. Relative Permeability \\ 5. Fracture Length \\ 6. Fracture Conductivity \\ 7. Gas Content \\ 8. Sorbtion Parameter \\ 9. Porosity \\ 10. Gas Composition \\ 11. Water Characteristics \\ 12. Capillary Pressure \\ 13. Reservoir size and Geometry
}

While all the above parameters are important in the determination of the magnitude of $\phi$, not all are needed in securing a predictive level of confidence in the final calculation of $\phi$. As an example, this can be ullustrated by discussing thickness. 
Any change in $\phi$ caused by changes in thickness is directly in proportion to that thickness change. If thickness doubles so does $\phi$. Therefore, the thickness was handled by normalizing the thickness at 10 feet. This enabled the list to be reduced to a final list of six. These variables are:

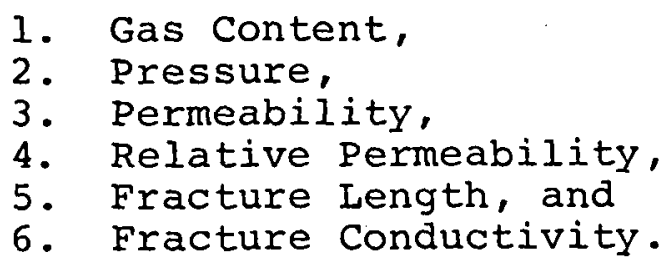

These remaining six important variables were treated as the indcpendont variables. Each variable was assigned a frequency distribution describing what is felt to be a representation as to the range and frequency of values for the various coals. This distribution is called an a priori distribution, and a set of values spanning its range were selected for each variable and simulation runs were performed to calculate $\phi$.

\section{B. Discussion of Independent Variables}

Each of the independent variables is discussed below. The estimated range of values and methods of measurement are discussed in considerable detail. Also included is a quantitative discussion of known measurements of each variable.

\section{Gas content}

Since gas is contained in coal by a sorbtion process, the gas content of coals is best described by equilibrium sorbtion isotherms. Input to the simulation model is an isotherm table that is a function of pressure. Figure 4 is a graphical display of the range of sorbtion isotherms that should be encountered during the test program for unminable coals.

More quantitative information has been gathered about this variable than any other of the independent variables. 
Some correlations have been developed that show a definite relationship between sorbtion isotherm and coal rank ${ }^{(4)}$. Several references have published a correlation developed by the U. S. Bureau of Mines that illustrates the variation of gas content with coal rank ${ }^{(4)}$. This correlation is shown as Figure 5. The same correlation is evident on Figure 1 if moisture content is used as a measure of rank. This correlation, while unjustified by complete publication, was used as the basis for establishing the limit of the upper range of gas content isotherms. The lower limit: was established by independent INTERCOMP analysis which extended the correlation to low rank coals. The INTERCOMP work tends to fit the Kim correlation quite well, making the range cover from sub-bituminous or lignite to low volatile bituminous coals. These are thought to represent the best data available to describe the gas content of coals in the United States. INTERCOMP has requested the basic unpublished data that would help establish this correlation, but said data has not been received.

The distribution of gas content in the coals to be tested is unknown. It was assumed that the "unminable" coals would be distributed among different ranks in the same proportion as the known underground coal reserves as " described by Averitt (10). This distribution is that about $34 \%$ of the coal can be represented by the low isotherm, 378 by the medium isotherm and $27 z$ by the high isotherm.

There are two methods available to test for gas content. The first or so called "Direct Method"(5) requires a fresh sample from a core which is placed in a closed canister and slowly the gas is drained off and measured over a period of several weeks. The second method is to take a sample of coal and adsorb methane in a laboratory procedure: The direct method has the disadvantage of measuring only a single point on the 
sorbtion isotherm while the second method traces the entire isotherm curve. Both methods should be employed in the test program. However, if the direct method is the only data available, the isotherm can be computed uding the Langmuir equation (11).

$$
\frac{\mathrm{p}}{\mathrm{V}}=\frac{\mathrm{p}}{\mathrm{V}_{\mathrm{m}}}+\frac{1}{\mathrm{bV}_{\mathrm{m}}} \cdot \cdot \cdot \cdot \cdot \cdot \cdot \cdot \cdot \cdot
$$

where $\mathrm{p}$ = pressure, atm

$$
\begin{aligned}
& \mathrm{V}=\text { volume adsorbed } \mathrm{cm}^{3} / \mathrm{g} \\
& \mathrm{v}_{\mathrm{m}}=\text { monolayer value (a constant) } \mathrm{cm}^{3} / \mathrm{g} \\
& \mathrm{b}=\mathrm{a} \text { constant, atm }
\end{aligned}
$$

\section{Initial Pressure}

Pressure is the internal pressure of the coal at virgin conditions. It is a measure of the energy avail.. able to force the flow of fluids through the fracture system or "cleat" of the coal. Pressure increases with depth at a rate of about 0.43 psi/ft under ideal conditions. In some geologic basins the pressure can be predicted directly from the depth. In others the gradient is somewhat lower than hydrostatic and may be as low as $0.3 \mathrm{psi} / \mathrm{ft}$.

The range in pressures used was from $100 \mathrm{psi}$ to 2000 psi. This would correlate roughly to depths of from 250 to $5000 \mathrm{ft}$. In underpressured basins the depth could be as. great as 6000 to 7000 it and not exceed the estimated range. Coal pressure data is very sparse. INTERCOMP las requested somc unpublichod data taken by the U. S. Bureau of Mines that would help to define the pressures in several basins, but it has not been received.

What data does exist indicates pressure gradients of about $0.35 \mathrm{psi} / \mathrm{ft}$ in the Northern Appalachian Basins and 
.4 or .42 in the Warrior Basin. The Illinois Basin appears to be somewhat underpressured in the coal seams. No known data is available in the various Rocky Mountain Basins, but oil and gas operations indicate them to be somewhat underpressure. The Arkoma Basin of the Mid-Continent area is. apparently at near the hydrostatic gradient of $0.43 \mathrm{psi} / \mathrm{ft}$.

\section{Permeability}

Measurements of coal seam permeability are nearly nonexistent. A few core sample permeabilities can be found in the literature (7). Experience with fractured oil and gas reservoirs has shown that core sample permeabilities are not very meaningful if the fracture spacing is on the same order of magnitude or larger than the sample size. This is thought to be true in coal.

This makes it necessary to attempt to determine permeability from some well test which will give an average over a fairly large volume of coal. Short-term tests can be run as drill stem tests while wells are not cased or by a water injection test through casing.

A few successful drill stem tests have been found and analyzed by INTERCOMP. Several more are known to exist and may be helpful to establish the range anticipated for permeability. Based on the limited data and the general consideration that coal permeahility will decrease with increased depth, the range was set at between 0.1 md and $100 \mathrm{md}$. No permeabilities have been calculated outside those limits and the bulk of the eight or ten data points fall in the center of from 1 to $20 \mathrm{md}$.

4. Relative Permeability

Relative permeability to gas is the variable that determines the relative amounts of gas and water that are 
produced. Early sensitivity runs showed that the best way to characterize relative permeability. effects was to use a constant relative permeability to water and then vary the gas relative permeability. This is val-. idated by the only available published data on relative permeability characteristics of coal (7). Generally the results of the referenced study have proved reliable for INTERCOMP to analyze data from various gas production projects.

The only way to calculate relative permeability is to measure gas and water rates where the other independent variables are known from other tests. This procedure is described later when discussing testing philosophy.

The range of relative permeability is shown on Figure 6. The end points, minimum and maximum, are represented by the curves measured in the above reference for the pittsburgh and Pocohontas coals. The space was scaled into ten equal parts and the ten curves were numbered $1.0,1.1,1.2$, etc. . This then allows a single value to represent the curve, i.e. a 1 or 2 .

\section{Fracture Length}

Fracture length is defined as the distance a hydraulic fracture can be extended in a single direction from the wellbore. There has been a great deal of interest in hydraulic fracturing of coalbeds. A very recent publication by the U. S. Bureau of Mines (12) shows that hydraulic fractures can be created which extend several hundred feet from the well. It is believed and actual field experience indicates that fractures of over $1000 \mathrm{ft}$ can be created in coals. For this analysis the upper limit on fracture length was estimated to be $2000 \mathrm{ft}$. 
The only way known to determine fracture length other than mining is to use a carefully run production or injection test and fracture length can be determined with a limited degree of accuracy (13). The simpler the flow regime that the reservoir is in, the more precise the determination. This means that for the case of coal, the fracturing parameters are best determined while the reservoir is in single phase water flow. This makes it imperative that good data be observed in the very early life of the well, a time at which it is most difficult to do.

\section{Fracture Conductivity}

Like fracture length, fracture conductivity is a parameter that describes an induced hydraulic fracture. The technical definition of fracture conductivity used for this study is the width of the fracture multiplied by the permeability of the fracture itself. The units are md-in.

Fracture length and conductivity are not totally independent of each other. To create a very long fracture, the width must be kept relatively narrow thus making it less conductive. On the other hand, to make a highly conductive sand packed fracture, a wider fracture is necessary to enable the use of larger proping sand which in turn has a higher permeability. One technique (14) uses in situ material broken during the fracturing itself to prop the fracture open. This enables a long, thin fracture to be created but since it is not sand packed it can have wide, open flow channels and maintain a very high conductivity.

Ranges estimated are from 25,000 md-in to $150,000 \mathrm{md}-$ in. The lower limit was established for a fracture packed with 20-40 sand at $5000 \mathrm{ft}$ and the upper limit was calculated for a fracture with some wide open flow channels. 
Determination of fracture conductivity is not precise at best. The same test will be utilized to determine fracture conductivity as was used for fracture length.

\section{Sensitivity Analysis}

\section{Assumptions}

In order to quantitatively evaluate the effect of each independent variable on the characterization parameter, $\phi$, a large number of simulator runs were mare, In orier to in this certain assumptions had to be made. These are listed below.

a. All testing will be done with vertical wells. While this is probably a valid assumption for the test program, other configurations should be investigated for demonstration and commercial projects. These other configurations such as directional holes and horizontal holes from the bottom of shafts are either not proved technology or an order of magnitude more expensive than vertical wells for sampling and testing.

b. Symmetry exists about the wellbore so that a $90^{\circ}$ segment of the reservoir represents onefourth of the well. The values of $\phi$ reported are thus for one-fourth of a total well.

c. Mechanical water removal equipment will be available at each site which will be adequate to prevent a hydrostatic head to be built-up on the coal. This assumption is that the well boundary condition can be maintained at atmospheric pressure. 
d. All results are normalized for a $10 \mathrm{ft}$ thick coalbed and 100\% methane gas. Thickness changes or gas containing inert components can be rigorously accounted for external to. the simulator by direct ratio.

e. Each test well is assumed to be completed in an infinite acting relatively flat lying coal seam. Both these requirements appear to be valid for the basins to be studied.

\section{Sampling the Independent Variables}

Values of each independent variable were chosen for the sensitivity analysis. Five values of permeability were chosen to represent the range of permeability - . 1, $0.5,1.0,10.0$, and $100 \mathrm{md}$; four values for pressure - 100 300,600 , and 1800 psia; two values for relative permeability - minimum and maximum; three values for sorbtion isotherm - low, medium and high; four values for fracture length - 200, 500, 1000 and $2000 \mathrm{ft}$; and four values of fracture conductivity - 25;000, 50,000, 100,000 and 150,000 md-in. If all possible combinations of all these variables were run, over 2000 simulator runs would need to be made. The computer charges would be prohibitive for the number of runs.

It was possible to eliminate some of the combinations simply because of their small probability of occurrence. For example, only selected combinations of fracture length and conductivity were used. This reduced the combinations from 17 to 7. Further it was assumed that if 100 md coal was found, hydraulic fracturing would not be necessary. The final number of simulations was 456 . Each one calculated the complete deliverability schedule for one-fourth well and converted that schedule to the characterization parameter, $\phi$. The entire set of runs is shown in tabular form as Appendix A. 
This resulted in a very well behaved array of $\phi$ as a function of the six independent variables. The statistical treatment of this array and the test program development are discussed in later sections. 
IV. DEVELOPMENT OF. TESTING AND - TEST MODULES

A. Possible Tests and Measurements

Possible tests and measurements are shown in Table 2. This table shows name of the test, the items measured, the variables determined from the measurements, the recommended frequency of the test or activity, the prospective accuracy, and the constraints on the test.

These tests and activities are for the most part standard activities; however, a few of these deserve some explanation. The first of these is the water level measurement. This measurement is simply a determination of the static water level in the well. It can be conducted using a galvanometer type well sounder or with an acoustic device. The galvanometer type sounder is difficult to use when there is gas pressure at the surface. The static bottom-hole pressure is the objective of the test and a surface gas pressure plus the water level would allow the calculation of static bottom-hole pressure.

The bottom-hole pressure test using a wireline instrument is ideal for determining bottom-hole pressure plus establishing the gradient for thc cxtrapolation of water level measurements.

The water injection test is a way to determine reservoir permeability prior to producing a well. This test consists of injecting water at a constant rate into the well and monitoring the pressure. A plot of the logarithm of time vs. pressure will yield a straight-line, the slope of which is proportional to permeability. This test assumes virgin conditions with the coal saturated with water which is the general condition of the conceptual model discussed earlier. The constant rate injection is accomplished using an injection pump which can be purchased 
from companies supplying the chemical industry. Pressure is measured with a dead weight pressure gauge or test gauge and time recorded. A refinement is possible by observing the pressure falloff after the injection period. The pressure falloff can be extrapolated to initial pressure and evaluation can be done by standard petroleum engineering practices.

The echo meter survey is for determining the well flowing pressure. Assuming water is pumped up the tubing, and gas is produced up the annulus, the water level in the annulus determines the back pressure on the formation. This back pressure needs to be evaluated. The way to determine it is to use an acoustic device that records reflections of soundwaves in the annulus. An alternative method is to use the galvonometer type well sounder but this is not good practice in an annular space.

The remainder of the tests are self-explanatory. However, the duration of the production tests deserves mention. The production tests are best characterized by declining water production rates and gas rates that increase initially, pass through a maximum and decline. The duration of the production tests should encompass this entire period. The exact timing is difficult to predict bccausc some wclls producc gas almoct immediately and some have been known to produce only water for several weeks. A more quantified estimate will be forthcoming after some testing is done in the 1978 testing program.

B. Testing Philosophy

The objective of the test program is to develop reservoir. information about coal and its associated gas. One of the primary constraints is that the data must be able to be correlated from basin-to-basin and from coal-to-coal. For this reason the tests need to be standardized as much as possible. The second constraint is that of finite funding. Recognizing that all basins under consideration are also active oil and gas exploration areas, it may be possible to achieve significant cost savings 
by utilizing either existing wells or wells being drilled for conventional oil and gas exploration and production. Further, in several basins there are active coal exploration programs, and some of these activities may be utilized. All of these activities use vertical wells for evaluation. For this reason, the testing program is centered on vertical wells drilled for various purposes.

The philosophy used in developing the test procedures and test modules is partially reflected in Table 2 which shows the recommended frequency of the various tests. There are basically three classes of variables that are to be evaluated by the field test program. First, those tests that validate the concepts of the coal system should be run at every opportunity. These are tests of the equilibrium sorbtion condition (gas content vs. pressure) and of the gas quality (gas must be of commercial quality).

The second class of variables are those independent variables that cause wide variations in $\phi$. These variables are to be determined only to the extent necessary to minimize the variability of $\phi$. The testing procedure is sequential such that the" tests described earlier are in the proper order so that only one new set of variables is introduced with each step. This procedure gives the greatest confidence in the determination and will help eliminate non-unique solutions.

The third class of variables are those that have no significant effect on the gas production performance, but are useful for correlating from coal-to-coal. These data would include such items as the lab derived proximate and ultimate analyses of the coal, log derived properties, water quality, etc.

The testing program makes use of five different types of wells. These different types of wells make use of all the different tests shown in Table 2 . The Type $I$ well is a conventional gas or oil well being drilled to potential reservoirs 
below the coal. Activities for a Type I' well must be confined to a short period of one or two days. A Type II well is a well that has been drilled for other purposes and is ready for abandonment. All activities with Type II wells assume that the coal is cased with good cement over the coal zone. A Type III well is a well drilled expressly for completion as a production well from coalbeds and can be used for the entire suite of tests. A Type IV well is a well drilled and cored for coal exploration, and is similar to a Type I well except the hole diameter is small and the hole may be available for a long period: of time. A Type $\mathrm{V}$ well is an observation well used in conjunction with a Type II or Type III well. This assumes a small diameter hole drilled with a temporary string of pipe set on an open hole packer to isolate the coal zone.

C. Test Modulcs

The test modules are explained below and are coded according to well type. Table 3 is a matrix of the variables to be determined and which ones can be determined at what precision by the various test modules. Modules of the same well type are arranged sequentially, and it is feasible to terminate the sequence at any time as there is generally a significant break in terms of equipment, expense or time between the modules.

\section{Module I-1}

This module aesumes that a conventional oil or gas well is temporarily made available for testing. It further assumes that the hole is uncased and logged with sufficient tools to identify any coalbeds present. For these assumptions to be valid, the well will probably need to be available before surface casing is set.

The feasible tests at this point include taking sidewall core samples, field testing for gas content, saving the core samples for porosity and permeability 
test and proximate analysis. This is followed immediately by a drill stem test for evaluation of pressure and permeability. It is recommended that the "closed chamber method" of drill stem testing ${ }^{(9)}$ be used since this gives best results at low flow rates.

This sequence is recommended because of the tendency for coalbeds to exhibit severe wellbore damage on drill stem test. The sidewall cores may have penetration as deep as a few inches which will help remove any wellbore damage and improve performance on drill stem test.' Unfortunately, there is little track record for sidewall coring in coal: Coal exploration is traditionally done in small diameter holes where the sidewall cores are not feasible. However, coal should be a classic application for sidewall cores. Historically, sidewall coring has been very successful in soft, unconsolidated, or slightly consolidated formations; which also describes coalbeds. What little experience is available indicates that recovery of samples is good.

If a conventional core is possible, the sidewall sampling is not necessary. A full core should be analyzed for porosity and permeability. Special analysis for gas-water relative permeability should be done. If this full core is available, the value of Module I-l is much higher. This fact is mentioned throughout this report.

Care must be exercised with the core samples so that the samples are recovered as rapidly as possible and the early desorbtion:process is monitored. The "direct method procedure" (5) prepared by the Bureau of Mines is adequate if samples of large enough size are available. At least one commercial laboratory offers a service to do the desorbtion of samples using a gas chromatograph. This procedure is probably more precise and may be better for 
the small samples recovered using sidewall tools. Either case requires a trained technician to be on-site when the well is cored.

One problem that may arise with the sidewall cores is that of time if the well is drilled with air. The sampling should be done as rapidly as possible after the coal is drilled. If the hole is drilled with air, the coal will desorb its gas into the well and direct methods may not be adequate. This is the reason that adsorbed isotherms are recommended to be run as a check of the direot desorption.

Cost of this module exclusive of rig time and evaluation is estimated to be $\$ 7,500$ and includes 20 sidewall samples, a DST, proximate analysis of the coal, an equilibrium isotherm, porosity-permeability measurements on several core samples, and technical supervision.

Additional costs may vary from site-to-site depending on the cooperation of the operator phase and any cost sharing agreements. The primary additional cost is for rig time while the tests are being run. Typical costs for rigs in the basins under study are about $\$ 4,000$ per 24 hour day.

Evaluation.would include analysis of the drill stem test, prediction of $\phi$ and preparation of a standardized data report. Cost would be about $\$ 2,500$ making the total cost of the module about $\$ 10,000$ plus rig time. If two days are required the total would be about $\$ 18,000$ per test. This figure is used for hudgetary purposes.

\section{Module II-1}

This module utilizes a Type II well which is a well ready for abandonment either as a dry hole or as a depleted production well. The assumption is that casing is cemented 
over the coal zone and the well is ready for perforation. A string of tubing should be available. All these assumptions should be readily fulfilled in most areas. It is likely that the coalbeds will be behind surface casing where cement has been circulated to surface so the cement job is apt to be good; but any production casing will have to have, been pulled.

The testing procedure will include perforating the coal, acidizing with a small acid treatment to clean up any cement or mud damage to the coal, and running an injection test. The acid clean up job should be run ahead of the injection test such that the water level is allowed to stabilize ahead of the injection test. Care should be exercised to measure the static water level.

The injection test simply injects water at a constant rate into the coal. Pressure at the surface is measured with an accurate pressure gauge, the logarithm of time is plotted against pressure, and the slope of the line is directly proportional to permeability. The duration of the test is estimated to be between one and two days. Limited experience has demonstrated two problems with this test. First, the coal may be so badly damaged that adequate injection rates are not possible. This is the reason for the small acid treatment. Second, some coal has a tendency to fracture easily. If the pressure is allowed to go too high, no usable data may be possible. In some cases this may be at only a few psi surface pressure in which case the test is not valid at all.

Costs for this module are estimated to be $\$ 10,000$ and include perforating; acidizing, injection test, a workover rig, and evaluation by INTERCOMP. 


\section{Module II-2}

This module is designed to follow Module II-1 and is basically a natural production test. Tubing, rods and pump are run into the well and pumping is initiated. Knowing the permeability and pressure, the primary unknown variable is the relative permeability characteristic of the coal.

The items to be measured are instantaneous and cumulative gas and water volumes on a daily basis. At least three analyses nf gas and water samples need to be taken during the test. Documentation of the water level in the producing well either with an acoustic well sounder or with detailed data collection showing the well completely pumped down is required.

Cost of this module is based on four weeks of production and is estimated to be $\$ 8,000$ which includes only the cost of running the pump, operating and monitoring the test, and evaluation of the results. In addition is the cost of equipment which will range from $\$ 5,000$ to $\$ 10,000$ and includes costs for tubing, rods, pump, pumping unit, gas meter, water meter, surface piping, etc. All of these items are reusable and some or all of them may be available for the duration of the test by the owner of the Type II we 11 .

\section{Module II-3}

This module consists of principally a stimulation and post-stimulation test. The independent variables to be determined are the hydraulic fracture parameters of length and conductivity, utilizing values of all the other independent variables determined by previous testing.

Activities include pulling the pumping equipment, stimulating the well, reinstalling the pumping equipment 
and evaluating the results. Data gathered is essentially the same as for the natural production test. The same gas and water meters can be used and several gàs and water samples must be taken and analyzed. A guide of two samples per week for the first two weeks and one per week thereafter should suffice. Gas and water analysis can be done routinely at commercial laboratories all over the country. Costs are estimated again based on four weeks production at $\$ 15,000$ for the stimulation. Total costs are estimated to be $\$ 24,000$.

Note: It is possible to eliminate the natural production test in Module II-2 and insert a second injection test after stimulation into Module II-3. This will give determination of all variables with equal accuracy, but does not give demonstrated, field measured effects of stimulation. Cost savings would be on the order of $\$ 5,000$ and time savings of about four weeks.

\section{Module III-1}

This module simply is the drilling of a Type III well, one drilled for the express purpose of producing gas from coal. Assuming a depth of 1,000 feet. The costs are estimated to be about $\$ 61,500$. These are itemized in the table below.

\section{COSTS OF TEST WELL TO PRODUCE GAS FROM COAL \\ (Depth 1000')}

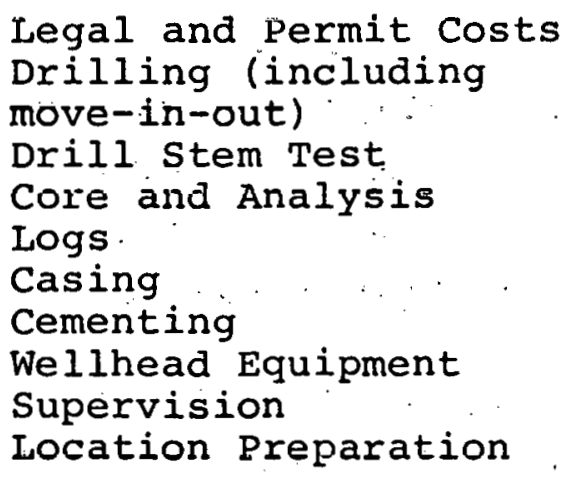

$$
\begin{array}{r}
\$ 5,000 \\
22,000 \\
2,500 \\
4,500 \\
3,500 \\
4,500 \\
5,000 \\
1,500 \\
8,000 \\
5,000 \\
\hline \$ 61,500
\end{array}
$$


The tests run are the same as Module I-1. The core samples could be taken with either a sidewall sampler or conventional core barrel. The conventional core barrel would yield a sample that could ba analyzed in the laboratory for permeability and relative permeability; again, this makes the early module more effective.

6. Module III-2

(Identical to Module II-I)

7. Module III-3

(Identical to Module II-2)

8. Module III-4

(Identical to Module II-3)

9. Module IV-1

This module utilizes a well or hole drilled for coal exploration. It assumes that the hole was cored and logged: The hole is simply drill stem tested and the appropriate lab work done. The same constraints of having a trained technician on-site held for analyzing the core desorbtion as in Modules $I-I$ and III-I.

Evaluation would be the same as for Module I-l. Cost would be about $\$ 6,500$ including evaluation.

10. Module V-1

This module must be used in conjunction with the Type II or Type III wells. For complete value of this module to be achieved, the entire testing sequence on the Type II or III well should be done. This module involves drilling two observation wells adjacent to the 
Type II or III wells. These holes would be small diameter holes that would be temporarily completed with a string of smali diameter tubing set on an open hole packer above the coal. These could be retrieved at the end of the testing. Test equipment would include only recorders that continuousiy record water level.

The observation wells should be completed at the same time the production well is and the water level monitored continuously. This is standard practice in the vicinity of underground gas storage fields.

Assuming 1000 feet depths, the cost of completing two wells is estimated to be $\$ 30,000$. Advantage of this type of procedure is to get pressure measurements at a distance from the production well. From these, a much more accurate determination of permeability can be made. Also, porosity can be determined as well as the directional properties of the coal. If the coal is friable and directional properties are not important, a single observation well could be drilled at one-half the cost.

Evaluation is included in Modules II-3 and III-4 and would involve only very minor adjustments to procedures planned for those modules. 
POFENTIAL TEST ACTIVITIES

COAL DEGASIFICATION FIELD TEST PROGRAM

\section{Test or}

Activity

\section{Parameters Measured}

Core

Field

Lab

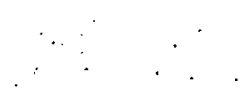

Logs

$\stackrel{\omega}{N}$

\section{Drill Stem}

Test

Water Leve1

\section{Measure}

Bottom-hole

Pressure

Water Injection Test
Thickness, Gas Content

Proximate Analysis

Ul timate Analysis

Sorbtion Isotherm

Porosity, Permeability

Depth, Thickness, Density, Resistivity, Gamma Zay, Cement Bond, Caliper

Flows, Pressure,

Temperature

Water Level

Pressure, Temperature

Water Injection Rate, Pressure, Time
Parameters Determined and Precision

Sorbtion Coefficient Young's Modules Poisson's Ratio

Porosity, Water Saturation, Coal Quality

Pressure, + 10 psi Permeability $\pm 50 \%$

Pressure \pm 1 psi

Pressure \pm 1 psi Temperature $\pm 1^{\circ} \mathrm{F}$

Pressure \pm 1 psi

Permeability $\pm 10 \%$

Saturations,

$\mathrm{P}_{\text {error }}=.2$, Porosity

\section{Recommended}

Frequency

Every opportunity Every oppo=tuni=y Infrequent

Infrequent

Infrequent

Every opportunicy

As determined br... optimization

Every opportunity

Infrequent

As determired by optimizaticn
Quick core retrieval Sample needs preservation Sample needs preservation Sample needs preservation None

Assumes vertical well Acceptable formation for packer seats, etc

Assumes no gas saturation

Alternative BHP when there is gas pressure.

Assumes virgin reservoir 
TABLE 2 - Continued

POTENTIAL TEST ACTIVITIES

COAL DEGASIFICATION FIELD TEST PROGRAM

\section{Test or}

Activity

Natura1 Production Test

\section{Stimulated}

Production Test

\section{Parameters Measured}

Water Rate, Gas Rate, Flowing Pressure, Time Gas and Water Quality

Water Rate, Gas Rate, Flowing Pressure, Time

Gas Composition

Water Impurities

Water Leve1

\section{Parameters Determined and Precision}

Relative Permealility, +.07 , Saturatiors,

$\bar{P}_{\text {error }}=0$, Porosity

Hydraulic Stimulation Parameters, (Length $\pm 20 \%$ and Conductivity $\pm 50 \%$ )

Water: Analysis

Echo Meter Survey
Bottom-hole flowing Pressure \pm 5 psi

\section{Recommended}

Frequency

\section{As determined by} optimization

As determined by optimization.

Regular scheduled basis

One time each well

Regular scheduled basis
Constraints

Can be done only in Stimulated wells

Should be. taken during stable production

Should be taken prior to stimulation 
TABLE 3

TEST MODULE - PARAMETZR DETERMINATION MATZIX

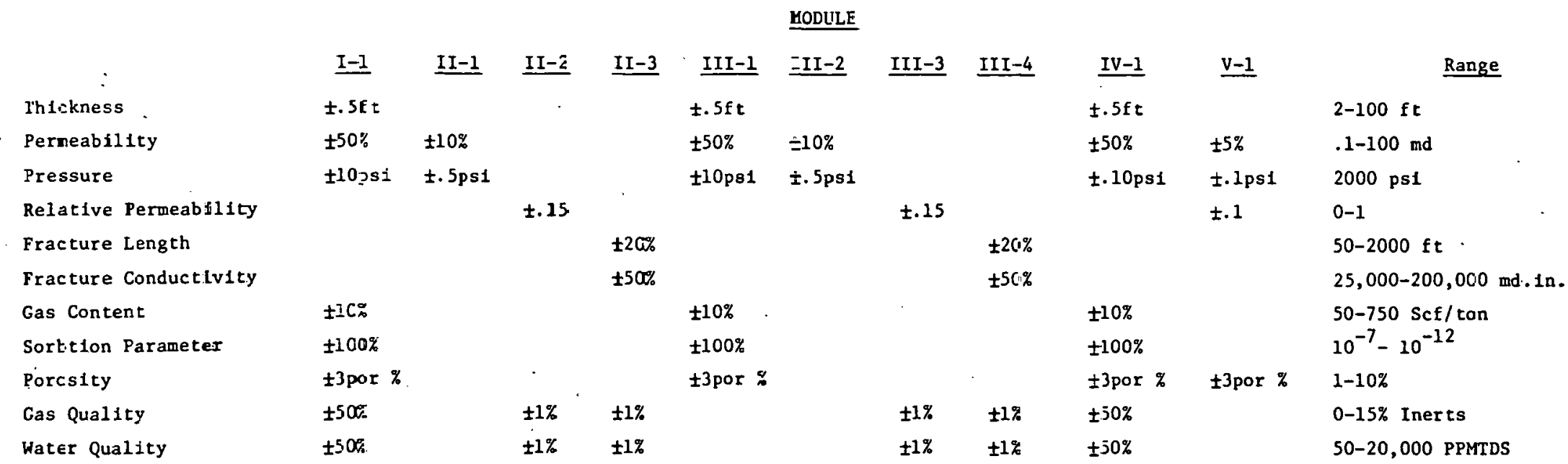




\section{MATHEMATICAL REPRESENTATION \\ OF SIMULATION RESULTS}

The preceding sections discussed the variables that are important to determine gas production from coal and the methods available for assessing their ranges and distributions and effect on gas deliverability. This section covers a statistical treatment of the simulation data to develop methodology for specifying a program of field testing and evaluation.

\section{A. Distribution of Independent Variables}

The independent variables are permeability (k), relative permeability $\left(k_{r}\right)$, pressure $(p)$, gas content ( $\left.I_{s o}\right)$, fracture length $\left(F_{1}\right)$ and fracture conductivity $\left(F_{C}\right)$. These six variables were the most sensitive and important in simulating and predicting gas deliverability, $\phi$, the dependent variable. Since only a sample from a uniform distribution of each variable was used in the simulation, the expected distribution and the ranges over which the independent variables could be expected to vary was required. This information, which is subjective, was estimated based upon expert opinion instead of sampling data. In all cases the type of distribution; normal, log normal, uniform, etc., was provided along with the range of expected observations. All variables are assumed to be independent of each other except for the following:

(1) fracture length and fracture conductivity were considered to be negatively covarient; and

(2) gas content and pressure were considered mildly positively covarient, i.e., gas content is somewhat dependent on pressure.

The distribution expected for each independent variable is shown in Figures 7 through 12 . 


\section{B. Potential Sources of Uncertainty}

The test modules proposed for the sampling program are described in detail in an earlier section. This description includes a discussion of how the test is to be accomplished with an estimate of the cost per test. Each module measures one or more of the independent variables to a predefined, estimated accuracy level. The test modules, variables measured and accuracy levels are summarized in Table 3 . These will be the information gathering tools for the testing phase of, the project.

\section{Measurement. Error}

Measurement errors are introduced due to a lack of preisiun in the test procedures and equipment. Each test module has a level of accuracy associated with the measurement of each independent variable. Accuracy, expressed as tolerancc around the measured value, is a function of the type of test to be performed which is in turn subject to budget and site availability constraints. For example, expensive highly accurate tests cannot be performed in all of the required sampling locations. The errors associated with the measurement of a variable are assumed to be normally distributed. Table 3 shows measurement errors at the two standard deviation (95\%) levels.

\section{prediction Error}

A measure of the accuracy with which the gas deliverability can be predicted is the prediction error. This measure is identified in regression equations as the standard error of regression and is calculated as the standard deviation of the residuals (the predicted value minus the value of the dependent variable for each case) for each equation. The standard deviation is calculated as the square root of the variance. Thus the terms error, variance and standard deviation, as used.in this report, are descriptive of the same concept; lack of accuracy or lack of ability to predict perfectly. 
Module I-l is used in gas or oil wells that have been drilled through an unminable coal seam. To execute testing with the module, drilling activity is halted, the tests are carried out and the well'is completed. The nature of this test and the imputed cost in terms of a delayed well completion requires that all work be completed quickly. It is a basic survey tool which can be used in many locations to characterize the distributions of the independent variables. This module measures pressure, permeability, thickness and gas content. After conducting the statistical anlayses, it. is recommended that relative permeability be included as a Module I-l variable when field operating conditions permit. The predictive result of adding this measurement is to substantialiy reduce the error of the Module I-l regression model. It could also provide a 2 to 5 fold increase in the number of observations of relative permeability which is one of the most sensitive variables.

Modules II-1,2,3 and III-2,3,4 are more intensive and accurate. They are also expensive which precludes their use for obtaining survey information on gas deliverability from various geological and geographical coals. They are very important for:

(1) highly accurate and low error tolerance prediction of gas deliverability,

(2) calibration of Module I-l measurement errors,

(3) calibration of Module I-l prediction errors, and

(4) validation of the simulation model.

Module V-l adds an observation well to Modules II and III and will result in more accurate measurements of the independent variables. 
Module IV-l consists of tests performed in a well drilled and cored for coal exploration. This module is as accurate as a Module I-I program; however, it is not a desirable approach because the tests are more difficult to execute and, compared, with oil and gas wells, there are fewer choices.

\section{Regression Equation Development}

Mathematical models can be categorized as predictive, descriptive or instructive. They are also classified as theoretical or empirical based upon how they are developed. Two different kinds of models were used in this project. The simulation model is theoretical and predictive of gas deliverability, $\phi$. The other model, which is a regression model, is empirically derived and is both predictive and descriptive. The regression equations derived in this project used the independent variables from the simulation model. Both the simulation model and the regression equation use gas deliverability $(\phi)$ as the dependent variable. The regression equations represent a least squares (minimum error) linear equation. They are empirically derived and represent a linear description of the nonlinear simulation process.

Certain nonlinear methods (e.g. multiplicative terms, ratios, squared terms) were avoided even though they may have enhanced the predictive capabilities of the equations. A more simple linear equation is more appropriate because a) the simpler the equation the more straight-forward is the interpretation of the predicted $\phi$, estimated by regression; and b) the effects of limited input data and the efficiency of single versus multiple samples are easier to analyze. Due to this descriptive approach, it is possible to accurately estimate the cost/benefit/efficiency relationship for various modules, various levels of measurement errors and various multiple sample schemes. 
Separate regression equations were developed to describe natural production cases and stimulated production cases. This approach reflects the difference in levels of gas delivery obtainable from each process and is verified by the differences in equation parameters for the two cases. An approach utilizing two equations for each test module is required to obtain a more accurate estimate of gas deliverability for stimulated and natural production and to make separate evaluations of the predictive variance corresponding to each module in a testing strategy.

\section{Data Source and Treatment}

\section{Source}

All input data to the regression models were obtained from the simulation runs described in section III and shown as Appendix. A. Input variables representing permeability, pressure, relative permeability, gas content, fracture length and fracture conductivity with the output gas deliverability were obtained on a case-by-case basis for a total of 456 cases. These data covered the expected range of each variable and included approximately one-third of: all possible combinations of the six independent variables (from the three to seven discrete values selected for each variable).

The data base is considered adequate to describe the behavior of gas deliverability in any testing situation that might be encountered. Conceptually, the data base can be viewed as a roughly uniform distribution in seven dimensions over the ranges of the six independent variables plus the dependent variable, $\phi$.

\section{Data Treatment}

In order to formulate an equation consistent with the expected real-world test results, the original data base was slightly modified. This was accomplished by sampling the 
simulation data to reduce the distribution of each variable from a uniform distribution to its expected population distribution as shown in Figures 7 through 12. The procedure for sampling the data preserved the independence of samples in the data base and resulted in a new data base in seven dimensions in. which each independent variable conforms to its expected range and distribution.

Three important objectives were achieved by this operation: (1) since independence of observations was preserved, an implicit population distribution of gas deliverability $(\phi)$ for stimulated and natural production was obtained directly from the data base. These: distributions are log normal and are shown as Figure 13 (stimulated) and Figure 14 (natural production); (2) since the number of observations for regression analysis are greater at values of gas deliverability which occur most frequently in the population, the descriptive and predictive powers of the regression model are highest at these more frequent values. In other words, some explanatory accuracy has been sacrificed at extreme values of gas deliverability in order to put maximum explanatory power in the ranges where most observations are expected to occur in the testing program. This loss in explanatory power at extreme values took the form of systematic errors (overprediction at low values and underprediction at high) as opposed to random errors; (3) when the distributions of any or all independent variables are revised on the basis of test results, the same uniform distribution data base san bo used as the basis to rocolcct obscrvations conforming to rcviscd distributions. That is, it is cunsidered quite likely that no additional simulations will be needed regardless of how many times the distributions of the independent variables are revised, providing that the range of each variable does not increase substantially. 
In order to present the data in a manner of more physical significance, the distributions of stimulated production and natural production are shown as histograms on Figures 15 and 16. Through comparison of these figures, it is obvious that stimulation will have large effect on the economics of methane production from coal.

3. Other Data Treatment

Models were developed for various combinations of data in natural $\log$ form and actual units form. With all variables in the natural log form, models were found to have a smaller standard error and to be better predictors of $\phi$. For those variables with relative values for units (e.g. relative permeability was expressed as 1 or 2 ). various other values were tested to obtain the best model fit. Gas content was calculated from its given isotherm and pressure to enhance the equation.

E. Determination of Regression Equation

The following objectives were satisfied during the regression modeling activity.

1. Develop an equation corresponding to each test module.

2. Compare prediction error among test modules.

3. Establish the minimum prediction error achievable by the test program.

4. Assess the relative importance of each variable in each model.

The following summarizes how each objective was addressed during the project. 
Objective 1

A regression equation was developed to correspond to each test module described in section IV. The variables included in each model correspond to the variables measured in the associated test module. These equations are shown following this discussion section. A new symbol $\hat{\phi}$ is introduced which is defined as the estimate of $\phi$ computed from the regression equations.

It is necessary to note that the addition of observation wells did not change the equation for either Module II-1,2,3 or III-1,2,3,4. This means that the improved precision from observation wells does not materially affect the ability to predict $\phi$.

Objective 2

The ability to compare the standard error shown on Table 4 of each model is a key input to the test program design because the standard error indicates directly the predictive confidence that can be associated with each test module (assuming zero measurement error). In other words, the confidence level for predicting gas deliverability with the limited informaliun yathered by each test module can be assessed by comparing the standard error statistic for each regression equation.

\section{Objective 3}

The minimum predictive error arhievable by these modcls is the standind error associaled with Module III 1-4. This is considered to be the base level (minimum) error because it includes all variables under consideration and inputs them at zero measurement error. It is assumed in the first stage of testing that this base error level is not subject to further minimization and is therefore the ultimate level of reduction in standard error which the test program design can approach. 
Objective 4

The relative importance of each variable in any equation is indicated by the Beta statistic shown in Table 4 . This information is important in indicating where measurement errors should be held to a minimum. For example, analysis of the Beta statistic was instrumental in the recommendation to expand the Module I-1 test to include relative permeability whenever field conditions permit. The significant finding which resulted from this analysis is that, generally, in these modules either permeability or relative permeability is the most important variable, followed by pressure. 
REGRESSION EQUATIONS: SIMULATED PRODUCTION

Module I-1

$$
\ln \hat{\phi}=4.246+.435(\ell n k)+.650(\operatorname{lnp})+.673\left(\ln I_{s o}\right) . .
$$

\section{Module III-1,2,4}

$$
\begin{aligned}
\ln \hat{\phi} & =-1.05+.422(\ell \mathrm{nk})+.644(\mathrm{lnp})+.399\left(\ell n F_{1}\right) \\
& +.251\left(\ell n F_{c}\right)+.666\left(\operatorname{lnI} \mathrm{IO}_{\mathrm{S}}\right) . . . . . . . . . .
\end{aligned}
$$

Module II-1,3

$$
\begin{aligned}
. \mathrm{n} \phi & =-1.929+.425(\ell n k)+.781(\ell n p)+.116\left(\ell n F_{1}\right) \\
& +.330\left(\ell n F_{C}\right) \ldots . . . . . . . . . . . . . .
\end{aligned}
$$

Module III-1,2,3,4 and $\mathrm{V}-1$

$$
\begin{aligned}
\ln \hat{\phi} & =-2.206+.460(\ell n k)+.704(\ell n p)+1.91\left(\ell n k_{r}\right) \\
& +.370\left(\ell \mathrm{nF}_{1}\right)+.286\left(\ell \mathrm{nF}_{c}\right) . . . . . . . . . . .(10)
\end{aligned}
$$

Module II $-1,2,3$ and $\mathrm{V}-1$

$$
\begin{aligned}
\ln \phi & =-2.944+.464(\ell n k)+.813(\ell n p)+2.044\left(\ell n k_{r}\right) \\
& +.404\left(\ell n F_{1}\right)+.347\left(\ell n F_{c}\right) . . . . . . . . . . .
\end{aligned}
$$


REEGRESSION EQUUATIONS: NATURAL PRODUCTION

Module I-1

$\ln \hat{\phi}=2.821+.749(\operatorname{lnk})+.552(\operatorname{lnp})+.451\left(\operatorname{lnI} \mathrm{so}_{\text {so }}\right) \cdot \because \therefore(12)$

Module II-1,2

$\ln \phi=.1715+.821(\operatorname{lnk})+1.219(\ln p)+2.951\left(\operatorname{lnk}_{\mathrm{r}}\right) . .$.

Module III-1,2,3

$\ln \phi=-1.668+.819(\operatorname{lnk})+1.087(\operatorname{lnp})+2.928\left(\ell n k_{r}\right)$

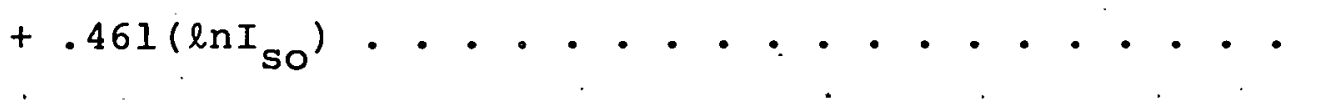

Module III-1,2,3,5 (also, Module II-1,2,5)

ln $\phi=-1.508+.850(\ell n k)+1.046(\ell n p)+3.029\left(\ell n k_{r}\right)$

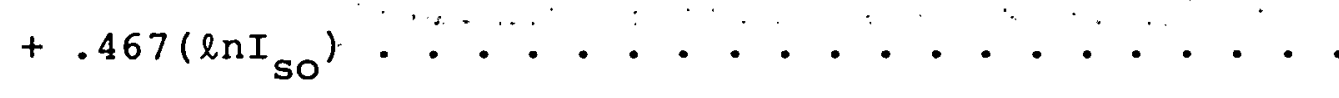


Module Standard F-Ratio

$$
\text { Error }
$$

Beta

k $\quad \mathrm{p} \quad \mathrm{k}_{\mathrm{r}} \quad \mathrm{I}_{\text {so }} \quad \mathrm{F}_{\mathrm{e}} \quad \mathrm{F}_{\mathrm{C}}$

stimulated

$\begin{array}{lrrrrrrrr}\text { I-1 } & .794 & 59 & .446 & .375 & -- & .374 & & \\ \text { II-1,2,4 } & .777 & 38 & .443 & .371 & -- & .370 & .239 & .136 \\ \text { II-1,3 } & .894 & 29 & .435 & .451 & -- & -- & .258 & .179 \\ \text { III-1,2,3,4 } & & & & & & & \\ \text { and V-1 } & .313 & 302 & .471 & .405 & .577 & .283 & .222 & .155 \\ \text { II-1,2,3 } & .462 & 154 & .476 & .468 & .617 & -- & .243 & .188 \\ \text { and V-1 } & .462 & & & & & & \end{array}$

Natural

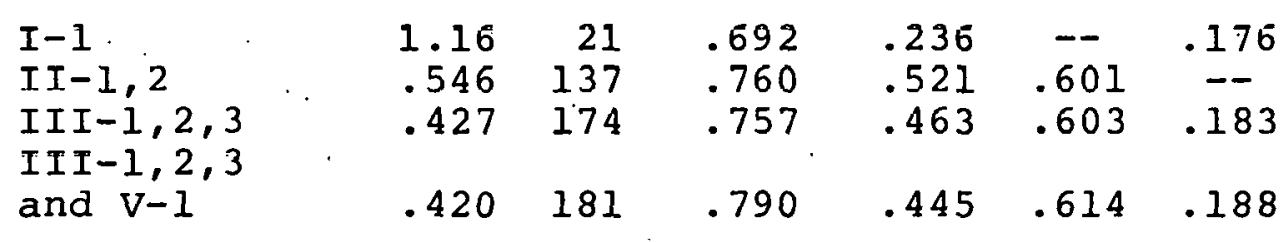


F. Measurement Error Simulation

The comparison of standard errors in Section $E$ is a good indication of comparative prediction variance. However, it is not a completely realistic indication because measurement errors are more severe in some test modules than in others. Utilizing the regression equations developed in the previous section and the various levels of measurement error discussed in section $c$, a Monte Carlo simulation was conducted to randomly assign the measurement errors associated with each testing module to the distribution of independent variables. This procedure made it possible to address two objectives: 1) evaluate the best possible (most realistic) performance of the regression models under anticipated operating conditions, and 2) assess reduction achievable in standard error with multiple observation testing.

The standard errors for each model arrived at by Monte Carlo simulation are the most realistic measure of comparative prediction and are shown in Tables 5 and 6 . The measurement errors are assumed to be distributed normally around the measurement. This results in a cancelling of the errors from multiple measurements. Note that the standard error for the least accurate test (Module I-1) remained constant while the more accurate tests showed a greater increase in prediction error. Although the procedure just described normally completes the simulation process, an additional step was performed in which several equations were reformulated using the error adjusted data as input variables instead of overlaying eriors after equation formulation, as was previously described. Prediction error of this model was then compared with the original models. The original models exhibited smaller errors compared to the reformulated models with the exception of Modules II-2 and III-3 natural production equations; these two are used in place of the original equations. 
TABLE 5

SUMMARY OF SIMULATED MEASUREMENT ERROR

STIMULATED PRODUCTION MODELS

\begin{tabular}{|c|c|c|}
\hline Moduie : & $\begin{array}{l}\text { Model Error } \\
\text { with Perfect } \\
\text { Information }\end{array}$ & $\begin{array}{c}\text { Model Error } \\
\text { After } \\
\text { Simulation }\end{array}$ \\
\hline$I=1$ & .794 & .794 \\
\hline $\begin{array}{l}\text { II- } 1,3 \\
\text { III-1, } 2,4\end{array}$ & .335 & .384 \\
\hline $\begin{array}{l}\text { III-1, } 2,3,4 \\
V-1\end{array}$ & .313 & .336 \\
\hline
\end{tabular}


TABLE 6

SUMMARY OF. SIMULATED MEASUREMENT ERROR

NATURAL PRODUCTION MODELS

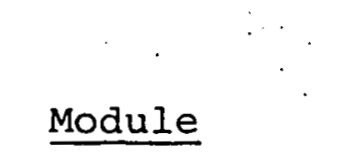

$I-1$

$I I-1,2$

III-1,2,3

$\operatorname{III}-1,2,3,5$

II $-1,2,5$
Model Error with Perfect Information

$$
1.16
$$

*

*
Model Error

After.

Simulation

1.12

.427

.420

* These models were formulated using error adjusted input data: no perfect information error measurements are available. 
The second objective of the Monte Carlo simulation process was to assess the reduction in error that could be achieved by multiple observations of the variable at one test site. This testing procedure demonstrated approximately the same effect as substituting a more accurate test for a less accurate one.

\section{G. Test Program Simulation}

At the initiation of the study several assumptions were made regarding the validity of the simulation model, the distributions of the dependent variables, a homogeneous resource base, etc. These assumptions supported the development of regreceion modela, representing liesl inulules, which when provided a set of independent variables, would predict $\phi$. For example, based upon measures of pressure, permeability and gas content from a module, a $I-1$ test, a regression model is available to predict $\phi$ for stimulated production and for natural production. Each model has a standard error associated with it which is a measure of its predictive quality. Module III-1, 2, 3, 4 is the most accurate predictor, error of .313 , and is considered the base error. This module is a standard for cumparing the prealctive capability of other modules.

A Monte Carlo simulation process was selected for determining the amount of testing required to draw valid statistical inferences about the results. The process consisted of an analysis of changes in the standard deviation as testing with a module was simulated. The procedure consisted of the following:

1. The distribution of each independent variable was sampled 500 times creating 500 individual sample cases. Since this distribution was subjectively derived and supplied as a priori information, it must be quantitatively measured during the test program. 
2. Each equation was exercised 500 times with the same data with mean $\hat{\phi}$ and the standard deviation calcu-. lated. This data is illustrated in the following table. Note the arrow pointing out Module III-1,2; 3,4 the standard.

TABLE 7

SIMULATED SAMPLING OF PREDICTIONS OF $\phi$

\section{Module}

$I-1$

III- $1,2,4$

II $-1,3$

III- $1,2,3,4$

II $-1,2,3$

$I-1$

II $-1,2$

III- $1,2,3$

III $-1,2,3$ and II $-1,2$
Mean

10.4450

10.4542

10.3632

10.6486

10.5936

8.6705

10.9879

9.1814

9.2205
Deviation

0.9522

0.9360

0.9904

$1.1436+$

1.2162

1.3644

1.9511

1.8819

1.9175

3. The same data base was then used to simulate testing of the resource base to determine how many samples would be required if every module were to be used. The standard deviation was calculated for samples with incremental observations to include 5, 10, 15, $20,25,30,40,50$ and 100. This data is graphically demonstrated in Figures $17 \mathrm{~A}, \mathrm{~B}, \mathrm{C}$ and $\mathrm{D}$ for stimulated production and $18 \mathrm{~A}, \mathrm{~B}, \mathrm{C}$ and $\mathrm{D}$ for natural production. Each graph has the true population deviation of $\phi$. superimposed. The ability of the standard deviation to approach this line asymtotic from above or below, is a reflection of the standard error and the predictive capability of the module. The rate of change, in the slopes suggests that a minimum of 25 samples be taken with each module that is to be used. In addition 
since multiple locations within a basin must be sampled, it is recommended that Module $I-I$ be the basic survey tool, because of its low cost relative to other alternatives.

Module III-1,2,3,4 or Module II-1,2,3 is recommended as the basic test module for measuring gas deliverability as a function of the independent variables. The inclusion of an observation well is not warranted based upon the results of the statistical analysis. However, since the simulation program and the test module analysis is predicated on some key assumptions, a llisinum or live ubservaliun wells shuuld be included.

This is recommended to assess measurement errors. If the errors associated with Modules $I I-1,2,3$ and III-1,2,3,4 need to be increased through experience, the exror for observation wells also needs assessment to see if additional observation wells are warranted.

4. An additional simulation was performed in which a Monte Carlo process was used to randomly assign errors to samples of the independent variables. The independent variables, as in 3 above, were sampled from the prior distributions in Figures 7 through 12. The results of this process parallcled the rcsulto shown in Figurcs 17 and 18 . Each curve was offset slightly higher and to the right of Figures 1.7 and 18. The effect of simulating measurement error is to shift the confidence level from a minimum of 20 to a minimum of 25 observations. 


\section{TEST FRUGRAM DEVELUYMEN'I}

The overall objective of the program is to develop information - improve the state of knowledge -- about coal and its associated methane gas in several geological basins. In order to guide future programs designed to evaluate the commercial potential of extracting methane from the coals, the test program will address the improvement in the state of knowledge so as to form a solid base or foundation of information upon which these future programs can be reliably structured. This information includes characterization of the resource base as to methane content and deliverability, identification of the ranges and distribution of the independent variables, identification of the range and distribution. of gas deliverability, $\phi$, assessment of measurement errors, validation. of the simulation model and regression equations.

\section{A. Priorities}

Since the current state of knowledge is very limited, the initial set of tests must reduce present uncertainty about the independent variables which determine gas deliverability and the accuracy with which these variables can be measured. This information must then be fed back into the analysis to increase confidence in the procedure. Specifically, assessments must be developed as to the adequacy of the regression equation as predictors of simulated $\phi$ and of the simulation model as a predictor of actual gas deliverability, $\phi$. This assessment should be used to Einalize the proposed test program.

\section{B. Testing options}

Subject to the constraint that at least one test must be made in each area of interest, several orientations of the 
test program are available. These orientations are summarized as discrete activity blocks; however, there is flexibility and overlap among orientations.

\section{Survey the Resource Base}

This orientation requires tests in each basin of interest with measurement of variables associated with type and amount of coal and associated methane. This orientation is valuable to the extent it characterizes basin-to-basin differences in the independent variables but is of reduced value to the extent that it does not characterize variability within basins. This survey should include tests (samples) in each basin of interest without regard to quantity or quality of coal.

\section{Range and Distribution of Independent Variables - Quality and Quantity Considerations}

This orientation is similar to (1) in that it is a survey of independent variables in several basins and in the three coal ranks. It is different in that it seeks to locate tests more in relation to spatial qualities of coal than to discrete basins. This orientation requires statistically relevant samples within each coal rank.

This point is brought into perspective through a restatement of the distribution of gas deliverability, $\phi$, over the entire resource base. Thio objeotive of identifying this distribution can be achieved with 25 Type IT or TII. wells within the resource base. However, this distribution is made up of distributions of each coal type. To conclude anything about gas deliverability from measurement of the independent variables in a particular coal type, statistically relevant testing must be performed for each type. This cannot be accomplished with 25 gas deliverability tests alone. 
Then, this orientation requires that data be collected within each coal type in sufficient quantity to identify the range and distribution of independent variables per coal type. This indicates that this objective can be accomplished with less expensive survey tests (Module I-1) set-up to augment the data gathered from gas deliverability tests.

\section{Assessment of Measurement Errors}

This orientation emphasizes reducing the uncertainty concerning the precision and relative accuracy of the test modules. This is accomplished by repeating the same test from 4 to 10 times at the same test site and analyzing the distribution of measurements. This orientation is valuable for gaining confidence in the precision with which a variable can be measured.

4. Validation of the Simulation Model

This orientation seeks to verify the adequancy of the theoretically derived simulation model as a predictor of gas deliverability. It requires reliance on Type II or III wells in each coal type of interest. The actual production, both natural and stimulated are then compared with predicted.

These four orientations describe the basic options available that influence the structure of the testing program. The following considerations guide selection of a specific agenda.

a. This test program is the first step in a continuing effort to demonstrate the capability for commercial extraction of methane from coal.

b. Further testing will occur and provide information on measurement errors and the distribution of variables which will be essential to determining future analytical techniques and methods. 
c. There may be valid information on measurement errors outside the testing program. ".This information should be obtained whenever possible.

d. A minimum of 25 observations are necessary to make an inference about the population distribution of variables and to the distribution of $\phi$ over the resource base.

\section{Recommended Test Program}

The tollowing test program specifies the number of tests, with proximity and areal constraints, required to accomplish the four program orientations specified earlier. These, when viewed as objectives, have, the following requirements:

1. The program must determine the distribution of gas deliverability $(\phi)$ from the resource base, all target coal in the study area. The most cost effective tests available for accomplishing this objective are Module II-1, 2,3 and Module III-1,2, 3,4. These modules are described by the same regression equation as the modules with the observation well. When overlain with measurement error, the predictive capability without the observation well is within 18 of that with the observation well. A minimum of 25 gas production tests are required.

2. The program must determine the distribution of the independent and dependent variablcs in the coal types under consideration. 'Ihis.is required in order to predict gas deliverability from the specific types of coal within the target area. This will require a minimum of 20 additional Type I-l tests in each coal rank... As noted. 
earlier, when substituting a more accurate test for a less accurate test the number of observations can be reduced.

3. The preceding two recommendations should be constrained to ensure that the complete data collection effort can be statistically correlated. The following constraints are recommended.

a. Three areas should be selected, representing each type of coal with the following tests run.

Three (3) each - Module II-1,2,3 or Module III-1,2,3,4

Seven (7) each - Module I-1

This will total to 9 gas deliverability and 21 survey tests.

4. Perform the 16 remaining gas deliverability and 39 remaining survey tests within the remaining resource base. Select test sites to ensure that at least one test is performed in each basin.

5. Even though the observation well in the gas deliverability test showed a minimal statistical improvement, it is a prudent recommendation that at least five observation wells be drilled and tested. These should cover all coal types and preferably be added with recommendation $3 a$. The addition of these tests will provide sufficient data at the higher accuracy level to reformulate the relationships between the independent and dependent variables. This reformulation could 
be a requirement from the tests. It is a contingency that should be included in the test plan.

6. This program assumes that data on measurement error will be provided from another source. If this data is deemed inadequate, additional sampling is required. The objective is to ensure that some understanding is gained on the accuracy of a single measurement. This point is germane to predicting gas deliverability with a single Module I-l test. Without this data there will be less confidence in a prediction. Also, less sonfidance in potontial gao cconomies from a lie well test.

This data is obtained from multiple samples (10-15) of the same variables at the same test site. Approximately 150 samples are required, thus 10-15 wells will need to be tested.

\section{Estimated Costs}

While it is thought that the costs presented in section IV are realistic for the individual Test Modules, there can be wide variatione. Thesc variations may be caused by (I) drilling depths, (2) accessibility of sites, (3) seasonal and weather differences, or (4) availability of equipment. However, the sixty Module I-1 tests would cost an estimated $\$ 1,080,000$. Assuming that there is a $25 \%$ failure due to mechanical problems such as packer failure and poor core recovery, the estimate would be $\$ I, 440,000$.

The estimated costs for the 25 production tests would be $\$ 2,837,500$ if all Type III wells were used and funded completely. If all Type II wells were used, the 25 tests would be $\$ 1,300,000$. Actual costs will probably lie somewhere in this range. 
This makes a maximum budget estimate of $\$ 4.3$ million for the complete test program. The minimum cost could be $\$ 2.7$ million.

These tests are presented as a total number. They need not be new tests if existing data is available from which the determinations of the independent variables can be made. Unfortunately there is little data available of a quality from which these independent variables can be determined. Further, what data do exist, is in close proximity to mines and certainly is not in the "unminable" category.

\section{E. 1978 Test Program}

The constraints, orientations available, priorities and other considerations outlined in previous sections influence and, to a degree, specify the following 1978 program recommendation. This program will balance the four orientations to obtain maximum information on the resource base, the distribution of gas deliverability and the predictive capability of the regression equations.

\section{Specific Program}

a. Conduct fifteen Module $I-1$ tests in as many basins as possible.

1. Within a single basin attempt to sondust. two or three additional Module $\mathrm{I}-\mathrm{l}$ tests of the same coals in the same vicinity (multiple observations of the same independent variables).

2. Conduct a second Module $I-1$ test in two basins at a considerable distance from the first test site.

b. Support the drilling of a Type III well which includes a minimum of Modules III-1,2,3,4. 


\section{Costs}

Based on the costs projected in section IV, the costs for this program would be $\$ 322,000$ if a Type II well were used for the deliverability test. If a complete Type III well is necessary, the cost may be as high as $\$ 383,000$. Regardless of the validity of the cost estimates, there will undoubtedly be considerable negotiations involving the Department of Energy and the independent operators who may be involved. The outcome of these negotiations will have a larger impact on the total cost than the cost estimates contained herein.

This problem is one good reason to do the 1978 test program. The results of this effort will provide a sound base from which to project costs for the overall program.

\section{Flexible Budgeting}

Should the specified test programs be projected to exceed the testing budget at any time, the following tests should be deleted from the program (in this order):

\footnotetext{
- One of the Module I-l tests from paragraph 1.a.1.

- An additional Module I-l test from paragraph i.a.2.

- An additional Module I-l test from paragraph 1.a.1.
}

If, dur to the rooperation uf drilling companies, more tests become available within the budget constraint, the following should be considered (in this order):

- One additional Type II or III well, preferably in close proximity to a Module I-l test.

- Multiple observations in any test site. 


\section{REFERENCES}

1. Joubert;"J. 'I.; "Effect of Moisture on the Methane Capacity of American Coals"., FUEL, July, 1973.

2. Joubert, J.' I:, et al, "Sorption of Methane in Moist Coal", FUEL, July, : 1972 .

3. Ruppel, T. C.; et al', "Adsorption of Methane on Dry Coal at. Elevated Pressure", FUEL, Vol. 53, 1974.

4. Kim, A. G., "Extrapolating Laboratory Data to Estimate the Methane Content of Coalbeds", U. S. Bureau of Mines, RI (in press), 1976 .

5. Kissell, F. N., et al, "The Direct Method of Determining Methane Content of Coalbeds for Ventilation Design", U. S. Bureau of Mines, RI 7767, 1973.

6. McCulloch, C. M., et al, "Cleat in. Bituminous Coalbeds", U. S. Bureau of Mines, RI 7910, 1974.

7. Tabor; J. J.:, et al "Development of Techniques and the Measurement of Relative. Permeability and Capillary Pressure Relationships in Coal", NTIS PB-232-244, January, 1974 .

8. Kneuper, K., and Huckel, B. A., "Contribution to the Geochemistry of Mine Gas in the Carboniferous Coal Field of the Saar Region, Germany", Advances in Organic Geochemistry, Pergamon Press, Oxford, 1972.

9. Erdle, J. C.; et al, "Early Fluid Entry Determination, Key to Safe, uptimum Drill stem Testing", Society of Petroleum Engineers, Paper No. 6884, October, 1977.

10. Averitt, Paul, "Coal Resources of the United states, January 1, 1974", U. S. Geological Survey Bulletin 1412 .

11. Ruppel;, T. C., et al, "Adsorption of Methane on Coal to 140 Atmospheres Pressure", Presentation at 157 th National ACS Meeting, U. S. Bureau of Mines, 1969.

12. Elder, C. H., "Effects of Hydraulic Stimulation on Coalbeds and Associated Strata", U. S. Bureau of Mines, RI $8260,1977$. 
REFERENCES - Continued

13. Agrawal, R. G. et al, "Evaluation and Prediction of Performance of Low Permeability Gas Wells Stimulated by Massive Hydraulic Fracturing", Society of Petroleum Engineers Paper No. 6838, October, 1977.

14. Keil, O. M., U. S. Patent No. 3,933, 205. 
FIGURES 
EQUILIBRIUM ADSORPTION ISOTHERMS. Coal type and moisture levels selected to correspond to the cores extracted, from the vertical boreholes.

(FROM KISSELL ET AL, USBM RI 7767)

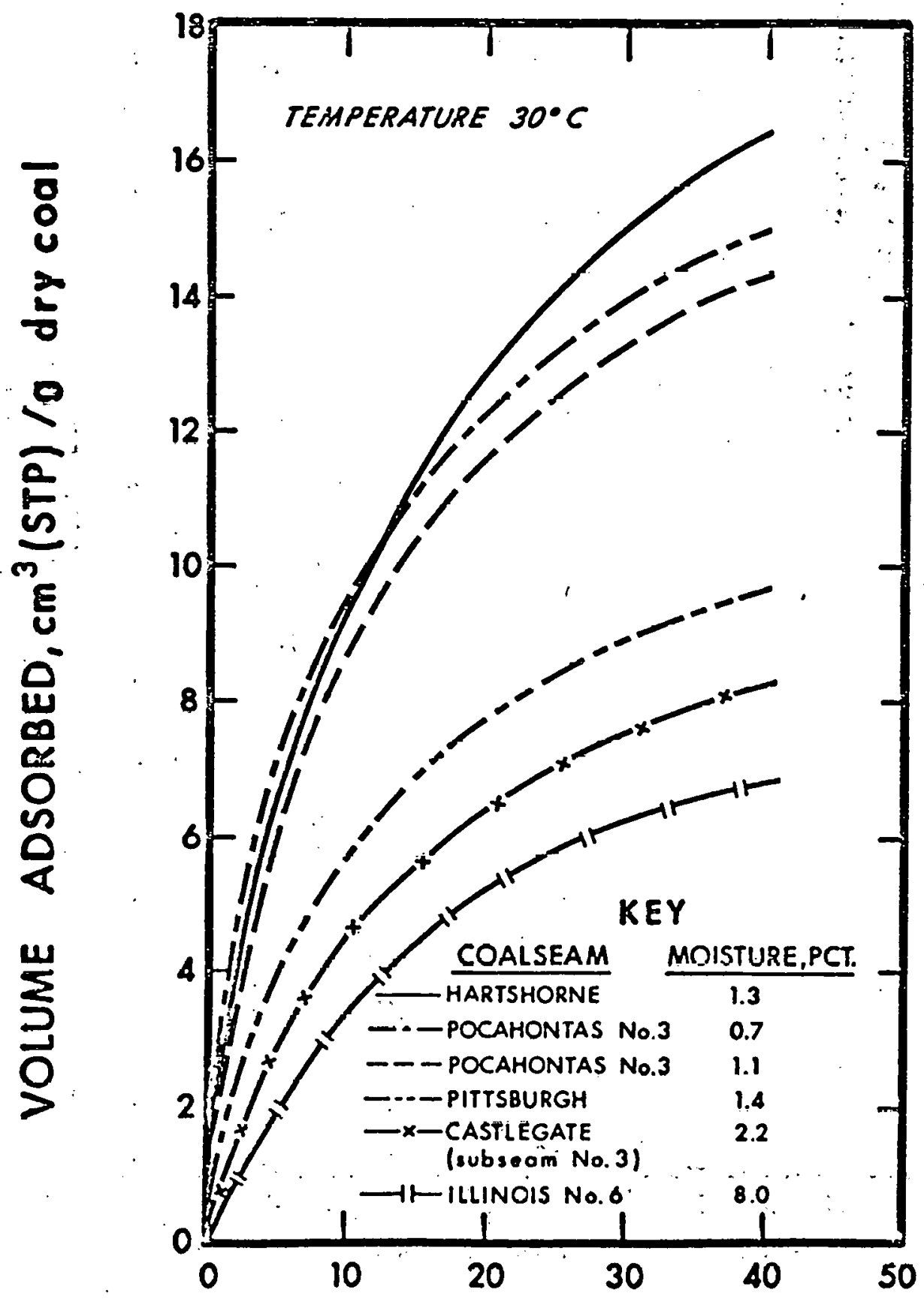

PRESSURE, atm 


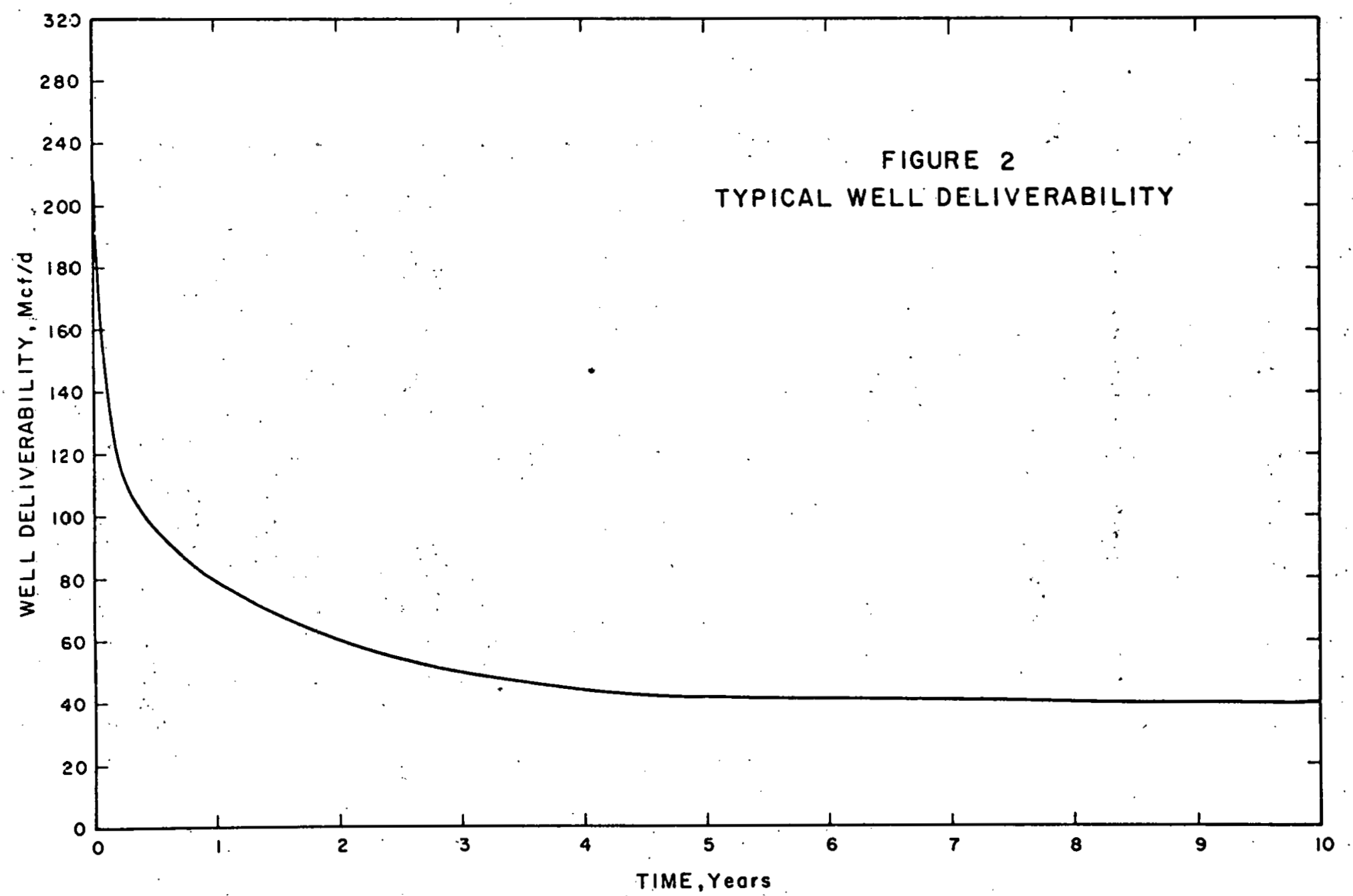




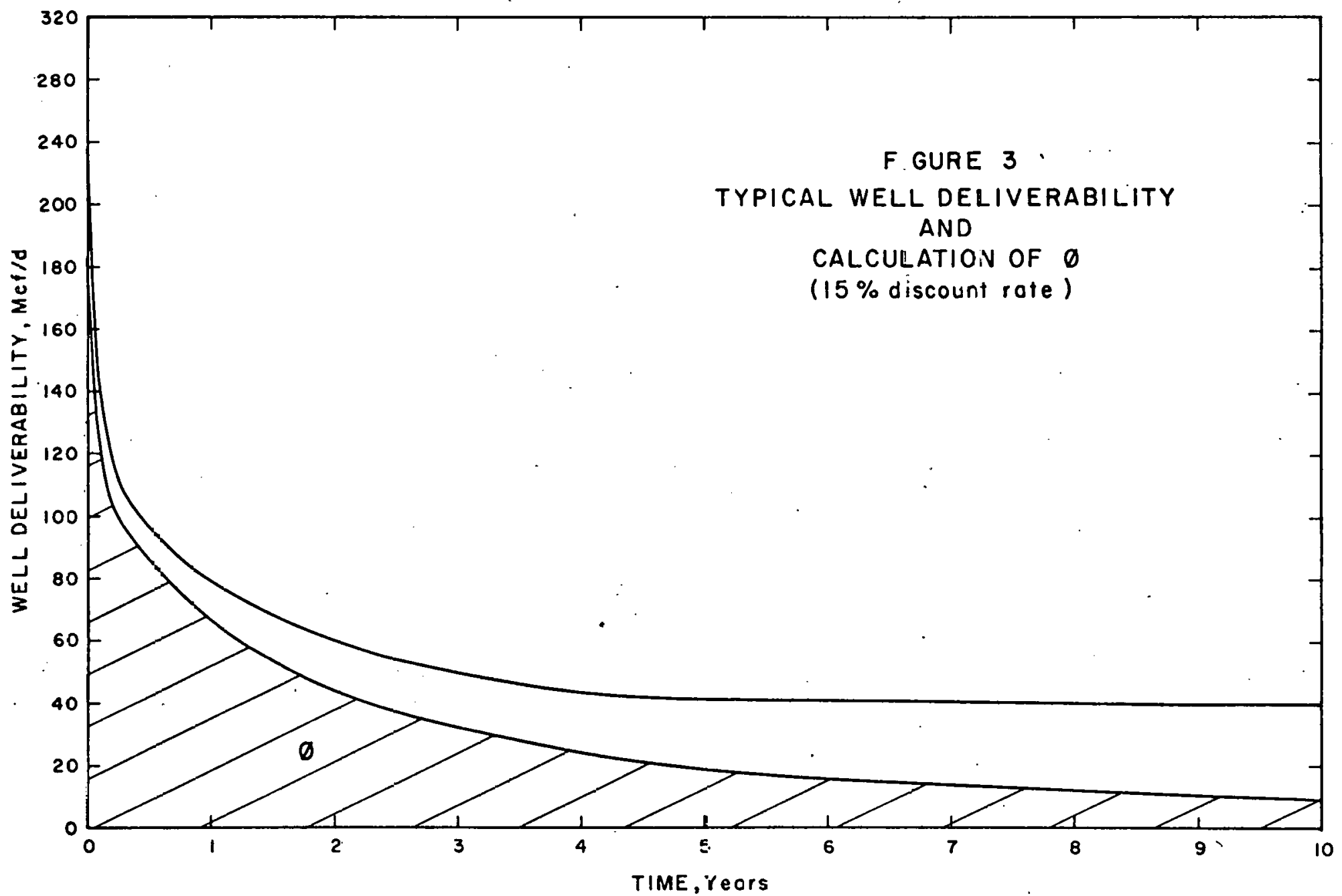


FIGURE 4

EXPECTED RANGE OF GAS CONTENT

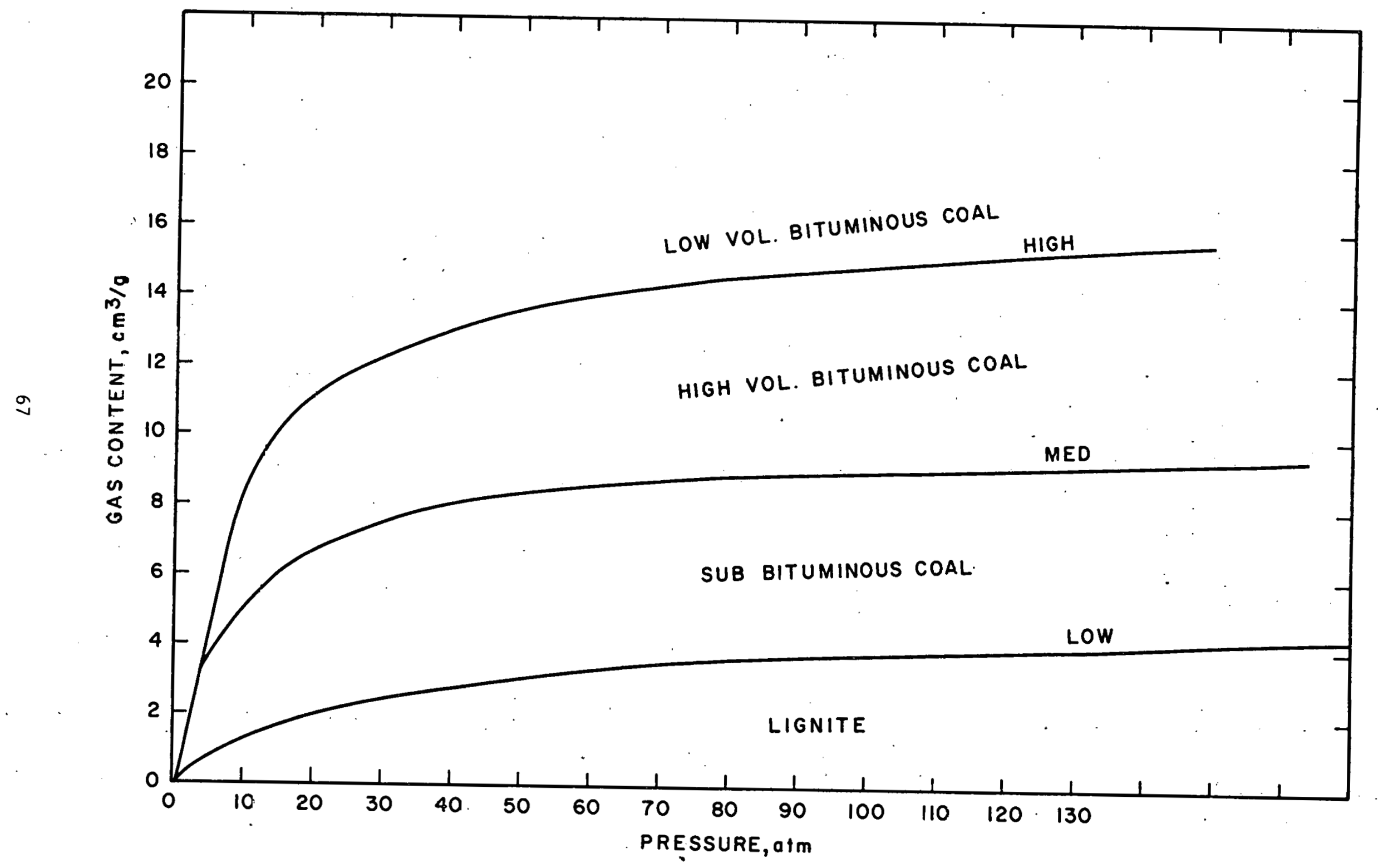


FIGURE 5

ESTIMATED METHANE CONTENT

WITH DEPTH AND RANK

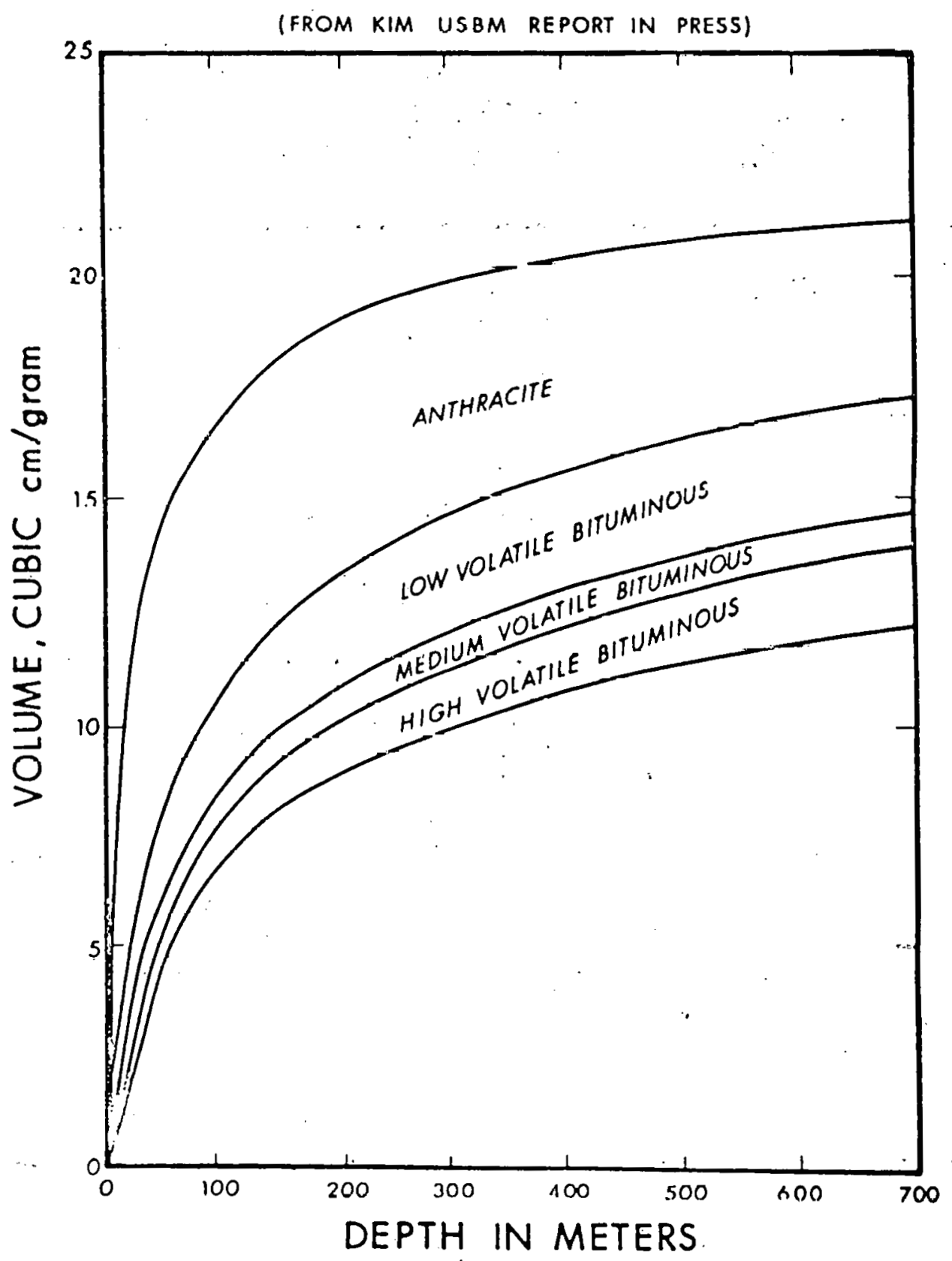




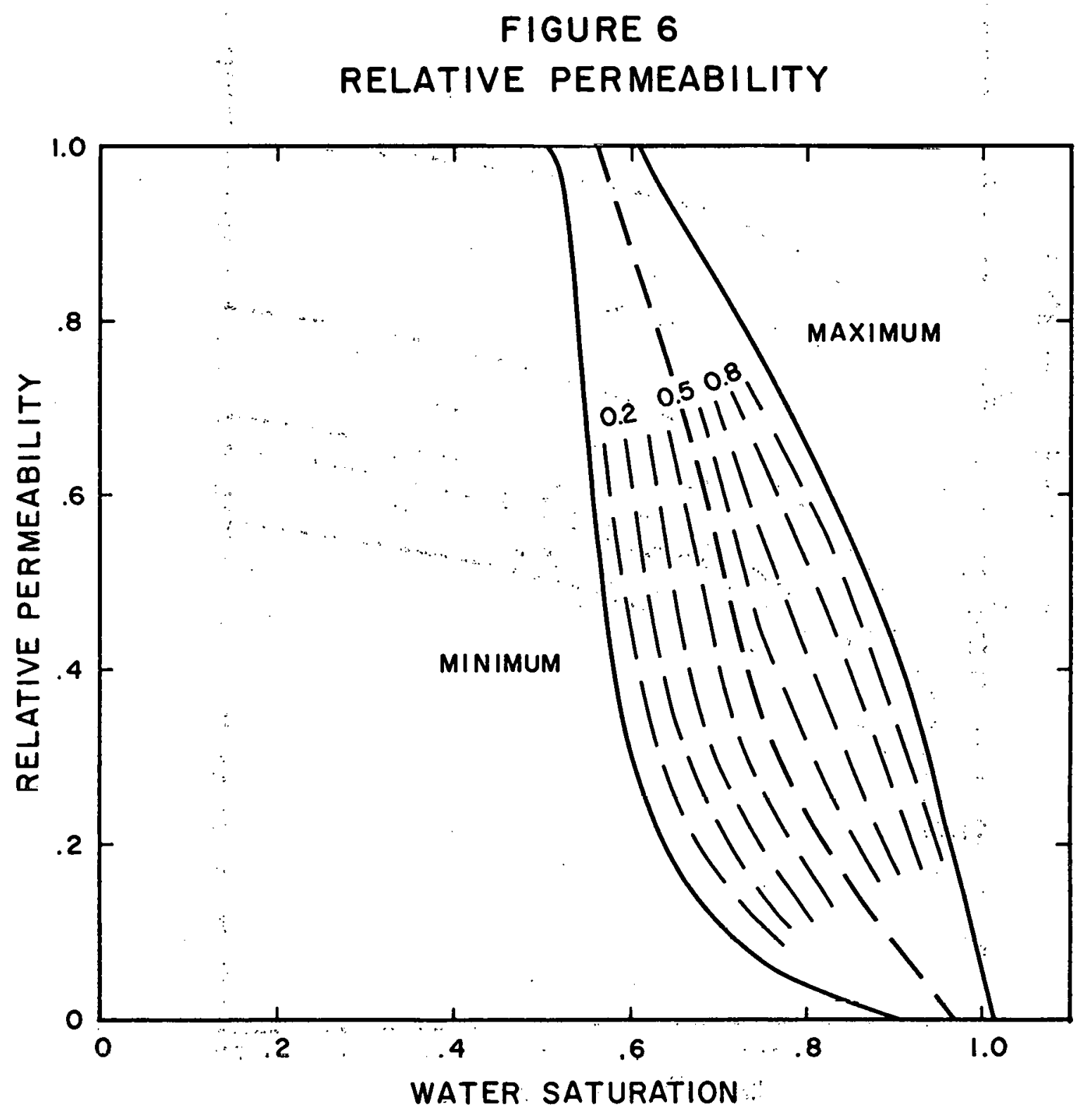


FIGURE 7

DISTRIBUTION OF GAS CONTENT

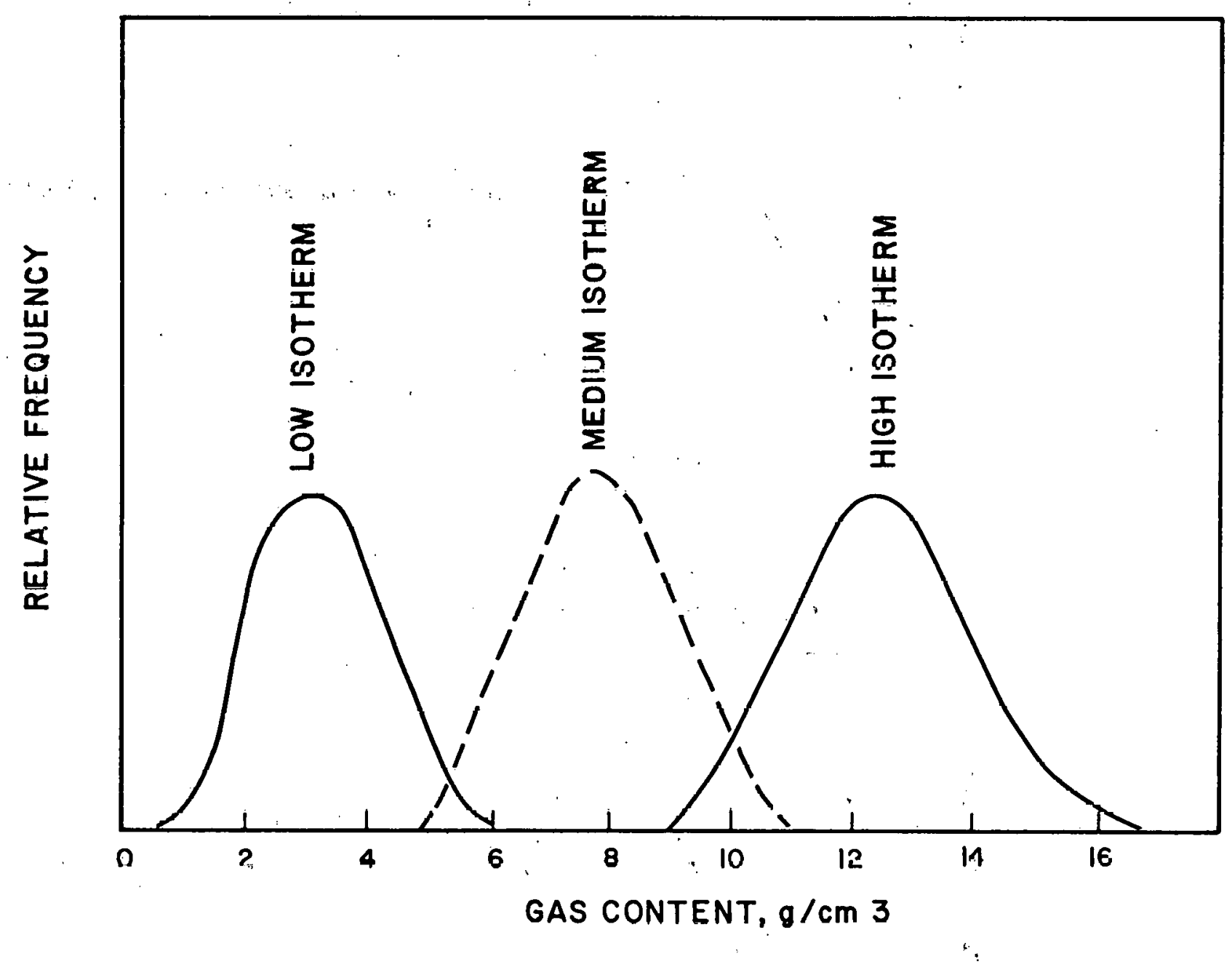




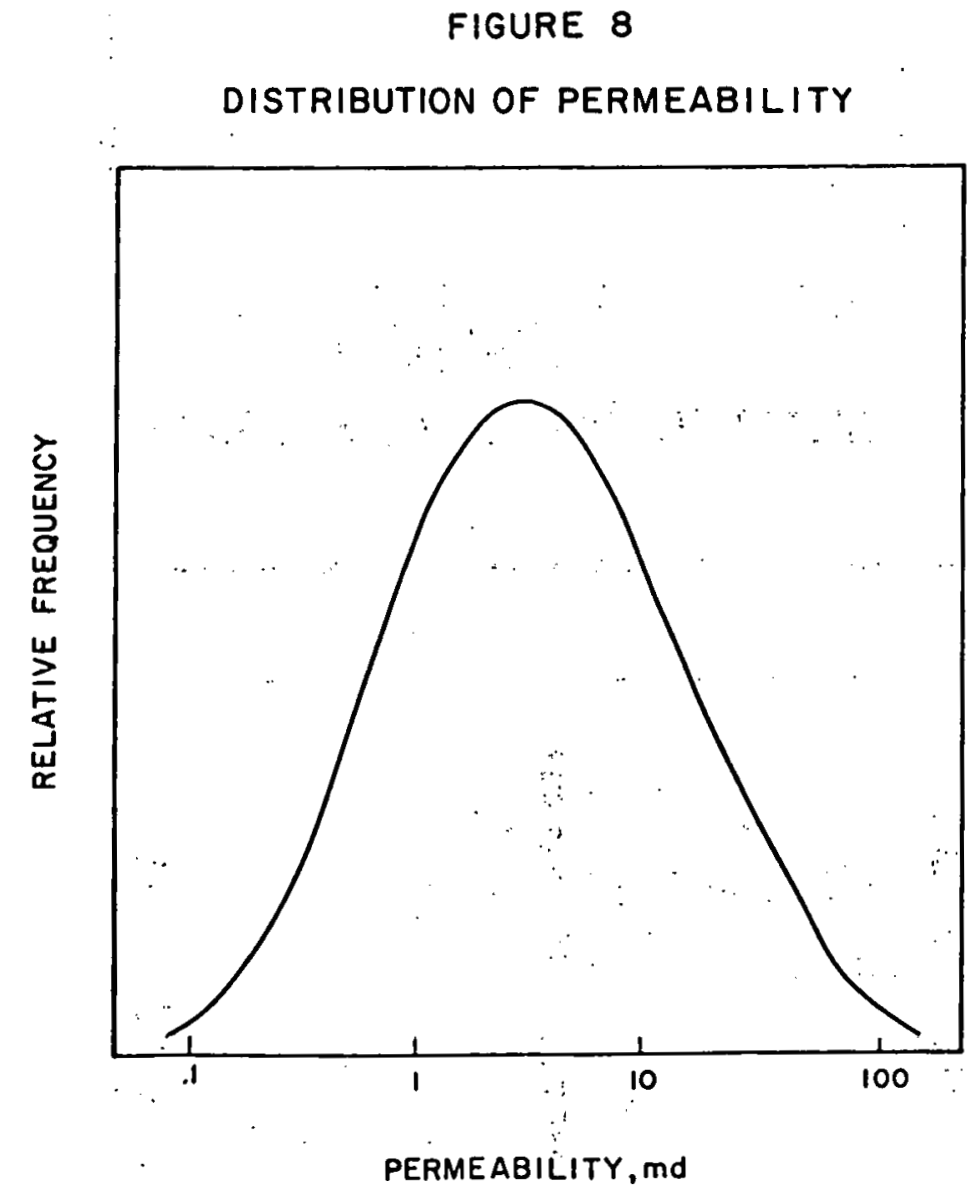

FIGURE 9

DISTRIBUTIION OF PRESSURE

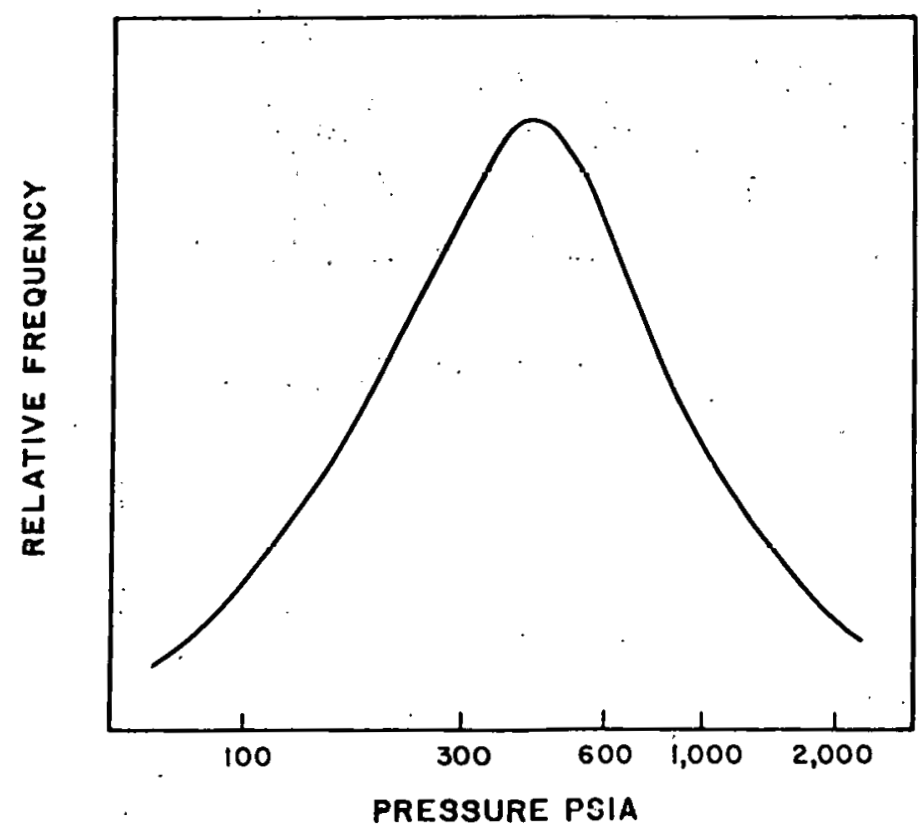


FIGURE 10

\section{DISTRIBUTION OF RELATIVE PERMEABILITY}

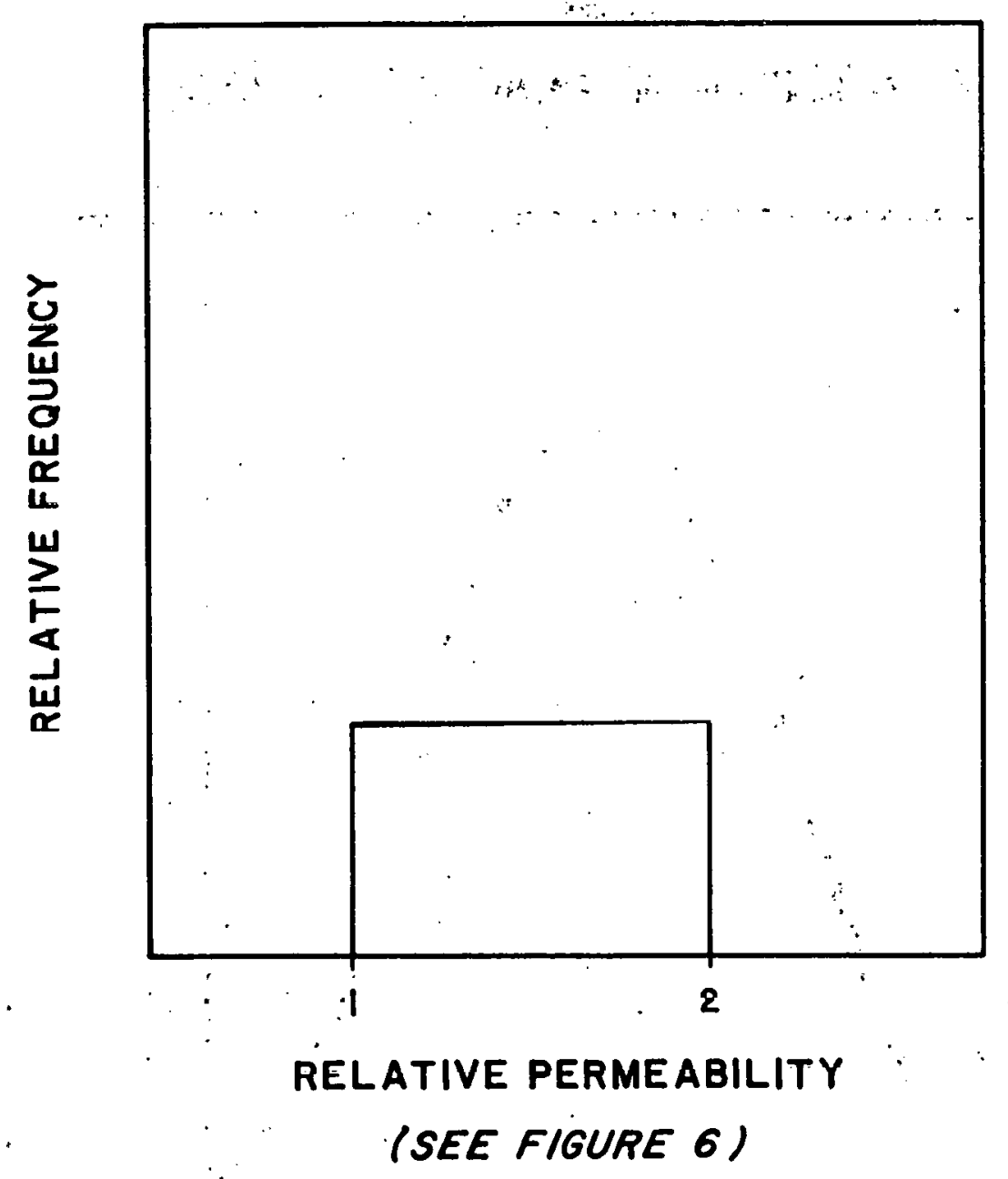


FIGURE. II DISTRIBUTION OF FRACTURE LENGTH

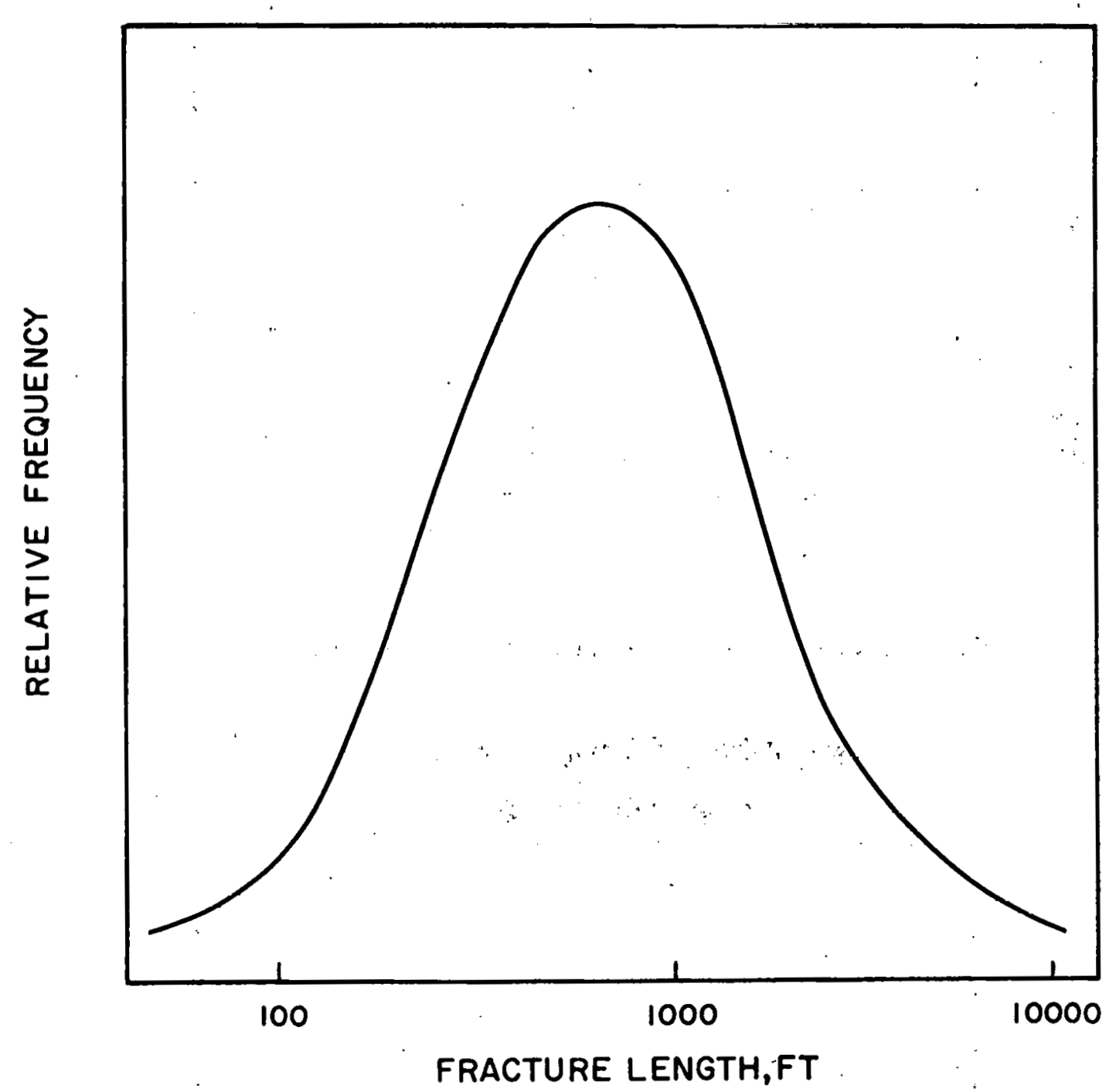

73 
FIGURE 12

DISTRIBUTION OF FRACTURE CONDUCTIVITY

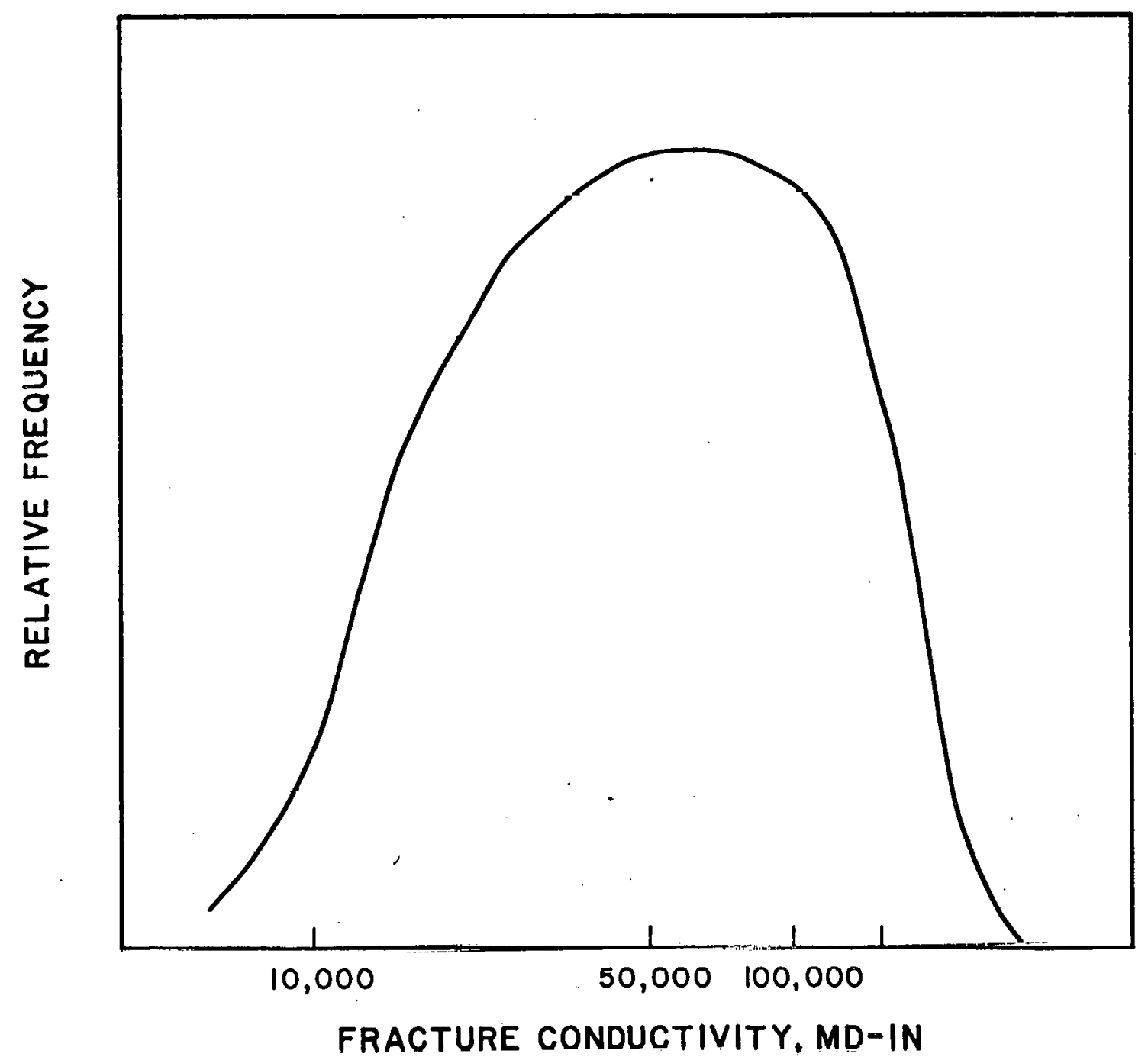


FIGURE 13

DISTRIBUTION OF $\varnothing$, STIMULATED

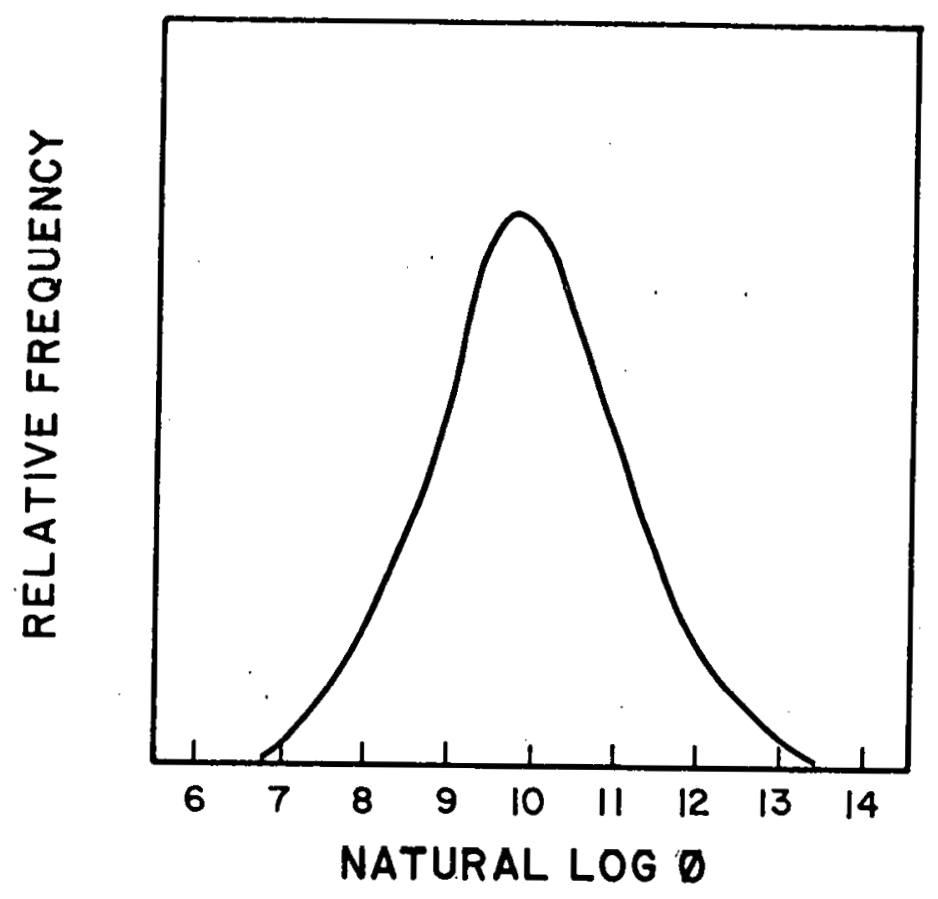


FIGURE 14

DISTRIBUTION OF $\emptyset$, NATURAL

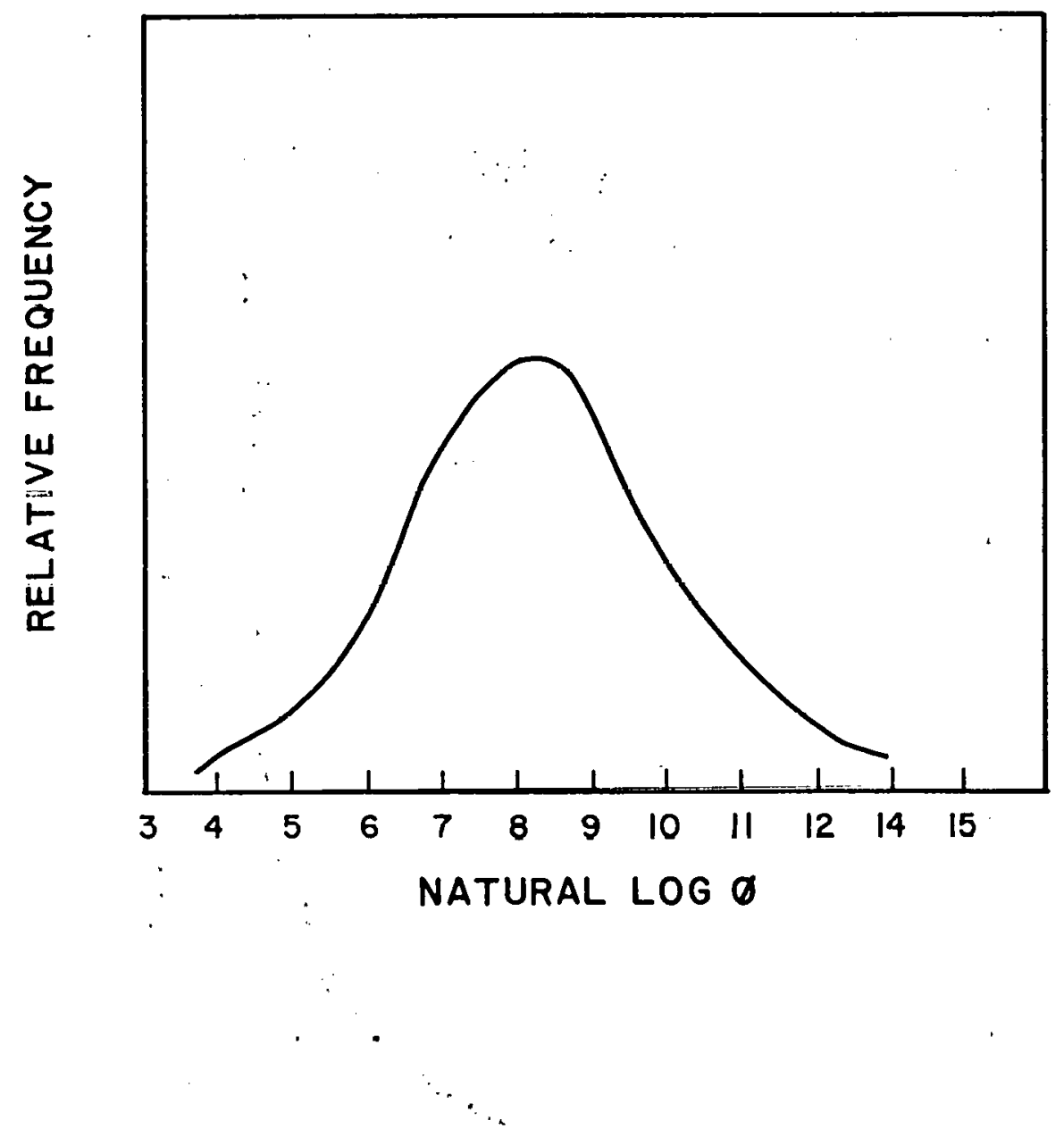


FIGURE 15

DISTRIBUTION OF $\emptyset$

STIMULATED PRODUCTION.

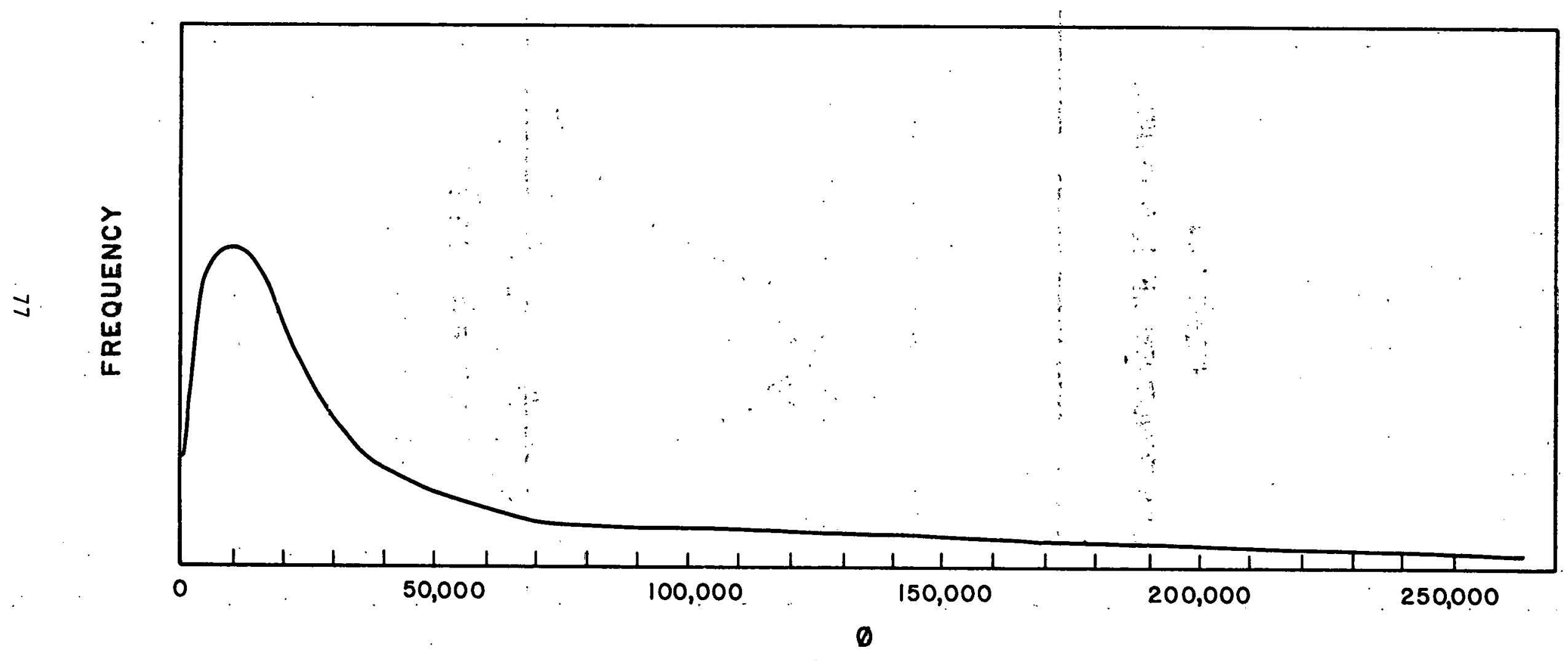


FIGURE 16

DISTRIBUTION OF $\emptyset$

NATURAL PRODUCTION

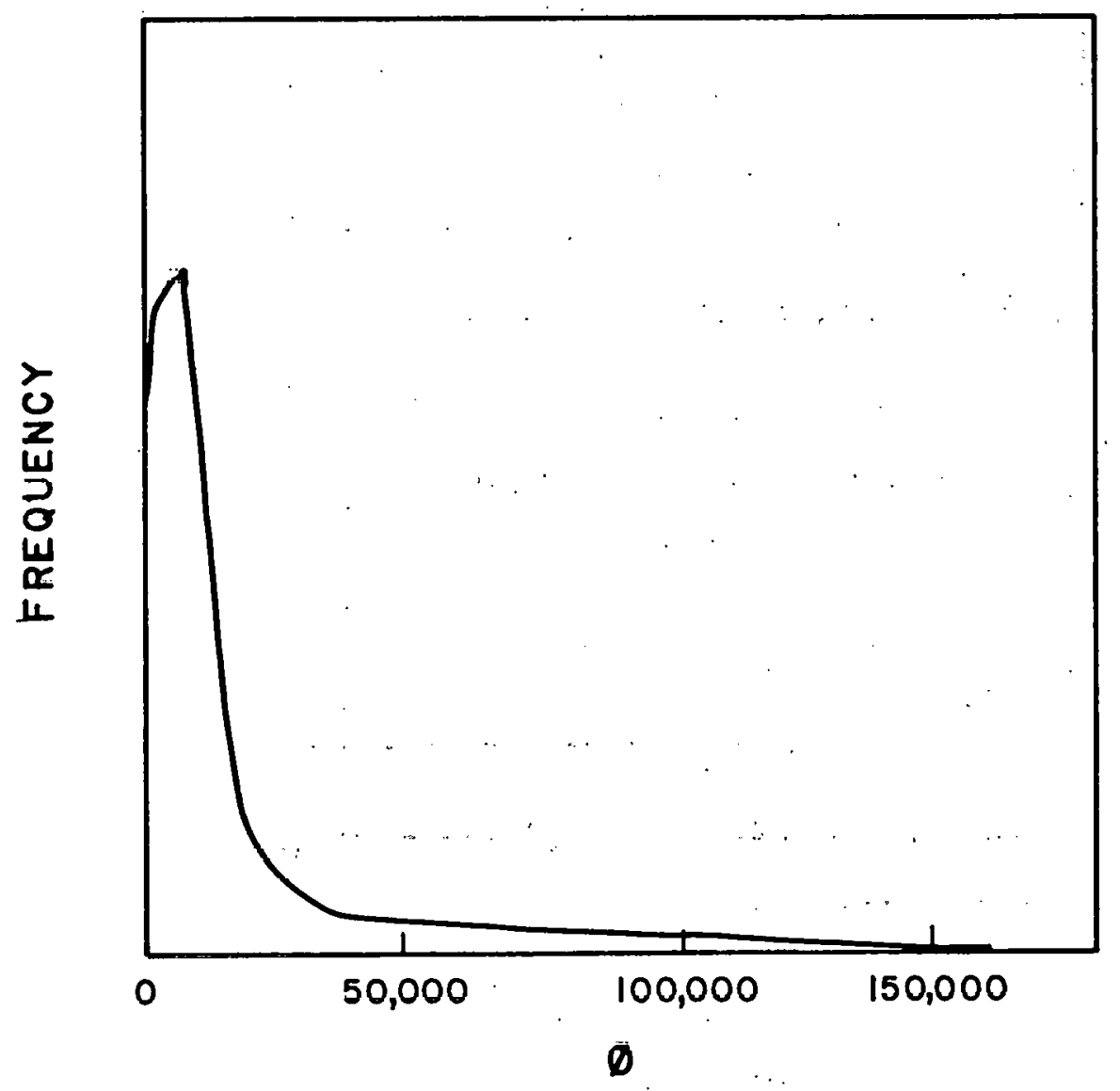


STIMULATED PRODUCTION MODULES

A.) MODULE I-I

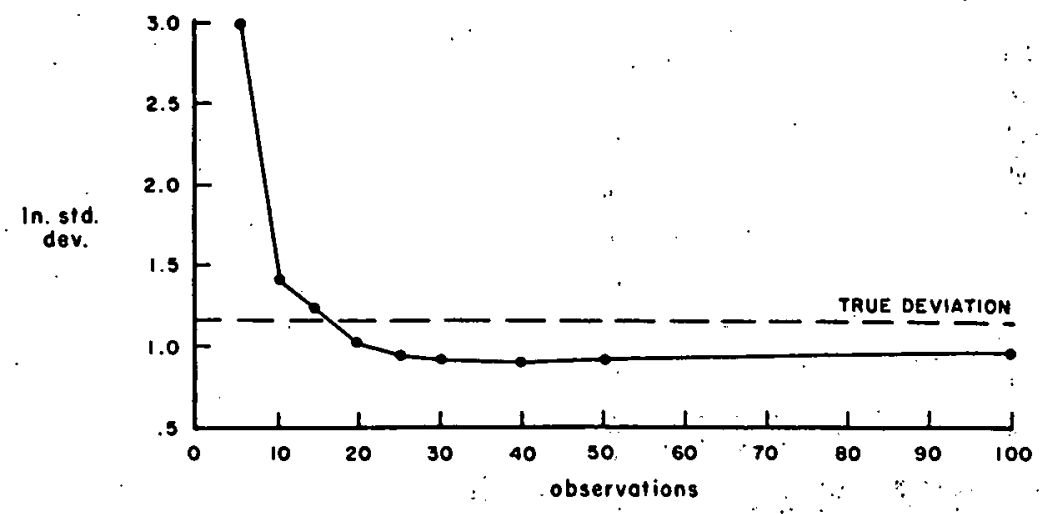

B.) MODULE III- $1,2,4$ and III-1,3 .

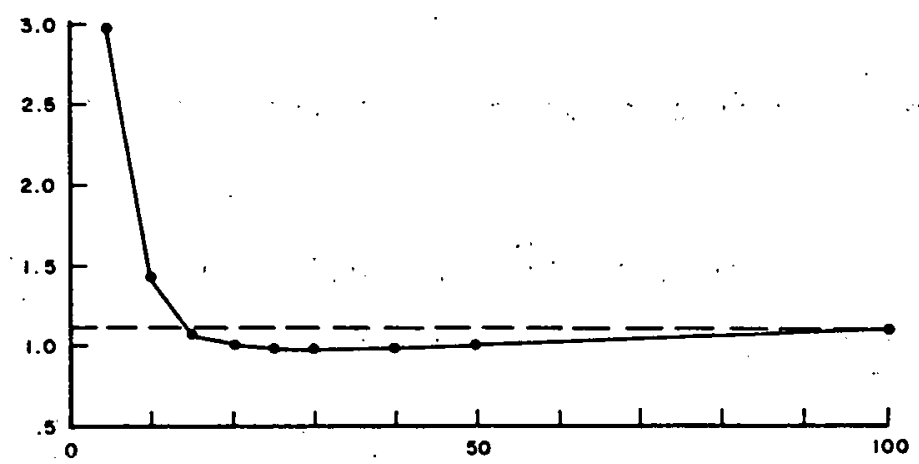

C.) MODULE III- $1,2,3,4$ and $I I-1,2,3$

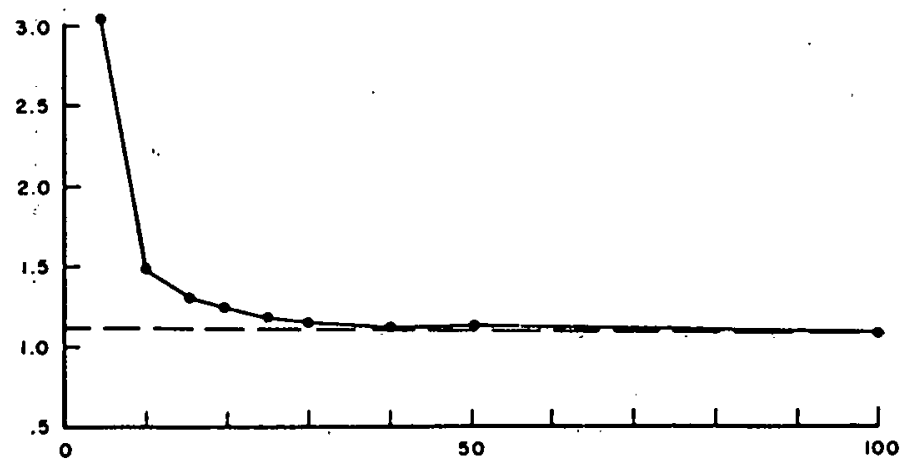

D.) MODULE III-1,2, and II-1,3

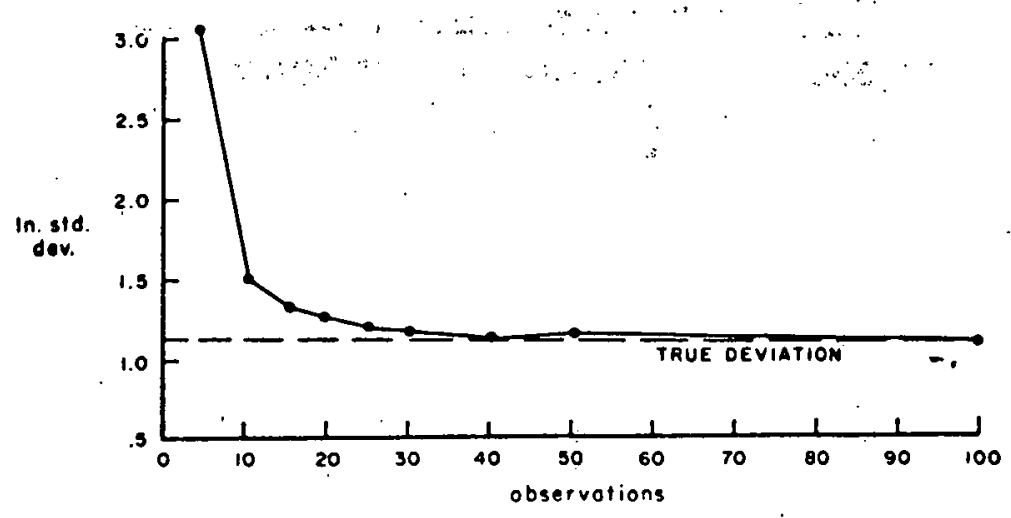


FIGURE 18

SAMPLING EFFICIENCY

NATURAL PRODUCTION MODULES

A.) MODULE I-1

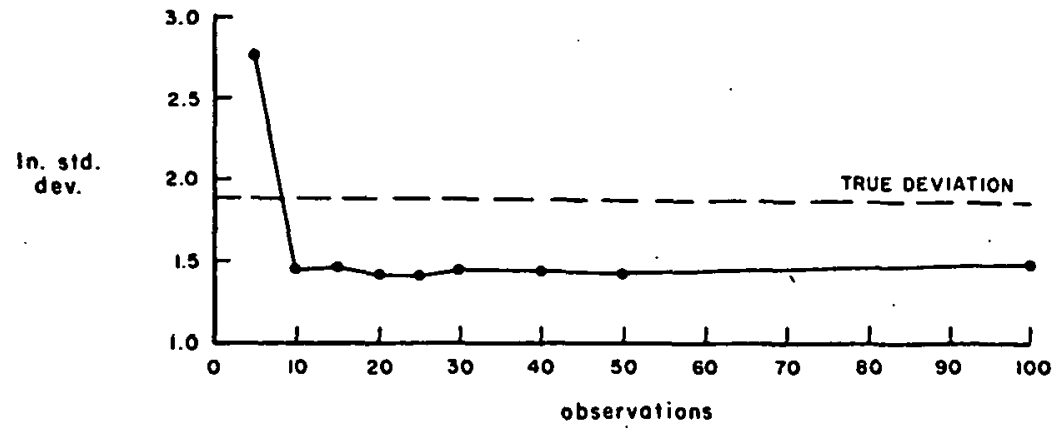

B.) MODULES III $-1,2,3$ and II $-1,2$

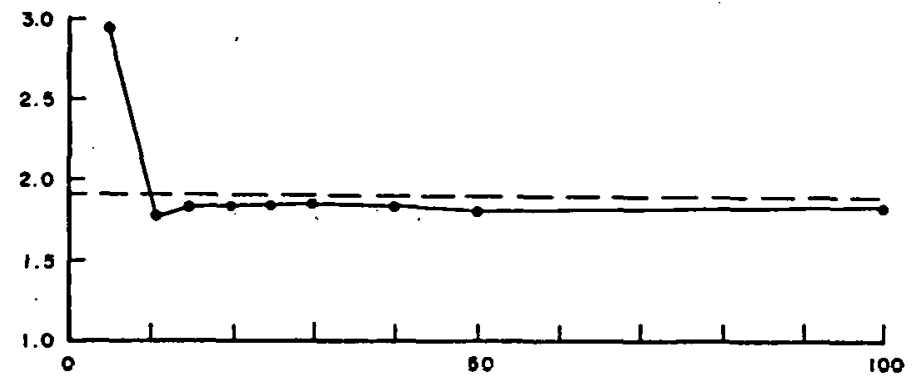

C.) MODULES III-1,2,3,4 and III-1,2,3

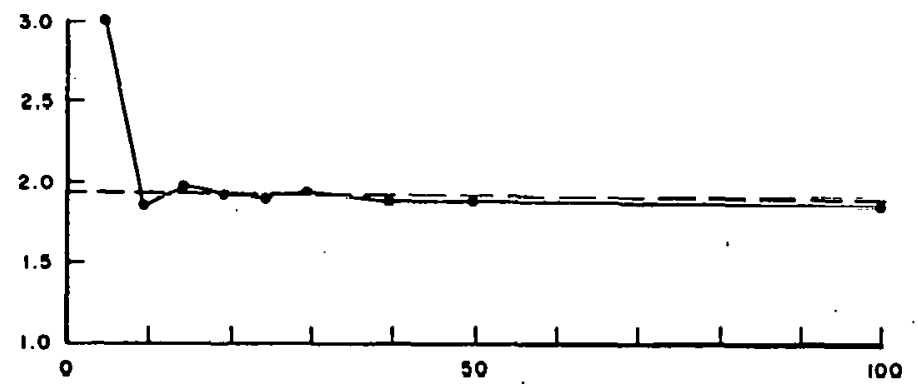

D.) MODULES III - 1,2 and II-1

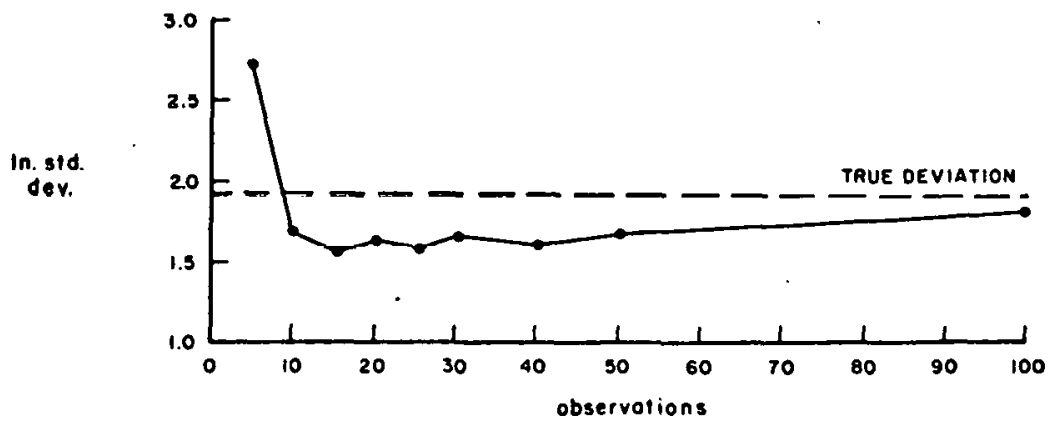


APPENDIX 
TABLE A-1

SENSITIVITY ANA_YSIS UATA

\begin{tabular}{|c|c|c|c|c|c|c|c|c|}
\hline $\begin{array}{l}\text { CASE } \\
\text { NUMBER }\end{array}$ & $\begin{array}{l}\text { PHI } \\
\text { MCF } \\
------\end{array}$ & $\begin{array}{c}\text { FRAETURE } \\
\text { LENGIH } \\
\text { FT }\end{array}$ & $\begin{array}{c}\text { FRACTURE } \\
\text { CONDUCIIVITY } \\
\text { MD-IN }\end{array}$ & $\begin{array}{l}\text { PERMEABILIIY } \\
\text { MD-IN }\end{array}$ & $\begin{array}{l}\text { PRESSURE } \\
\text { PSIA }\end{array}$ & $\begin{array}{l}\text { RELATIVE } \\
\text { PERMEABILIIY } \\
\text { CURVE NO. }\end{array}$ & $\begin{array}{l}\text { AOSORPI } \\
\text { ISUTHE } \\
\text { CURVE } \\
\text { CO- }\end{array}$ & $\begin{array}{l}\text { TION } \\
\text { HERM } \\
\text { NO. } \\
\text { No. }\end{array}$ \\
\hline $\begin{array}{l}1 \\
2 \\
3 \\
4 \\
5 \\
6 \\
7 \\
B \\
9 \\
10 \\
11 \\
12 \\
13 \\
14 \\
15 \\
15 \\
17 \\
19 \\
17 \\
21 \\
21 \\
22 \\
23 \\
24 \\
25 \\
20 \\
21 \\
28 \\
29 \\
30 \\
31 \\
32 \\
33 \\
34 \\
35 \\
35 \\
31 \\
33 \\
39 \\
40\end{array}$ & $\begin{array}{r}1861.80 \\
1149.80 \\
476.10 \\
1196.20 \\
725.60 \\
202.40 \\
5734.20 \\
3615.00 \\
1997.60 \\
3674.30 \\
2111.10 \\
995.00 \\
8983.20 \\
6290.30 \\
4027.00 \\
4859.10 \\
3178.30 \\
1791.30 \\
17032.20 \\
11924.30 \\
10518.90 \\
6770.90 \\
4189.60 \\
3413.00 \\
3877.50 \\
2456.20 \\
12910.40 \\
6856.80 \\
20829.30 \\
9722.70 \\
42400.50 \\
13226.50 \\
5367.100 \\
3295.90 \\
1533.00 \\
3211.30 \\
1831.30 \\
674.20 \\
18558.60 \\
12238.40\end{array}$ & $\begin{array}{l}500 . \\
500 . \\
500 . \\
500 . \\
500 . \\
500 . \\
500 . \\
500 . \\
500 . \\
500 . \\
500 . \\
500 . \\
500 . \\
500 . \\
500 . \\
500 . \\
500 . \\
500 . \\
500 . \\
500 . \\
500 . \\
500 . \\
500 . \\
500 . \\
500 . \\
500 . \\
500 . \\
500 . \\
500 . \\
500 . \\
500 . \\
500 . \\
500 . \\
500 . \\
500 . \\
500 . \\
500 . \\
500 . \\
500 . \\
500 .\end{array}$ & $\begin{array}{l}100000 . \\
100000 . \\
100000 . \\
100000 . \\
100000 . \\
100000 . \\
100000 . \\
100000 . \\
100000 . \\
100000 . \\
100000 . \\
100000 . \\
100000 . \\
100000 . \\
100000 . \\
100000 . \\
100000 . \\
100000 . \\
100000 . \\
100000 . \\
100000 . \\
100000 . \\
100000 . \\
100000 . \\
100000 . \\
100000 . \\
100000 . \\
100000 . \\
100000 . \\
100000 . \\
100000 . \\
100000 . \\
100000 . \\
100000 . \\
100000 . \\
100000 . \\
100000 . \\
100000 . \\
100000 . \\
100000 .\end{array}$ & $\begin{array}{l}0.10 \\
0.10 \\
0.10 \\
0.10 \\
0.10 \\
0.10 \\
0.10 \\
0.10 \\
0.10 \\
0.10 \\
0.10 \\
0.10 \\
0.10 \\
0.10 \\
0.10 \\
0.10 \\
0.10 \\
0.10 \\
0.10 \\
0.10 \\
0.10 \\
0.10 \\
0.10 \\
0.10 \\
0.50 \\
0.50 \\
0.51 \\
0.50 \\
0.50 \\
0.50 \\
0.50 \\
0.50 \\
1.00 \\
1.00 \\
1.00 \\
1.00 \\
1.00 \\
1.00 \\
1.00 \\
1.00\end{array}$ & $\begin{array}{l}100 . \\
100 . \\
100 . \\
100 . \\
100 . \\
100 . \\
300 . \\
300 . \\
300 . \\
100 . \\
100 . \\
200 . \\
600 . \\
600 . \\
600 . \\
600 . \\
600 . \\
600 . \\
1800 . \\
1800 . \\
1800 . \\
1800 . \\
1000 . \\
1000 . \\
1000 \\
100 . \\
300 . \\
300 . \\
600 . \\
600 . \\
1400 . \\
1000 . \\
100 . \\
100 . \\
100 . \\
100 . \\
100 . \\
100 . \\
500 . \\
500 .\end{array}$ & $\begin{array}{l}2 \\
2 \\
2 \\
1 \\
1 \\
1 \\
2 \\
2 \\
2 \\
1 \\
1 \\
1 \\
2 \\
2 \\
2 \\
1 \\
1 \\
1 \\
2 \\
2 \\
2 \\
1 \\
1 \\
1 \\
2 \\
1 \\
2 \\
1 \\
2 \\
1 \\
2 \\
1 \\
2 \\
2 \\
2 \\
1 \\
1 \\
1 \\
2 \\
2\end{array}$ & $\begin{array}{l}3 \\
2 \\
1 \\
3 \\
2 \\
1 \\
3 \\
2 \\
1 \\
3 \\
2 \\
1 \\
3 \\
2 \\
1 \\
3 \\
2 \\
1 \\
3 \\
2 \\
1 \\
3 \\
2 \\
1 \\
3 \\
3 \\
3 \\
3 \\
3 \\
3 \\
3 \\
3 \\
3 \\
2 \\
1 \\
3 \\
2 \\
1 \\
3 \\
2\end{array}$ & . \\
\hline
\end{tabular}


TABLE A-I

SENSIIIVIIY ANALYSIS DATA

\begin{tabular}{|c|c|c|c|c|c|c|c|}
\hline $\begin{array}{l}\text { CASE } \\
\text { NUNAER }\end{array}$ & $\begin{array}{l}\text { PHI } \\
\text { MCF }\end{array}$ & $\begin{array}{c}\text { FRACIURE } \\
\text { LENGIH } \\
\text { FT }\end{array}$ & $\begin{array}{c}\text { FRAC TURE } \\
\text { CUNDUCIIVIIY } \\
\text { MD-IN }\end{array}$ & $\begin{array}{c}\text { PERMEABIL } 1 \text { IY } \\
\text { MD-IN }\end{array}$ & $\begin{array}{l}\text { PKESSURE } \\
\text { PSIA }\end{array}$ & $\begin{array}{l}\text { RELATIVE } \\
\text { PERMEABILIIY } \\
\text { CURVE NU. }\end{array}$ & $\begin{array}{l}\text { ADSORPIION } \\
\text { ISOIHERM } \\
\text { CURVE NO. }\end{array}$ \\
\hline$-\infty-\infty-\infty$ & $-0-0-0-00$ & $--0-0-0-0$ & - - - - - & $-\infty-\infty-\infty-\infty+\infty$ & $-\infty+\infty-\infty,-\infty$ & $-\infty-\infty,-\infty-\infty$ & $--\infty-\infty$ \\
\hline $\begin{array}{r}.41 \\
42\end{array}$ & $\begin{array}{l}7434.05 \\
9310.20\end{array}$ & $\begin{array}{l}500 . \\
500 .\end{array}$ & $\begin{array}{l}100000 . \\
100000 .\end{array}$ & $\begin{array}{l}1.00 \\
1.00\end{array}$ & $\begin{array}{l}300 . \\
300 .\end{array}$ & $\begin{array}{l}2 \\
1\end{array}$ & $\begin{array}{l}1 \\
3\end{array}$ \\
\hline 43 & 5733.20 & 500. & 100000 & 1.00 & 300 & 1 & 2 \\
\hline 44 & 2441.60 & 500. & 100000. & 1.00 & 300. & $i$ & $i$ \\
\hline 45 & 31496.70 & 500. & 100000 & 1.00 & 000. & 2 & 3 \\
\hline$a 6$ & 23254.10 & 500. & 100000 & 1.00 & noo. & 2 & 2 \\
\hline 47 & 16174.90 & 500. & 100000 & 1.00 & 600. & 2 & $i$ \\
\hline 48 & 12790.70 & 500. & 100000 & 1.00 & 600. & 1 & 3 \\
\hline 49 & 8374.10 & 500. & 100000 & 1.00 & 000. & 1 & 2 \\
\hline 50 & 4970.40 & 500 . & 100000 & 1.00 & 600 . & 1 & 1 \\
\hline 51 & 69131.80 & 500. & 100000 & 1.00 & 1500. & 2 & 3 \\
\hline 52 & 51748.00 & 500. & 100000 & 1.00 & 1800. & 2 & 2 \\
\hline 53 & 40475.90 & $500:$ & 100000. & 1.00 & $1 B 00$. & 2 & $i$ \\
\hline 54 & 18187.10 & 500. & 100000. & 1.00 & 1800. & 1 & 3 \\
\hline 55 & 11700.30 & 500. & 100000 & 1.00 & $1800:$ & 1. & 2 \\
\hline 56 & 10105.20 & 500. & 100000 & 1.00 & 1800. & 1 & $i$ \\
\hline 57 & 16094.50 & 500. & 100000 & 10.00 & 100 & 2 & 3 \\
\hline 58 & 8896.50 & 500. & 100000. & 10.00 & 100 & 2 & 2 \\
\hline 59 & 5434.80 & 500. & 100000 & 10.00 & 100 & 2 & 1 \\
\hline 60 & 1455.70 & 500. & 100000 & 10.00 & 100. & 1 & 3 \\
\hline 01 & 3931.40 & 500. & 100000 & 10.00 & 100. & 1 & 2 \\
\hline 62 & 1611.50 & 500. & 100000 & 10.00 & 100 & $i$ & $i$ \\
\hline 63 & 61597.00 & 500. & 100000 & 10.00 & 300 & 2 & 3 \\
\hline 64 & 43196.00 & 500. & 100000 & 10.00 & 300 . & 2 & 2 \\
\hline 65 & 23651.80 & 500. & 100000 & 10.00 & 300. & 2 & $i$ \\
\hline 66 & 23176.30 & 500. & 100000 & 10.00. & 300. & $i$ & 3 \\
\hline 67 & 15997.90 & 500 。 & 100000. & 10.00 & 300. & 1 & 2 \\
\hline 68 & 8344.40 & 500. & 100000 . & 10.00 & 300. & $i$ & 1 \\
\hline 69 & 120925.70 & 500. & 100000 & 10.00 & 600. & 2 & 3 \\
\hline 70 & 95314.00 & 500. & 100000 & 10.00 & 600 . & 2 & 2 \\
\hline 71 & 74620.90 & 500 . & 100000. & 10.00 & 600. & 2 & $i$ \\
\hline 72 & 30571.80 & 500. & 100000. & 10.00 & 600. & 1 & 3 \\
\hline 73 & 20789.80 & 500. & 100000 & 10.00 & 600. & 1 & 2 \\
\hline 74 & 13433.20 & 500. & 100000 & 10.00 & 600. & 1 & 1 \\
\hline 75 & 295609.00 & 500. & 100000. & 10.00 & 1800. & 2 & 3 \\
\hline 76 & 248950.60 & 500. & 100000 & 10.00 & 1800. & 2 & 2 \\
\hline 77 & 227510.00 & 500. & 100000. & 10.00 & 1800 & 2 & 1 \\
\hline 78 & 44942.10 & 500. & 100000. & 10.00 & 1800. & 1 & 3 \\
\hline 79 & 31390.20 & 500. & 100000 & 10.00 & 1800. & 1 & 2 \\
\hline HO & 27493.60 & 500. & 100000 & 10.00 & 1000. & 1 & 1 \\
\hline
\end{tabular}


TAPLE $A-1$

SENSITIVITY ANALYSIE ONTA

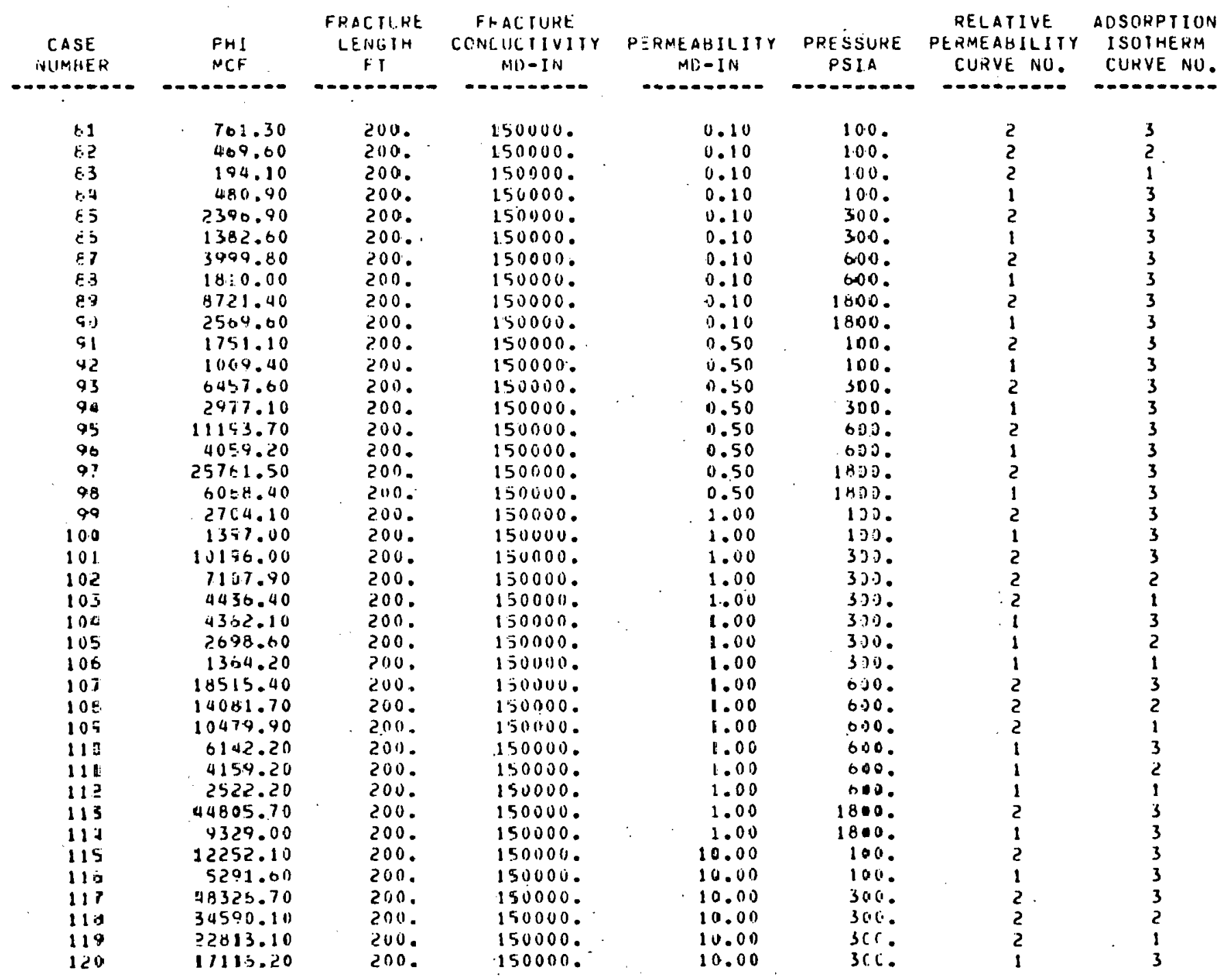


TAHLE $A-1$

SENSITIVITY ANALYSIS UATA

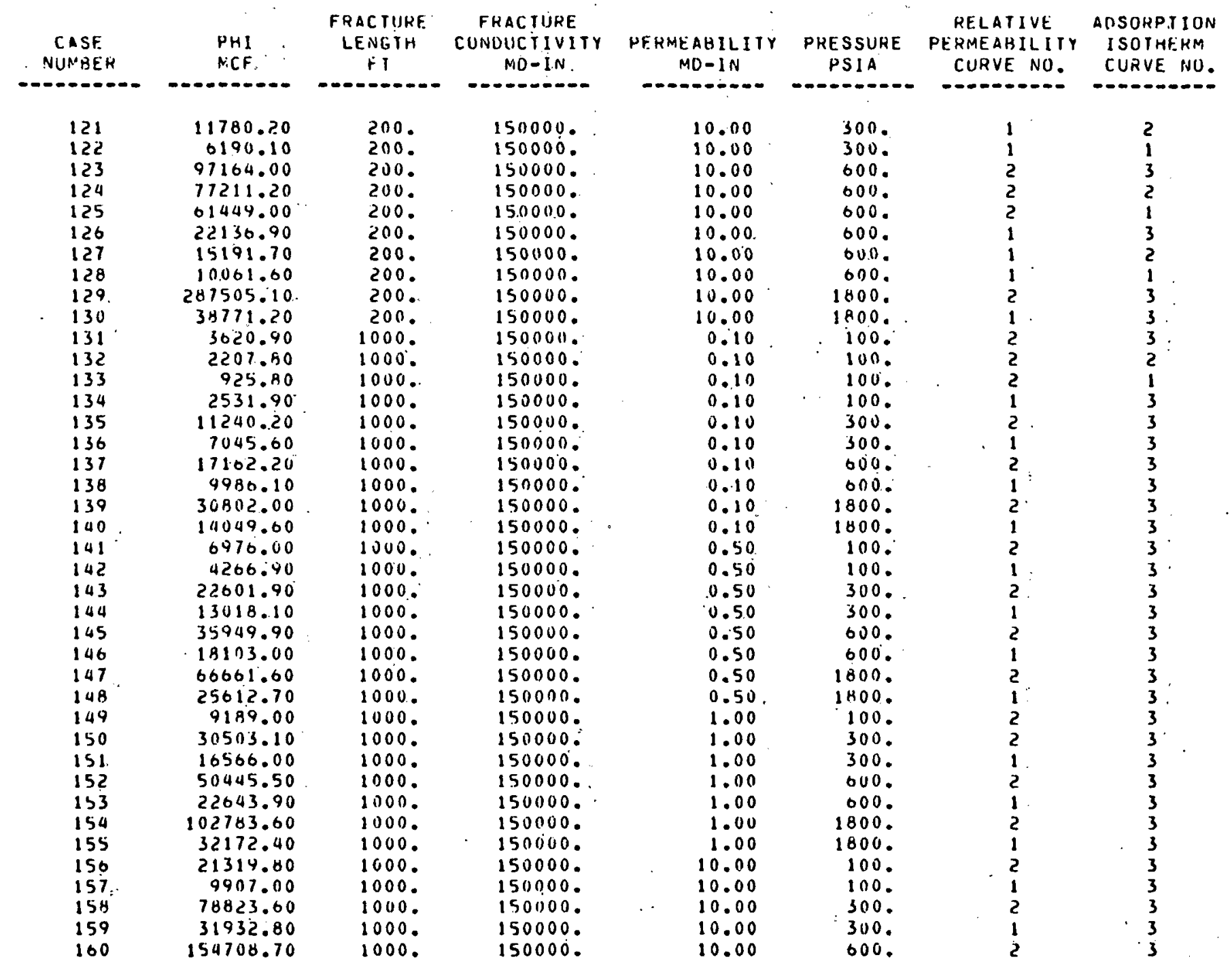


TABLE $A=1$

SEHSIIIVITY ANALYSIS DATA

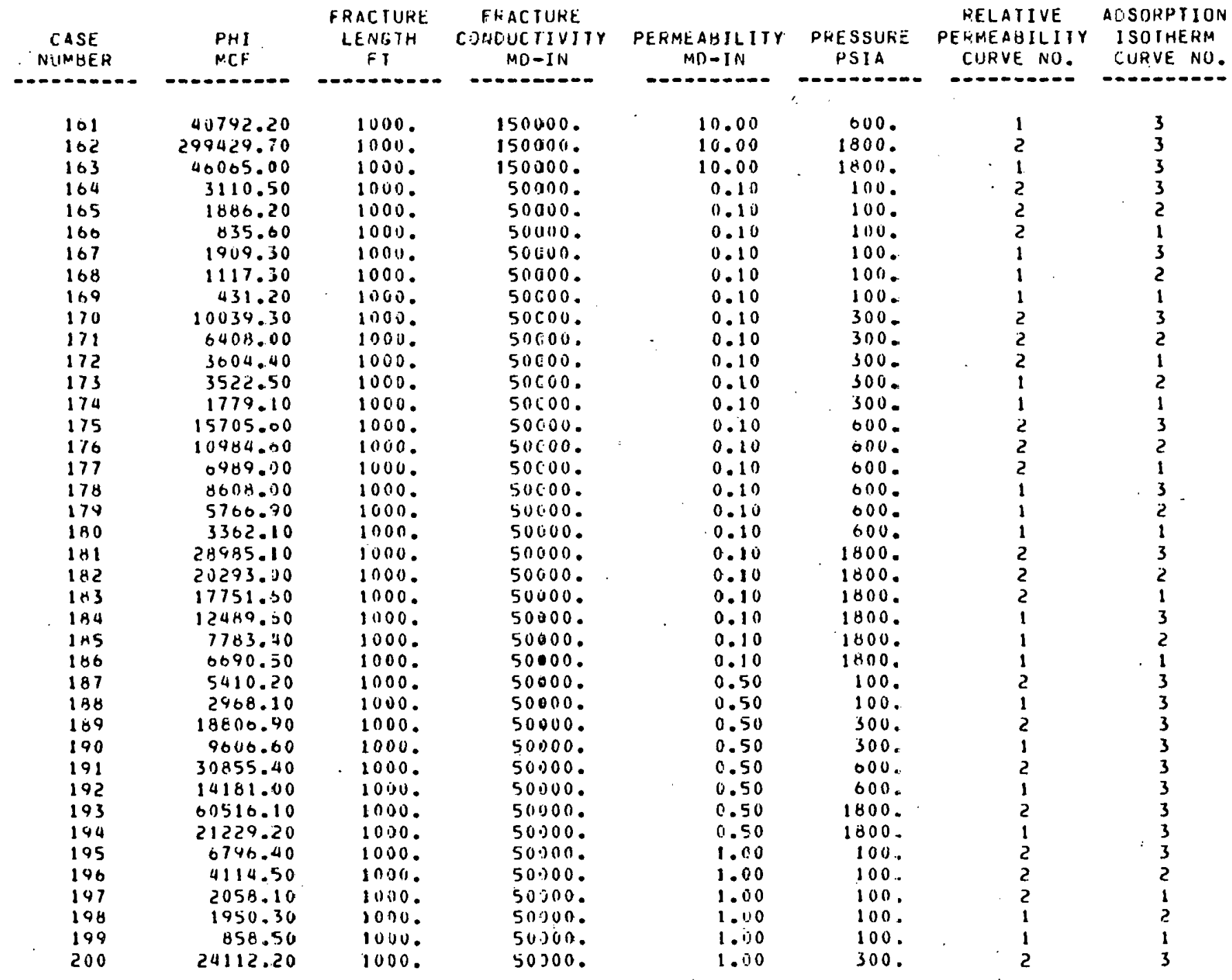


TABLE $A-1$

SENSITIVIIY ANALYSIS UATA

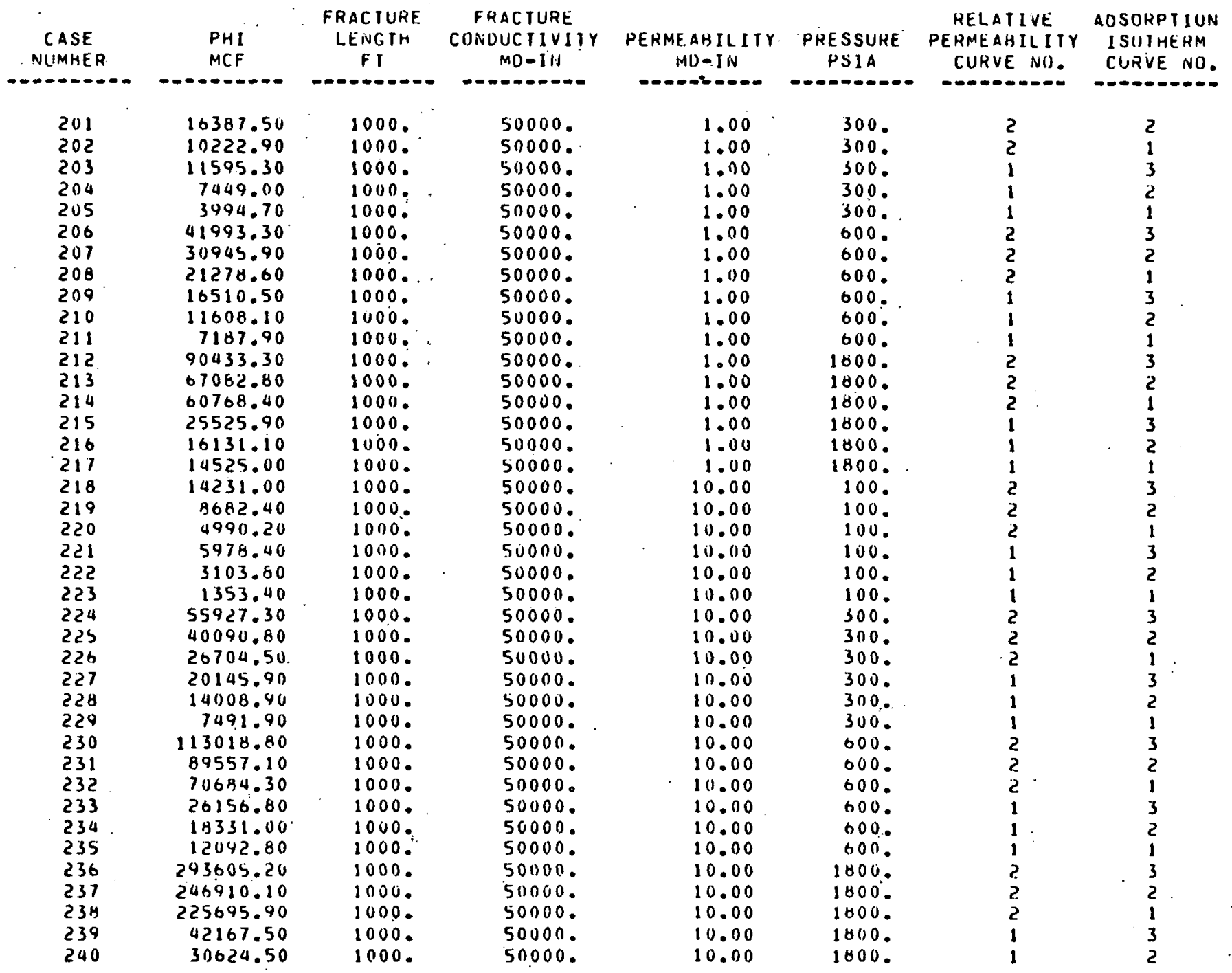


TABLE A-1

SENSITIVITY ANALYSIS DAIA

\begin{tabular}{|c|c|c|c|c|c|c|c|}
\hline $\begin{array}{l}\text { CASE } \\
\text { NUMBER }\end{array}$ & $\begin{array}{l}\text { PrI } \\
\text { MCF }\end{array}$ & $\begin{array}{c}\text { FHAC TUKE } \\
\text { LENGIH } \\
\text { FI }\end{array}$ & $\begin{array}{c}\text { FRAC TURE } \\
\text { CONOUCIIVIIY } \\
\text { MD-IN }\end{array}$ & $\begin{array}{c}\text { PERMEABILITY } \\
\text { M(I) }=I N\end{array}$ & $\begin{array}{c}\text { PKESSUKE } \\
\text { PSIA }\end{array}$ & $\begin{array}{c}\text { RE-ATIVE } \\
\text { PERMEABILIIY } \\
\text { CUPVE NU. }\end{array}$ & $\begin{array}{l}\text { ADSORPIION } \\
\text { ISOIHERM } \\
\text { CURVE NO. }\end{array}$ \\
\hline 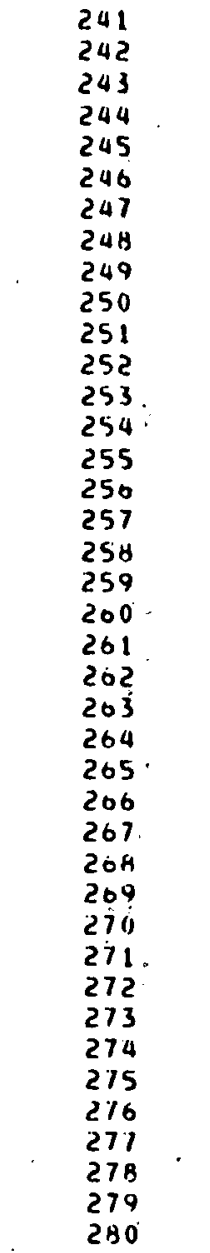 & 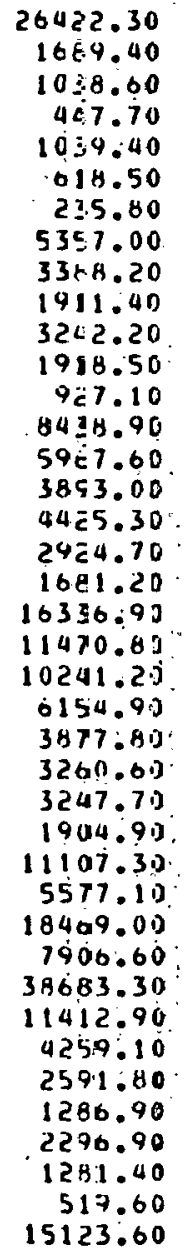 & $\begin{array}{l}1000 . \\
5000 \\
500 . \\
500 . \\
500 . \\
500 . \\
500 . \\
500 . \\
500 . \\
500 . \\
500 . \\
500 . \\
500 . \\
500 . \\
500 . \\
500 . \\
500 . \\
500 . \\
500 . \\
500 . \\
500 . \\
500 . \\
500 . \\
500 . \\
500 . \\
500 . \\
500 . \\
500 . \\
500 . \\
500 . \\
500 . \\
500 . \\
500 . \\
500 . \\
500 . \\
500 . \\
500 . \\
500 . \\
500 . \\
500 .\end{array}$ & 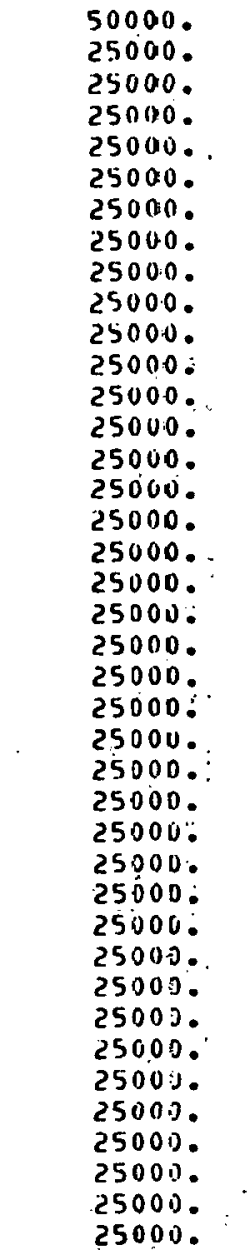 & $\begin{array}{l}80.00 \\
0.10 \\
0.10 \\
0.10 \\
0.10 \\
0.10 \\
0.100 \\
0.10 \\
0.10 \\
0.10 \\
0.10 \\
0.10 \\
0.10 \\
0.10 \\
0.10 \\
0.10 \\
0.10 \\
0.10 \\
0.10 \\
0.10 \\
0.10 \\
0.10 \\
0.10 \\
0.10 \\
0.10 \\
0.50 \\
0.50 \\
0.50 \\
0.50 \\
0.50 \\
0.50 \\
0.50 \\
0.50 \\
1.00 \\
1.00 \\
1.00 \\
1.00 \\
1.00 \\
1.00 \\
1.00\end{array}$ & 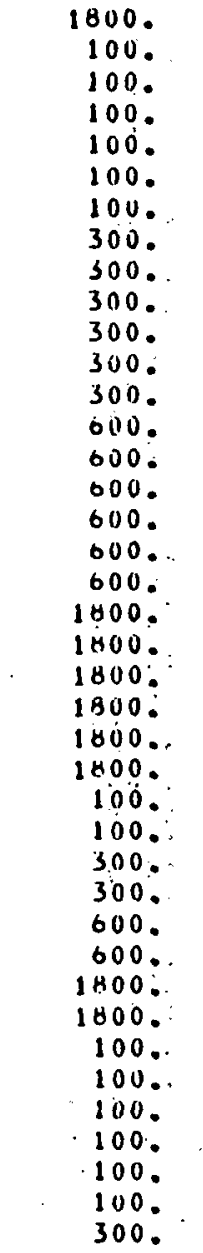 & $\begin{array}{l}1 \\
2 \\
2 \\
2 \\
1 \\
1 \\
1 \\
2 \\
2 \\
2 \\
1 \\
1 \\
1 \\
2 \\
2 \\
2 \\
1 \\
1 \\
1 \\
2 \\
2 \\
2 \\
1 \\
1 \\
1 \\
2 \\
1 \\
2 \\
1 \\
2 \\
1 \\
2 \\
1 \\
2 \\
2 \\
2 \\
1 \\
1 \\
1 \\
2\end{array}$ & $\begin{array}{l}1 \\
3 \\
2 \\
1 \\
3 \\
2 \\
1 \\
3 \\
2 \\
1 \\
3 \\
2 \\
1 \\
3 \\
2 \\
1 \\
3 \\
2 \\
1 \\
3 \\
2 \\
1 \\
3 \\
2 \\
1 \\
3 \\
3 \\
3 \\
3 \\
3 \\
3 \\
3 \\
3 \\
3 \\
2 \\
1 \\
3 \\
2 \\
1 \\
3\end{array}$ \\
\hline
\end{tabular}


I $\triangle$ BLE $A-1$

SENSITIVITY ANALYSIS DATA

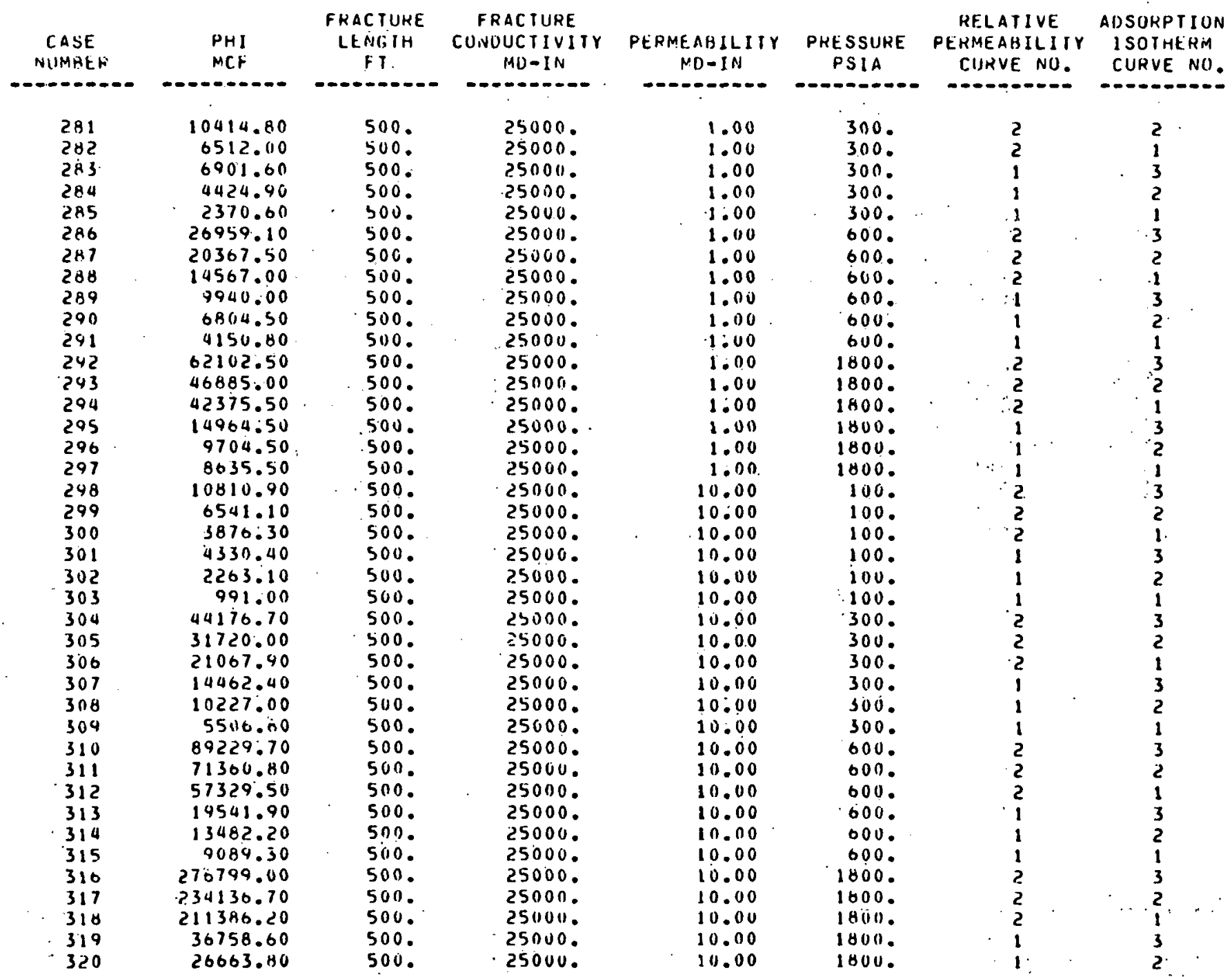


TABLE A-1

SENSITIVITY ANALYSIS DATA

\begin{tabular}{|c|c|c|c|c|c|c|c|}
\hline $\begin{array}{l}\text { CASE } \\
\text { NUMHE! } \\
\text { U.-- }\end{array}$ & $\begin{array}{l}\text { PHI } \\
\text { MCF } \\
H-\infty\end{array}$ & $\begin{array}{l}\text { FRACIURE } \\
\text { LENGIH } \\
\text { FI }\end{array}$ & $\begin{array}{c}\text { FRACTURE } \\
\text { CUNDUCIIVITY } \\
\text { MI)-IN }\end{array}$ & $\begin{array}{l}\text { PEKME.AHILIIY } \\
\text { MDDIN }\end{array}$ & $\begin{array}{l}\text { PKESSURE } \\
\text { PSIA }\end{array}$ & $\begin{array}{l}\text { RELATIVE } \\
\mu \equiv \text { RMEABILITY } \\
\text { CURVE NU. }\end{array}$ & $\begin{array}{l}\text { AUSORPIION } \\
\text { ISUIHERM } \\
\text { CURVE IND. }\end{array}$ \\
\hline $\begin{array}{l}321 \\
322 \\
323 \\
324 \\
325 \\
326 \\
327 \\
328 \\
329 \\
330 \\
331 \\
332 \\
333 \\
334 \\
335 \\
330 \\
337 \\
334 \\
339 \\
340 \\
341 \\
342 \\
343 \\
344 \\
345 \\
345 \\
347 \\
348 \\
349 \\
350 \\
351 \\
352 \\
353 \\
350 \\
355 \\
356 \\
357 \\
358 \\
359 \\
350\end{array}$ & $\begin{array}{r}23069.40 \\
2863.30 \\
1757.60 \\
448.00 \\
1292.20 \\
11453.80 \\
5075.70 \\
20143.90 \\
41835.40 \\
16451.10 \\
4133.60 \\
1909.90 \\
17371.50 \\
6479.00 \\
32440.20 \\
11721.00 \\
69321.00 \\
21562.110 \\
4995.70 \\
2213.20 \\
21023.00 \\
14955.00 \\
9819.00 \\
7950.40 \\
5333.40 \\
2988.40 \\
29245.70 \\
20893.50 \\
9430.40 \\
6166.60 \\
92561.110 \\
22435.20 \\
45859.80 \\
32848.80 \\
21942.40 \\
14652.80 \\
10506.00 \\
5667.90 \\
93045.00 \\
74354.40\end{array}$ & $\begin{array}{l}500 . \\
2000 . \\
2000 . \\
2000 . \\
2000 . \\
2000 . \\
2000 . \\
2000 . \\
2000 . \\
2000 . \\
2000 . \\
2000 . \\
2000 . \\
2000 . \\
2000 . \\
2000 . \\
2000 . \\
2000 . \\
2000 . \\
2000 . \\
2000 . \\
2000 . \\
2000 . \\
2000 . \\
2000 . \\
2000 . \\
2000 . \\
2000 . \\
2000 . \\
2000 . \\
2000 . \\
2000 . \\
2000 . \\
2000 . \\
2000 . \\
2000 . \\
2000 . \\
2000 . \\
2000 . \\
2000 .\end{array}$ & $\begin{array}{l}25000 . \\
25000 . \\
25000 . \\
25000 . \\
25000 . \\
25000 . \\
25000 . \\
25000 . \\
25000 . \\
25000 . \\
25000 . \\
25000 . \\
25000 . \\
25000 . \\
25000 . \\
25000 . \\
25000 . \\
25000 . \\
25000 . \\
25000 . \\
25000 . \\
25000 . \\
25000 . \\
25000 . \\
25000 . \\
25000 . \\
25000 . \\
25000 . \\
25000 . \\
25000 . \\
25000 . \\
25000 . \\
25000 . \\
25000 . \\
25000 . \\
25000 . \\
25000 . \\
25000 . \\
25000 . \\
25000 .\end{array}$ & $\begin{array}{l}10.00 \\
0.10 \\
0.10 \\
0.10 \\
0.10 \\
0.10 \\
0.10 \\
0.10 \\
0.10 \\
0.10 \\
0.50 \\
0.50 \\
0.50 \\
0.50 \\
0.50 \\
0.50 \\
0.50 \\
0.50 \\
1.00 \\
1.00 \\
1.00 \\
1.00 \\
1.00 \\
1.00 \\
1.00 \\
1.00 \\
1.00 \\
1.00 \\
1.00 \\
1.00 \\
1.00 \\
1.00 \\
10.00 \\
10.00 \\
10.00 \\
10.00 \\
10.00 \\
10.00 \\
10.00 \\
10.00\end{array}$ & $\begin{array}{l}1800 . \\
100 . \\
100 . \\
100 . \\
100 . \\
300 . \\
300 . \\
600 . \\
1800 . \\
1800 . \\
100 . \\
100 . \\
300 . \\
300 . \\
600 . \\
600 . \\
1000 . \\
1600 . \\
100 . \\
100 . \\
360 . \\
300 . \\
300 . \\
300 . \\
300 . \\
300 . \\
600 . \\
600 . \\
630 . \\
630 . \\
1830 . \\
1030 . \\
330 . \\
300 . \\
300 . \\
300 . \\
300 . \\
300 . \\
600 . \\
600 .\end{array}$ & $\begin{array}{l}1 \\
2 \\
2 \\
2 \\
1 \\
2 \\
1 \\
2 \\
2 \\
1 \\
2 \\
1 \\
2 \\
1 \\
2 \\
1 \\
2 \\
1 \\
2 \\
1 \\
2 \\
2 \\
2 \\
1 \\
1 \\
1 \\
2 \\
2 \\
1 \\
1 \\
2 \\
1 \\
2 \\
2 \\
2 \\
1 \\
1 \\
1 \\
2 \\
2\end{array}$ & $\begin{array}{l}1 \\
3 \\
2 \\
1 \\
3 \\
3 \\
3 \\
3 \\
3 \\
3 \\
3 \\
3 \\
3 \\
3 \\
3 \\
3 \\
3 \\
3 \\
3 \\
3 \\
3 \\
2 \\
1 \\
3 \\
2 \\
1 \\
2 \\
1 \\
2 \\
1 \\
3 \\
3 \\
3 \\
2 \\
1 \\
3 \\
2 \\
1 \\
3 \\
2\end{array}$ \\
\hline
\end{tabular}


TAKLE A-1

SENSITIVITY ANALYSIS DAIA

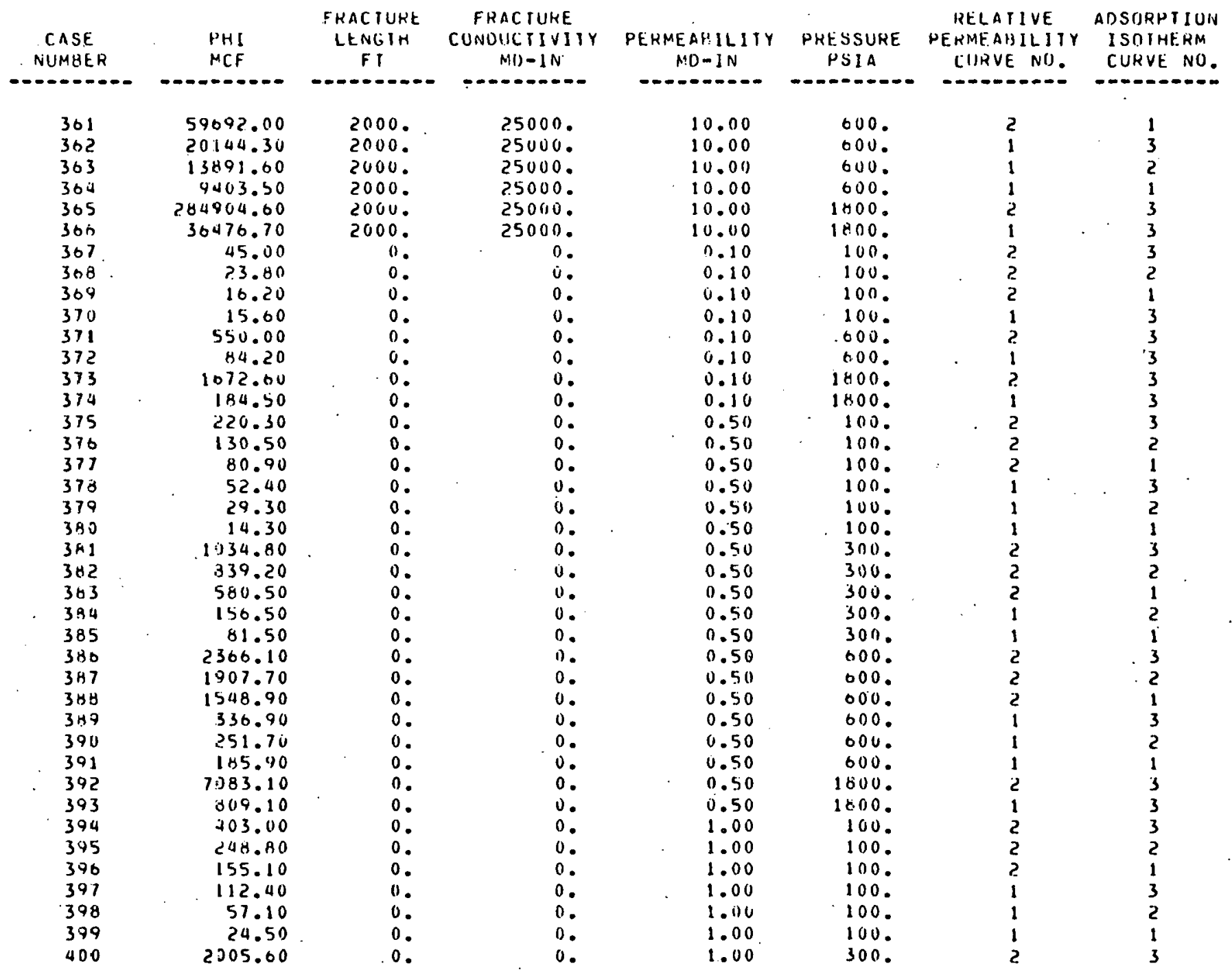


IABLE A-I

SENSITIVIIY ANALYSJS DATA

\begin{tabular}{|c|c|c|c|c|c|c|c|}
\hline $\begin{array}{l}\text { CASE } \\
\text { NIJMBEK }\end{array}$ & $\begin{array}{l}\text { PHI } \\
\text { MCF }\end{array}$ & $\begin{array}{l}\text { FRA } \\
\text { LEVGTURE } \\
=T\end{array}$ & $\begin{array}{c}\text { FRACTURE } \\
\text { CONDUCTIVIYY } \\
\text { MU-IN }\end{array}$ & $\begin{array}{l}\text { PERMEAHILITY } \\
\text { MD-IN }\end{array}$ & $\begin{array}{l}\text { PRESSUK } \\
\text { PSIA }\end{array}$ & $\begin{array}{l}\text { FELATIVE } \\
\text { PEFMEABILITY } \\
\text { CURVE NO. }\end{array}$ & $\begin{array}{l}\text { AISOKHIION } \\
\text { I SUTHERM } \\
\text { CURVE NO. }\end{array}$ \\
\hline 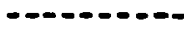 & n & 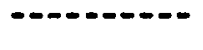 & $-\infty-\infty-\infty-\infty$ & $-\infty-\infty-\infty \ldots$ & 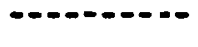 & 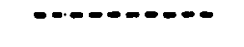 & $--------\infty$ \\
\hline 401 & 1573.40 & 0 . & 0. & 1.00 & 300. & 2 & 2 \\
\hline 402 & 1086.50 & 0 . & 0. & 1.00 & 300. & 2 & $i$ \\
\hline 403 & 413.10 & 0 . & 0. & 1.00 & 300. & 1 & 3 \\
\hline 404 & 297.10 & n. & 0 . & 1.00 & 300. & $i$ & 2 \\
\hline 405 & 150.00 & 0. & 0. & 1.00 & 300. & 1 & $i$ \\
\hline 406 & 43.63 .50 & 0 . & 0. & 1.00 & 600. & 2 & 3 \\
\hline 407 & 30.00 .50 & 0. & 0. & 1.00 & 600. & 2 & 2 \\
\hline 41$) 8$ & $3007 . t 0$ & 0 . & 0. & 1.00 & 600. & 2 & $i$ \\
\hline 409 & $6.46 . \bar{c} 0$ & 0. & 0. & 1.00 & oou. & 1 & 3 \\
\hline 410 & 904.50 & 0. & 0. & 1.00 & 000. & $i$ & 2 \\
\hline 411 & 348.00 & 0 . & 0. & 1.00 & 000. & i & $\overline{1}$ \\
\hline 412 & 12120.70 & 0. & 0. & 1.00 & 1800. & ? & 3 \\
\hline 413 & 15.19 .40 & 0 . & 0 . & 1.00 & 1000. & 1 & 3 \\
\hline 414 & 3351.100 & 0. & 0. & 10.00 & 100 & $\dot{2}$ & 3 \\
\hline 415 & 1993.80 & 0. & 0. & 10.00 & 100. & 2 & 2 \\
\hline 416 & 1267.100 & 0. & 0 . & 10.00 & 100. & 2 & $i$ \\
\hline 417 & 863.50 & 0. & 0. & 10.00 & 100 & 1 & 3 \\
\hline 418 & 4.29 .00 & 0. & 0. & 10.00 & 100 & 1 & 2 \\
\hline 419 & 189.30 & 0. & 0. & 10.00 & 100. & 1 & 1 \\
\hline 420 & 15175.00 & 0 . & 0. & 10.00 & 300. & 2 & 3 \\
\hline 421 & 12004.50 & 0. & 0. & 10.00 & 300 & 2 & 2 \\
\hline 422 & 18.4 .5 .10 & 0. & 0. & 10.00 & 300. & 2 & 1 \\
\hline 423 & 2879.70 & 0. & 0 . & 10.00 & 300. & 1 & 3 \\
\hline 424 & 2259.40 & 0 . & 0 . & 10.00 & 300. & $i$ & 2 \\
\hline 425 & 1181.00 & 0. & 0. & 10.00 & 300. & 1 & 1 \\
\hline 426 & 32768.10 & 0. & 0 . & 10.00 & 600 & 2 & 3 \\
\hline 427 & 27312.40 & 0. & 0 . & 10.00 & 600 . & 2 & 2 \\
\hline 425 & 22884.10 & 0. & 0. & 10.00 & 600. & 2 & $i$ \\
\hline 429 & 4841.10 & 0. & 0. & 10.011 & 600 & $i$ & 3 \\
\hline 430 & 3642.20 & 0 . & 0. & 10.00 & 000. & $i$ & ? \\
\hline 431 & .2734 .0 .0 & 0. & 0. & 10.00 & 600. & 1 & 1 \\
\hline 432 & 120079.30 & 0 . & 0 . & 10.00 & 1800. & 2 & 3 \\
\hline 433 & $11342: 60$ & 0. & 0. & 10.00 & 1000 . & $i$ & 3 \\
\hline 434 & 19879.50 & 0. & 0. & .00 .00 & 100. & 2 & 3 \\
\hline 435 & 13135.10 & 0. & 0. & $=00.00$ & 100. & 2 & ? \\
\hline 436 & 4760.20 & 0. & 0. & $=00.00$ & 100. & 2 & 1 \\
\hline 437 & 5529.50 & 0. & 0. & $\therefore 00.00$ & 100. & 1 & . 3 \\
\hline 438 & $3046 . t 0$ & 0. & 0. & $=00.00$ & 100. & i & 2 \\
\hline 439 & 1228.50 & 0. & n. & $: 00.00$ & 100. & 1 & 1 \\
\hline 440 & $1.18767 . t 0$ & 0. & 0. & $: 00.00$ & 300. & 2 & 3 \\
\hline
\end{tabular}


TAHLE A-1

SENSIIIVITY ANALYSIS DATA

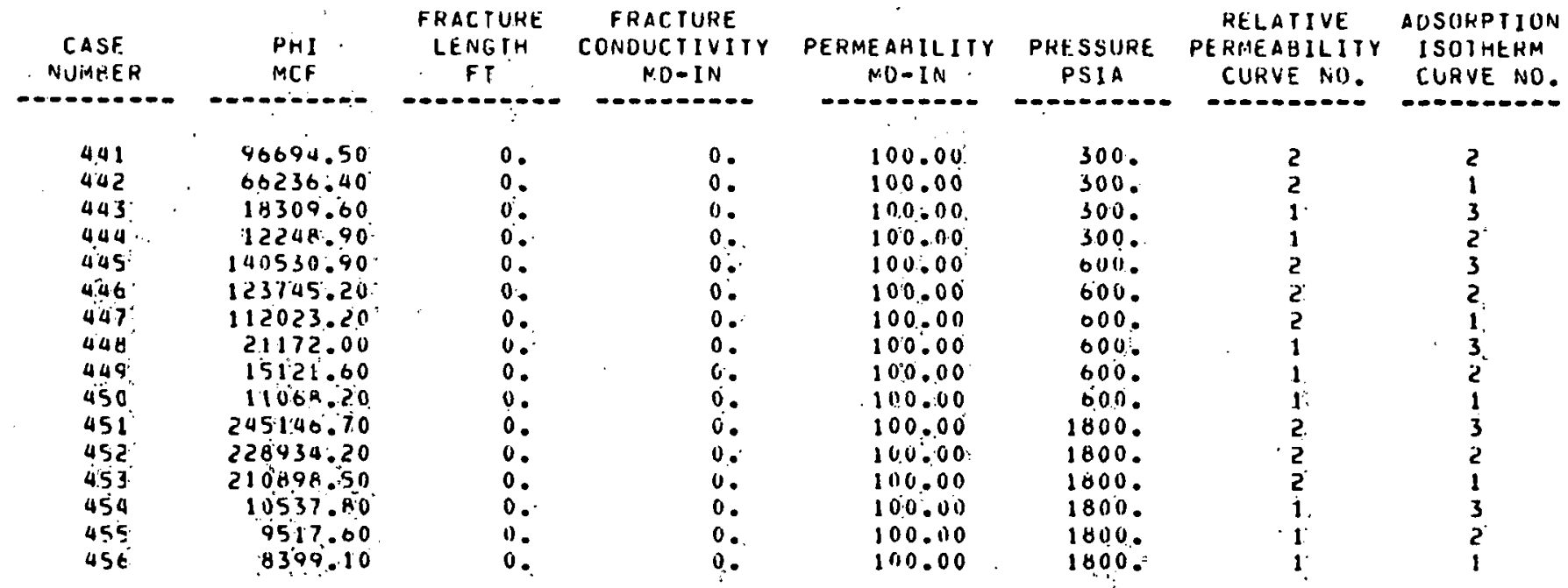


AN ANALYSIS OF METHANE POTENTIAL

FROM UNMINABLE COAL BEDS

IN SELECTED AREAS

OF THE UNITED STATES

INTRODUCTIION

This report presents the results of a study to evaluate and recommend suitable sites for the implementation of a testing program designed to examine the feasibility of producing methane from unminable coal beds.

The principal part of the report deals with the distribution of coal reserves in six areas of interest. These areas--the Powder River, Southeastern Uinta-Piceance, Raton, San Juan, Western Interior and Appalachian Basins--are located on the coal field index map in Appendix $A$. In addition, data from other known coal areas are presented to complete the survey on potential gas producing coal areas. Each geographic area and its potential gassy coals are discussed in separate sections of the report. In all, 23 areas are described.

The important principal uncertainties affecting the feasibility of producing methane from coal are the gas content of the coals and the permeability of the fracture system within the coal. This report assumes that this data can be obtained from a piggyback testing program and presents recommended sites, along with the names of cooperative operators. Since most of the existing data are on low volatile bituminous Pennsylvanian age coals, we have concentrated this program on obtaining data for other coals. These include deeper coals, younger Cretaceous age coals and lower rank coals. 
While data for deep coals tends to be scarce, some areas exist where information points to good gas production potential. These areas, as well as adjacent geologically similar areas, are outlined in black on the Figure 10 map. Dashed lines further delineate areas judged to be favorable for gas production based on criteria applied to the extent, thickness and composition of the coal as discussed below. The map also gives coal reserves as a function of rank, areal extent and structural depth. Rank, as a function of. the amount of fixed carbon, moisture and volatile matter present in the coal, is presented graphically on Figure 1. From the figure, it can be seen that fixed carbon over $45 \%$ and moisture below $20 \%$ are properties of higher rank coals. Figure 2, in turn, relates the rank and depth of the coal to its gas content. It is the gas content together with the thickness and areal extent that will establish the resource base for methane from coal beds. This report discusses the thickness, areal extent and composition of the coal as best it can be determined from existing literature and firsthand knowledge. 
All the coal areas reviewed in this report have been assigned to one of four categories based on the types and/or. availability of data. The four categories are defined as follows:

I. Areas where data exist, are positive, and contain emission information.

II. Areas adjacent to Category I areas where limited data are only interpreted as positive and no emission information is available.

III.

Areas not adjacent to Category I areas with very limited data interpreted as positive.

IV.

Poorly defined areas not adjacent to Category I areas with either no data, or incomplete data present.

Existing data were considered positive or leaning that way when they met the following criteria:

Depth - Pennsylvanian coals had to be a minimum of 4-500' deep; while Cretaceous, Jurrasic and Tertiary coals had minimum depths of 7-800'.

Total Footage - Varied with other criteria.

Extent - A minimum of 20,000 deep acres was required.

Thickness - Individual bed had to be at least 2' thick.

Continuity - Total footage over an area must remain fairly constant.

Fixed Carbon, Volatile and Moisture Content - In areas designated as Category I or II, bituminous coals were required.

Figures 3-9 are maps of the major coal basins discussed in this report. In each case, the areas designated I and II are outlined with a solid black line, and the categury I areas colored red. A dashed black line is used to define Category III and IV areas. 
The major coal basins and other known coal areas are discussed individually below. Among the points addressed in each area are the rank of the coal, individual bed thicknesses, as well as total coal footage, compositional analyses and geologic age. Twenty-three separate geographic areas are included in the review. 
1. Northern Appalachians

(Pennsylvania, Ohio and West Virginia)

(Category I).

Figure 3

In the Northern Appalachian area, shallow depths were the main test criteria used to eliminate areas as potentially unproductive. Individual coal beds ranged from thicknesses of only inches to 10 feet, but generally averaged 3 to 6 feet; total footages ranged between 20 and 60 feet. The coals are ranked as low to high volatile bituminous coals. Table 1 lista analyses of gasgy coals in Penrsylvania, Ohio and West Virginia. These coal beds have considerable emission data reported, but other beds in the basin are emitting gas at various depths also.

At present, only the Pittsburgh Coal has sufficient mine and well data available to be excluded from testing. Other seams should be tested throughout the area.

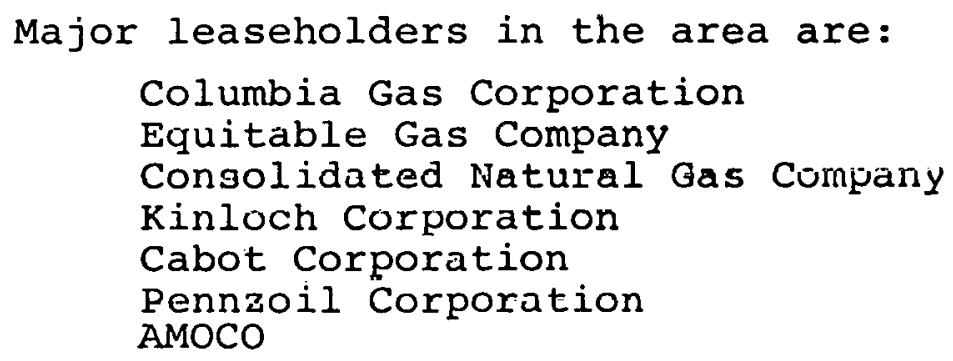

These companies all have active drilling programs in the Northern Appalachian area. 
Table 1. Analyses of Gassy Coals in the Northern Appalachians (numbers expressed as whole percent)

\begin{tabular}{|c|c|c|c|c|c|}
\hline State & Coal & County & Moisture & $\begin{array}{l}\text { Volatile } \\
\text { Matter }\end{array}$ & $\begin{array}{l}\text { Fixed } \\
\text { Carbon } \\
\end{array}$ \\
\hline \multirow[t]{7}{*}{ Pennsylvania } & $\begin{array}{l}\text { Lower } \\
\text { Kittanning }\end{array}$ & $\begin{array}{l}\text { Armstrong } \\
\text { Blair }\end{array}$ & 6.9 & 35.0 & 51.6 \\
\hline & & $\begin{array}{l}\text { Cambria } \\
\text { Centre }\end{array}$ & 2.7 & 21.3 & 67.4 \\
\hline & & $\begin{array}{l}\text { Clarion } \\
\text { Clearfield } \\
\text { Elk }\end{array}$ & $\begin{array}{l}3.9 \\
2.5\end{array}$ & $\begin{array}{l}34.1 \\
23.2\end{array}$ & $\begin{array}{l}52.4 \\
64.0\end{array}$ \\
\hline & & $\begin{array}{l}\text { Fayette } \\
\text { Indiana } \\
\text { Somerset }\end{array}$ & $\begin{array}{l}1.0 \\
3.1 \\
3.3\end{array}$ & $\begin{array}{l}26.1 \\
26.6 \\
17.9\end{array}$ & $\begin{array}{l}64.1 \\
62.4 \\
70.0\end{array}$ \\
\hline & Pittsburgh & $\begin{array}{l}\text { Washington } \\
\text { Greene }\end{array}$ & $\begin{array}{l}1.1-3.9 \\
1.7-3.7\end{array}$ & $\begin{array}{l}32.3-38.7 \\
33.0-36.4\end{array}$ & $\begin{array}{l}49.2-59.4 \\
52.2-57.3\end{array}$ \\
\hline & $\begin{array}{l}\text { Upper } \\
\text { Freeport }\end{array}$ & $\begin{array}{l}\text { Allegheny } \\
\text { Armstrong } \\
\text { Butler } \\
\text { Cambria } \\
\text { Clearfield } \\
\text { Indiana } \\
\text { Jefferson } \\
\text { Somerset } \\
\text { Westmoreland }\end{array}$ & $\begin{array}{l}1.4-3.4 \\
1.9-4.0 \\
2.3-4.9 \\
2.0-4.5 \\
1.8-4.2 \\
1.6-6.4 \\
2.2-4.3 \\
2.1-6.3 \\
1.7-3.5\end{array}$ & $\begin{array}{l}32.2-37.1 \\
31.8-37.0 \\
32.1-41.4 \\
14.9-26.5 \\
21.5-30.8 \\
23.4-32.3 \\
28.6-35.6 \\
17.1-24.2 \\
21.9-36.3\end{array}$ & $\begin{array}{l}52.0-57.1 \\
50.5-57.2 \\
49.1-55.6 \\
61.4-73.5 \\
58.1-67.9 \\
54.7-67.6 \\
49.1-59.9 \\
60.0-68.6 \\
50.1-64.4\end{array}$ \\
\hline & $\begin{array}{l}\text { Middle } \\
\text { Kittanning } \\
\text { (No. 6) }\end{array}$ & & $\begin{array}{l}7.14 \\
4.38 \\
8.22 \\
6.42\end{array}$ & $\begin{array}{l}35.06 \\
39.24 \\
38.61 \\
39.57\end{array}$ & $\begin{array}{l}51.16 \\
48.90 \\
44.37 \\
47.04\end{array}$ \\
\hline \multirow[t]{3}{*}{ Ohio } & $\begin{array}{l}\text { Lower Freeport } \\
\text { (No. 6A) }\end{array}$ & & 3.61 & 37.72 & 50.49 \\
\hline & $\begin{array}{l}\text { Upper Freeport } \\
\text { (No. 7) }\end{array}$ & & 5.65 & 36.47 & 49.70 \\
\hline & $\begin{array}{l}\text { Pittsburgh } \\
\text { (No. 8) }\end{array}$ & & 4.18 & 37.64 & 49.94 \\
\hline
\end{tabular}


TABLE 1, continued

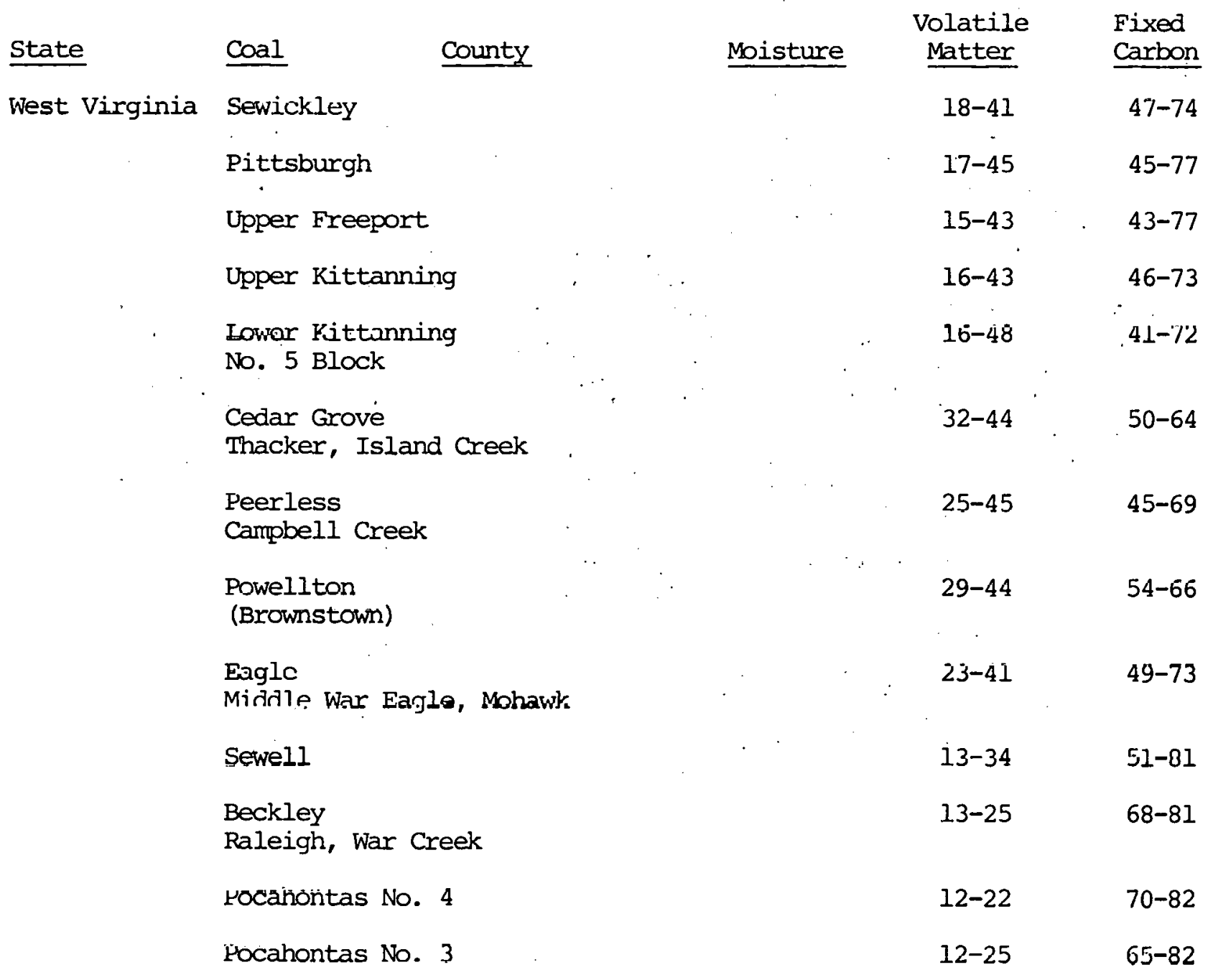


2. Middle Appalachians

(East Kentucky, Virginia and Tennessee)

(Category I)

Figure 4

In the Middle Appalachian area, shallow depths were again responsible for delineating unproductive zones. Coal beds average thicknesses of 3 to 4 feet, though the range went from just inches to 6 feet. Total footage was between 20 and 40 feet. Table 2 lists the analyses of reported gassy coals in eastern Kentucky, Virginia and Tennessee. Coals in the area are low to high volatile bituminous coals. Many potential beds, such as the Stearns \#2, are not listed in Table 2 because they are not mined at depth. Thin minable and unminable seams should be tested throughout the area. This would include 15 to 20 additional seams throughout the Middle Appalachians.

The major leaseholders with ongoing drilling programs are:

Kentucky-West Virginia Gas

Weaver Oil and Gas

Columbia Gas Transmission Corporation

Texas International Petroleum Corporation

Dixie Oil Company 
Table 2. Analyses of Gassy Coals in Middle Appalachians (numbers expressed as whole percent)

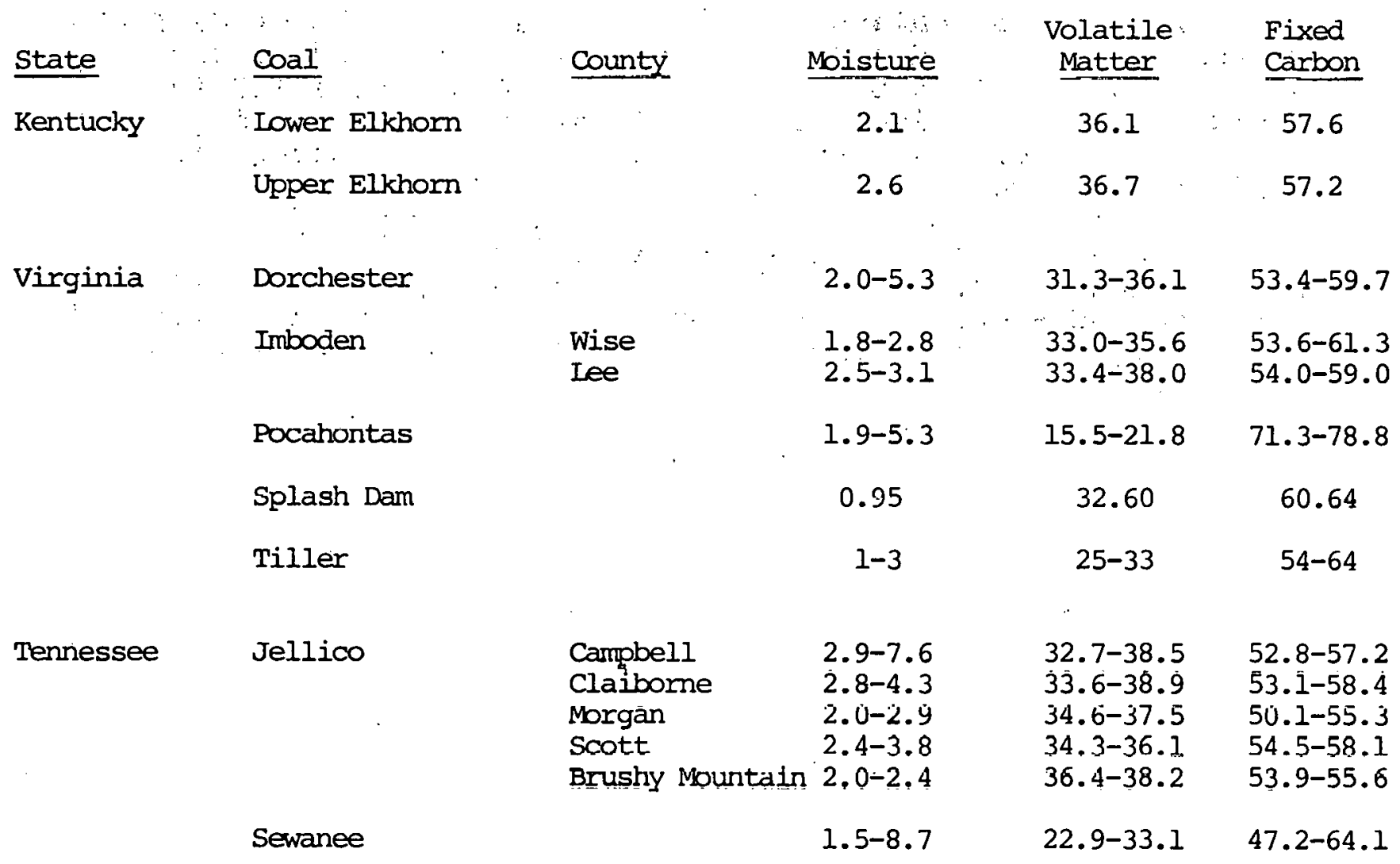


3. Lower Appalachians and/or Warrior Basin

(Alabama and Mississippi)

(Categories I, II and III)

Figure 5

The Lower Appalachians are the first areas to be categorized as Categories I, II and III. As previously mentioned, I and II are within the solid black line in Figure. 5, while "II is outlined by a dashed line. Coal beds vary from inches to 7 feet, but are generally 3 to 5 feet thick. Total footage is 15 to 50 feet. The rank varies from low to high volatile bituminous. Table 3 presents the analyses of reported gassy coals in the area. Twenty additional coal beds which are either not being mined or not being mined at depth are known in the area and should also be tested under the program. Table 4 shows the major leaseholders and those with active drilling programs. 
Table 3. Analyses of Gassy Coals in the Lower Appalachians (numbers expressed as whole percent)

\begin{tabular}{|c|c|c|c|c|}
\hline State & Coal & Misture & $\begin{array}{l}\text { Volatile } \\
\text { Matter }\end{array}$ & $\begin{array}{l}\text { Fixed } \\
\text { Carbon }\end{array}$ \\
\hline \multirow[t]{7}{*}{ Alabama } & Blue Creek & $2.4-3.9$ & $23.2-26.5$ & $53.2-64.4$ \\
\hline & Jagger & $1.6-6.7$ & $23.3-35.7$ & $47.0-68.5$ \\
\hline & Mary Lee & $1.2-4.0$ & $24.0-33.5$ & $48.1-65.3$ \\
\hline & & & $:$ & \\
\hline & America & $2.5-3.8$ & $31: 0-35.6$ & $52.9-61.6$ \\
\hline & Nickel Plate & $1.9-4.2$ & $19.1-32.0$ & $25.2-36.8$ \\
\hline & Pratt & $0.8-2.8$ & $25.2-36.8$ & $53.7-67.2$ \\
\hline
\end{tabular}


Table 4. Major Leaseholders in the Lower Appalachian Area

U.S. Steel

Republic Steel

* Jim Walter Resources

Gulf Oil

*National Exploration Company

AMOCO

*Warrior.: Drilling and Engineering Company

Sunmark Exploration

Southland Royalty

Louisiana Land and Exploration

*Terra Resources

Kerr-McGee

Gulf States Paper Company

Weyerhauser Corporation

*Cleary Petroleum Company

*Leaseholders with active drilling. 
4. Illinois Basin

(Illinois, Indiana and Kentucky)

(Category I)

Figure 6

Some areas in the Illinois Basin are not economically productive because of shallow depths. Total footage of the coal varies between 15 and 25 feet with individual beds ranging from a few inches to 10 feet in thickness, but averaging 4 to 5 feet thick. The rank of the coal is high volatile bituminous. Table 5 presents analyses on the various gassy coals reported in the area. In addition, five other beds are known to exist and should be tested under the program. Table 6 shows lease owners in the Illinois Basin, as well as those with active drilling programs. 
Table 5. Analysis of Gassy Coals in the Illinois Basin

(all numbers expressed as whole percent)

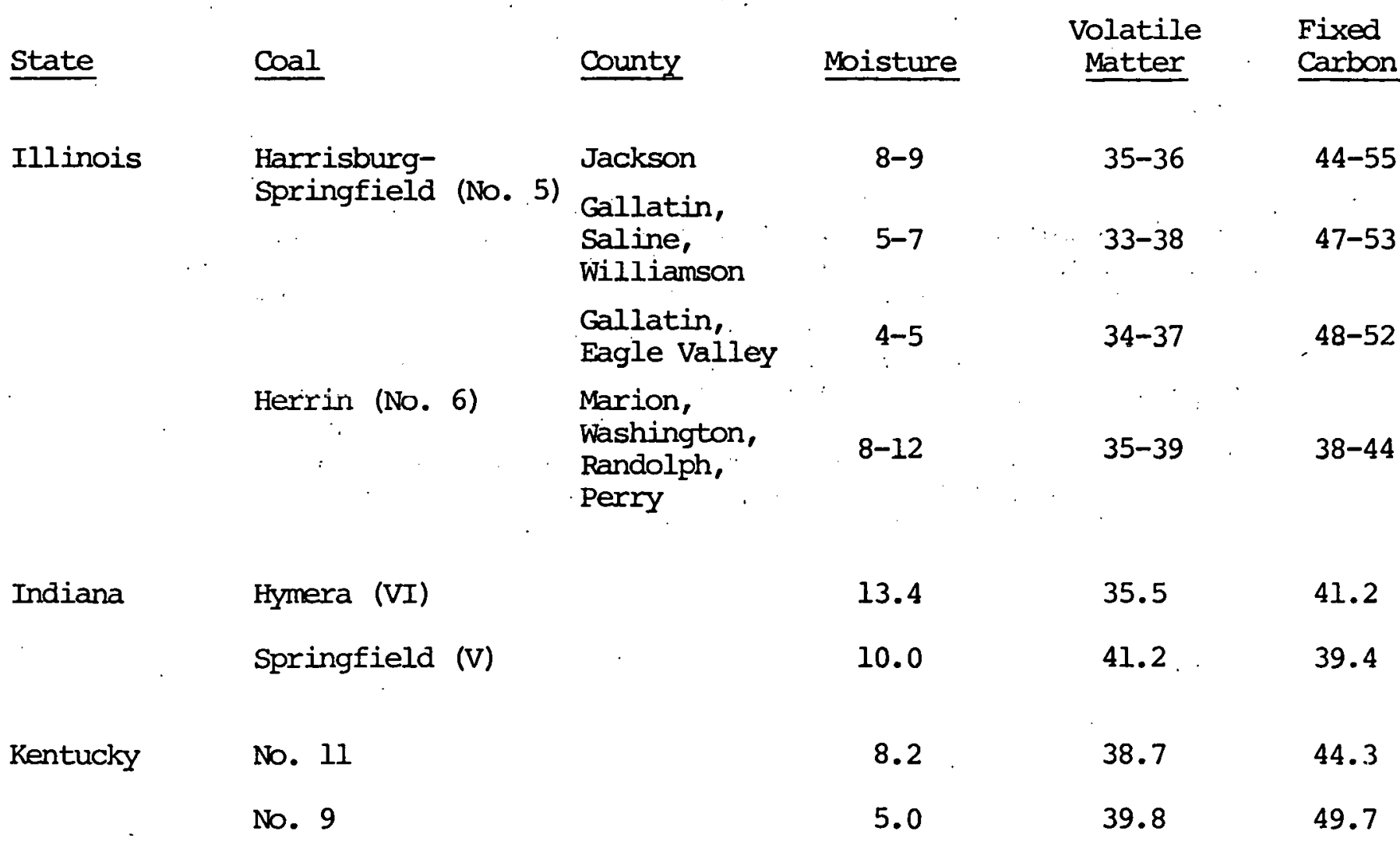


Table 6. Major Illinois Basin Leaseholders

* Shamrock Oil and Gas

* Texas Gas Transmission Corporation

* Ram Oil Company

*S \& W Drilling Company

${ }^{*} \mathrm{~K} \&$ L Company

* Royal Drilling Company

"Victor" K. Gallegher

* Rossi Oil Company ..

*George N. Mitchell Drilling

* Southeastern Illinois Oil Production.

*Viking Oil Company

$*_{\text {RK }}$ Petroleum

*Pogo Petroleum Inc.

${ }^{*}$ C. E. Brehm Drilling and Production

*Hocking oil. Company, Inc.

*Northwest Oil and Gas

*Fletcher Farrar

*Duke Resources Corporation

*Leaseholders with active drilling. 
5. Arkoma Basin

(Oklahoma and Arkansas)

(Western Interior)

(Categories I and II)

Figure 7

In general, the entire Western Interior Basin, except for the Arkoma, is too shallow for economic production. Where economic depths are reached, as in northwest Missouri and southwest Iowa, coal zones are not continuous. Total footage, which varies between 3 and 7 feet, is esisentially comprised of Upper and Lower Hartshorne beds which average 3 to 4 feet in thickness. Below the Lower Hartshorne coal lies the Hartshorne sandstone, a gas producing sand which should be tested along with the coal. Rank varies from low to high volatile bituminous. Table 7 presents the analyses for the gassy coals in the area. Table 8 presents the major lease owners in the Arkoma Basin and those with active drilling programs. 
Table 7. Analyses of Gassy Coals in the Arkoma Basin (numbers expressed as whole percent)

\begin{tabular}{|c|c|c|c|c|c|}
\hline State & Coal & County & Moisture & $\begin{array}{l}\text { Volatile } \\
\text { Matter }\end{array}$ & $\begin{array}{l}\text { Fixed } \\
\text { Carbon }\end{array}$ \\
\hline \multirow[t]{3}{*}{ Oklahoma } & Hartshorne & $\begin{array}{l}\text { Haskell } \\
\text { LeFlore } \\
\text { Sequoyah }\end{array}$ & $\begin{array}{l}3.1 \\
2.4 \\
5.3\end{array}$ & $\begin{array}{l}22.0 \\
20.6 \\
16.8\end{array}$ & $\begin{array}{l}68.2 \\
71.4 \\
72.4\end{array}$ \\
\hline & Ijpper Hartshorne & $\begin{array}{l}\text { IeFlore } \\
\text { Latimer } \\
\text { Pittsburg }\end{array}$ & $\begin{array}{l}2.5 \\
3.4 \\
4.5\end{array}$ & $\begin{array}{l}21.3 \\
37.1 \\
35.4\end{array}$ & $\begin{array}{l}66.3 \\
55.0 \\
53.7\end{array}$ \\
\hline & Lower Hartshorne & $\begin{array}{l}\text { Latimer } \\
\text { LeFlore } \\
\text { Pittsburg }\end{array}$ & $\begin{array}{r}4.7 \\
2.9 \\
3.6\end{array}$ & $\begin{array}{l}35.9 \\
17.8 \\
37.2\end{array}$ & $\begin{array}{l}53.5 \\
72.3 \\
52.8\end{array}$ \\
\hline Arkansas & Lower Hartshorne & $\begin{array}{l}\text { Sebastian } \\
\text { Johnson } \\
\text { Pope }\end{array}$ & $\begin{array}{l}2.4 \\
2.5 \\
2.1\end{array}$ & $\begin{array}{l}17.5 \\
12.6 \\
12.3\end{array}$ & $\begin{array}{l}72.8 \\
75.4 \\
75.1\end{array}$ \\
\hline
\end{tabular}


Table 8. Major Leaseholders in the Arkoma Basin

\author{
Kerr-McGee \\ Gulf oil \\ Arkansas-Louisiana Gas \\ Kirby Exploration \\ Texas $O i l$ and Gas \\ Service Drilling Company \\ .Getty Oil. \\ Global Oil \\ *Arkla Exploration \\ *Hanna Oil and Gas \\ *Texas Oil and Gas \\ *Stephens Production Company \\ *W. C. Payne. \\ *PetroDavis Inc. \\ *Glenco Petroleum Company \\ *Continental Oil \\ *Supron Energy Company \\ * Lamar Petroleum \\ *Eagle Petroleum \\ *Tridon Oil Inc. \\ *Estoril Producing Company \\ * Reserve Oil Inc. \\ *Hudson Ohio Oil Company
}

*Leaseholders with active drilling. 
6. Raton Basin

(Colorado and New Mexico)

(Category I)

Figure 8

Shallow depths were used for identifying areas in the Raton Basin as unproductive. In the Trinidad Field; the total footage is in the 15 to 35 -foot range with beds usually 2 to 4 feet but varying from only a few inches to 5 feet. Mine emission data indicate that the Coreula (Allen), York Canyon, Frederick, Morley and Berwind Hastings coals are gassy at depth. A general analysis indicates moisture, volatile and fixed carbon values to be 1.0 to $5.8,35.7$ and 54.9 respectively. In addition, 9 to 12 other seams in the area should be tested.

Leaseholders include CF\&I Steel, Kaiser Steel, Phelps Dodge, Brooks Exploration and Texaco, all of whom have active drilling programs underway. 
7. San Juan Basin

(Colorado and New Mexico)

(Categories:I, II and III)

In the San Juan Basin, the total footages vary between 15 to 25 feet, with individual beds generally 3 to 6 feet thick. The minimal mine data available indicate gas present in the Menefee Formation of the Mesa Verde Group in the Red Mesa (Hesperus) area of the Durango Field. Rank is high volatile bituminous with average values for moisture, volatiles and fixed carbon equal to $4.6 \%, 40.5 \%$ and $53.1 \%$. Testing of the other Mesa Verde coals, as well as coals present in the Dakota and Fruitland, should be included in the testing program. The following leaseholders are supporting active drilling programs in the area:

El Paso Natural Gas

InterAmerican Petroleum Corporation

Kirby Exploration

Tenneco.

Southern Union

AMOCO

Dome Petroleum

TEXACO

CONOCO

skelly 
8. Uinta Basin and Wasatch Plateau

(Utah)

(Categories I, II and III)

The Uinta Basin which has total footages in the 35 to 50-foot range is comprised of individual coal beds up to 20 feet thick. The Wasatch, with similar coal bed thickness, measures 30 to 70 feet of total footage. The coals are ranked as high volatile bituminous and mine emission data indicate the sunnyside, Castlegate, Rock Canyon and Ferron $J$ coals to be gassy at depth. Analyses of some coal beds in the area are presented in Table 9.

While the Mesa Verde coals are the most prolific in the area, other Cretaceous rocks are coal-bearing. The Ferron, Frontier and Dakota sandstones have known coal zones. With this in mind, all Cretaceous coal zones should be tested when possible. Table 10 lists the main leaseholders in the twó areas, as well as the companies actively drilling in the area. 
Table 9. Analyses of Coals in the Uinta Basin and Wasatch Plateau

(numbers given as whole percent)

Coal

Castlegate

Soldier Canyon

Sunnyside

Woodside

Scofield Area

Huntington Canyon

Southern Half
Volatile

Moisture

$4 \cdot 3$

$4 \cdot 8$

5.0

$5 \cdot 5$

7.2

5.4

8.0

7.4
Matter

42.6

38.6

38.2

37.5

41.4

42.4

38.2

38.0
Fixed

Carbon

46.4

49.3

50.5

50.1

45.3

45.5

47.1

45.7 
Table 10. Leaseholders and Companies Involved in Drilling in the Wasatch Plateau and the Uinta. Basin

Wasatch Leaseholders

Cities Service

Natural:Gas Corporation of California

TENNECO

Sun Gas

Southland Royalty

Cordillera Corporation

Uinta Leaseholders

Geosearch Inc.

Gas Producing Enterprises

Oil Development Company

Chevron

Champlin

Anschutz

Great Basins

Mountain Fuel

Narmco

Active Drilling Program

Gas Producing Enterprises

Geosearch Inc.

Belco Development Corporation

EXXON Inc.

Mapco Inc.

Colorado Interstate Gas Company

Continental oil Company

Réseive oil Inc.

Pacific Transmission Supply Inc.

Chevron USA Inc.

Anschutz

Ensearch Inc. 
9. Uinta-Piceance Basin

(Colorado)

(Categories 1 and 11 )

In the Uinta-Piceance Basin, the Mesa Verde group of coals is again prominent, alone supplying a total footage that ranges between 30 and 80 feet. Individual beds are up to 20 feet thick, though the average bed is 10 feet thick. Coals in the basin rank from subbituminous to anthracite. Table 11 provides the analyses of coals believed gassy on the basis of mine emission data. Emission data are also available for the Dutch Creek coal. Moreover, in any given region of the basin, as many as six other seams should also be tested in the program. Table 12 lists the leaseholders actively drilling in the basin. 


\section{Table 11. Analyses of Gassy Coals in the Uinta-Piceance Basin \\ (numbers given as whole percent)}

$\underline{\text { Coal }}$

"F" Seam

Green Valley

Palisade

Juanita $\mathrm{C}$

Bowie Lower ("B")

Bowio Upper ("C")

Hawks Nest ("E")

oliver ("D")

Cameo

Coal Basin B

Coal Basin C

"A and B" (Carbondale)
Moisture

4.5

9.3

9.3

5.7

5.0

6. 1

4.4

6.8

7.5

3.9

4. 2

3.1
Volatile

Matter

40.8

38.4

38.9

$4 \cap .8$

40.2

40.4

41.1

40.5

38.0

22.9

23.0

29.5
Fixed

Carbon

51.7

52.3

52.0

5.3 .1

51.2

51.4

54.3

32.6

50.6

68.8

67.3

58.2 
10. Green River---Sand Wash

(Colorado)

(Categories I, II and III)

Individual coal beds in the Green River-Sand wash area have been measured up to 18 feet in thickness. These single beds have combined to generate total footage thicknesses of 40 to 80 feet. The Pinnacle ("2" or "A") coal, whose analysis shows moisture, volatiles and fixed carbon measured at 9.1\%, $41.2 \%$ and 53.2\%, has mine emission data indicating it is gassy at depth. Rank varies from subbituminous to high volatile bituminous. Mesa verde coals, also present in the area, are divided into two formations--the Isles, with up to five seams in any given area, and the Williams Fork, with as many as seventeen seams.

Two thousand feet above the Mesa Verde coals, younger Cretaceous coals are found in the Lance Formation. These young, 10-foot thick, subbituminous coals should be included in the testing along with the previously mentioned coals.

Active leaseholders and drilling companies are listed in Table 12 . 
Table 12. Major Leaseholders in the Uinta-Piceance Basin and Colorado Green River Area

\section{Uinta-Piceance Leaseholders}

Fuelco

Taiga: Energy.

Tipperary

Chevron

coors

Flying Diamond

EXXON

Petro Lewis Corporation

Rainbow Resource

AMOCO

Cities Service

Green River-Sand Wash Leaseholders

Energy Reserves Group

Gulf

Colorado Interstate

C\&K Petroleum

Mountain Fuel

Wainoco

Fueleo

Ininn ni 1

cities service

ARCO 
11. Green River--Washakie, Great Divide and Rock Springs

(Wyoming)

(Categories III and IV)

Wyoming's Green River area has tertiary coals in the Wasatch and Ft. Union Formations and Cretaceous coals in the Lance, Mesa Verde and Frontier. Total footages are believed to be extremely large for the coals which rank from subbituminous to high volatile bituminous. Analyses of three coal zones and representative thicknesses are presented in Table 13. 
Table 13. Analyses and Thicknesses of the Wyoming-Green River Coals

(numbers expressed as whole percent)

Coal

Ft. Union

Lance

Mesa Verde
Thickness

(Feet)

$10-25$

$5-22$

12
Moisture

20.5

17.5

16.4
Volatile

Matter

29.1

29.8

31.0
Fixed

Carbon

40.7

48.6

47.7 
12. Hanna Basin and Rock Creek Field

(Wyoming)

(Category IV)

While the Tertiary Hanna contains coal in the Hanna Basin-Rock Creek Field area, the Cretaceous coals of the Ferris, Medicine Bow and Mesa Verde formations are considered more important as potential gas producers. Mesa verde coal is high volatile bituminous and the Ferris and Medicine Bow are subbituminous. Analysis data on the Ferris indicates moisture content to be 9.6-18.9\%; volatiles, 32.5$37.2 \%$ and fixed carbon 39.3-49.0\%. 


\section{Wind River Basin}

(Wyoming)

(Category IV)

The wind River Basin has coal beds reported in the Tertiary Ft. Union formation, as well as the Cody shale, Mesa Verde and MeeTeeTsee of Cretaceous age. Surface outcrops indicate the coals to be subbituminous; other information suggests total footage values to be large and individual beds to be thick. 
14. Jackson Hole Coal Field

Little is known about the Jackson Hole Coals other than that they are Tertiary and Cretaceous in age, as are most coal beds in the Rocky Mountain area. The subbituminous coals appear to meet the necessary thickness and footage requirements for testing: 
Table 14. Analyses for Coals in the Powder River, Big Horn, Henry Mountains, Bellingham and Kaiparowits Areas

(figures given as whole percent, except where noted)

\begin{tabular}{|c|c|c|c|c|c|}
\hline Area/Basin & Coal & $\begin{array}{l}\text { hickness } \\
\text { (Feet) }\end{array}$ & Moisture & $\begin{array}{l}\text { Volatile } \\
\text { Matter }\end{array}$ & $\begin{array}{l}\text { Fixed } \\
\text { Carbon }\end{array}$ \\
\hline \multirow[t]{2}{*}{ Powder River } & Wasatch & & $17.8-30.7$ & $29.1-36.4$ & $28.4-39.4$ \\
\hline & Ft. Union & & $14.5-31.0$ & $26.5-38.5$ & $30.5-40.7$ \\
\hline \multirow[t]{2}{*}{ Rivg Horn } & rt. Union & $6-11$ & 12.3 & 35.6 & 44.7 \\
\hline & Mesa Verde & $6-38$ & 15.5 & $34: 2$ & 16 \\
\hline \multirow[t]{3}{*}{ Henry Mountains } & Emery & 5 & 9.8 & 36.5 & 43.9 \\
\hline & Ferron & 2 & 5 & 35.3 & 42.9 \\
\hline & Dakota & 1 & 5.8 & 58.2 & 34.2 \\
\hline \multirow{2}{*}{ Kaiparowits } & Straight Cliffs & & $9.6-19.5$ & $38.4-40.6$ & $33.6-44.1$ \\
\hline & Dakota & & $13.8-18.8$ & 33 & 40 \\
\hline \multirow[t]{4}{*}{ Bellingham } & Bellingham & & 7.3 & 35.8 & 41.3 \\
\hline & Blue Canyon & & 1.6 & 41.3 & 55.0 \\
\hline & Cokertale & & 3.0 & 35 & 60 \\
\hline & Anthracite & & 5.0 & 7.2 & 76.8 \\
\hline
\end{tabular}


15. Powder River Basin

(Wyoming and Montana)

(Category IV)

The Tertiary Wasatch and Ft. Union, as well as the Cretaceous Lance and Mesa Verde, again act as hosts for coal beds, this time in the Powder River Basin. Total footage is expected to be large, as are the individual bed thicknesses. Analyses of surface samples show the rank to be subbituminous. Moisture, volatiles and fixed carbon percentages determined from the surface samples are listed in Table 14. 
16. Big Horn Basin

(Wyoming and Montana)

(Category IV)

In the Big Horn Basin, the Tertiary and Cretaceous

coals are found in the Ft. Union, Lance, MeeTeeTsee and Mesa Verde formations. Individual coal bed thicknesses, as well as total footage, are expected to be large. Rank appears to be a function of depth and is bituminous to subbituminous. Analyses of the Ft. Union and Mesa Verde coals in the basin are given in Table 14. 
17. Black Mesa

(Ar1zona)

(Category IV)

Only cretaceous subbituminous coals from the Mesa Verde, Mancos and Dakota formations are found in Arizona's Black Mesa area. Little is known about the thickness of individual beds, but the coals all lie within 1700 feet of the surface. 
18. Nuclu-Naurita

(Colorado)

(Category IV)

The Nuclu-Naurita area's coal is found in the Cretaceous Dakota sandstone. It is a high volatile bituminous coal with an expected total footage of 20 to 40 feet. 
19. North Park and South Park

(Colorado)

(Category IV)

The Coalmont or Ft. Union of Tertiary age and the Cretaceous Laramie provide the coal beds in the North Park and South Park areas. Since individual beds can reach 70 feet in thickness, the total footage should be sufficient. coal outcrops indicate a subbituminous rank. 


\section{Henry Mountains}

\section{(Utah)}

(Category IV)

The high volatile bituminous coals of the Henry Mountains are Cretaceous in age and located in the Emery, Ferron and Dakota formations. Representative analyses of the coals and their thicknesses are presented in Table 14. 
21. Kaiparowits Basin

\section{(Utah)}

(Category IV)

Twelve to 15-foot coal beds from the straight cliffs and Dakota of the Cretaceous make up the coals of the Kaiparowits Basin. Little is known about the total footage of these highly volatile bituminous coals. Analyses of the coals are presented in Table 14 . 
22. Bellingham, Cokedale-Hamilton

(Washington)

(Category IV)

known coals in the area are Tertiary in age. As many as 15 individual beds are believed to exist, ranging in thickness from just a few inches to 14 feet. Estimates of total footage are not available for the coals, which range from high volatile bituminous to anthracite. Analyses on four coals are given on Table 14 . 
23. Additional Areas

The Williston Basin, the Denver Basin and the North Central Plains of Montana are other areas suspected of containing coal beds capable of producing gas. The three areas should be flagged for future study. 
The specific locations recommended for testing are listed in Table 15. The individual sites within a particular basin or geographic area are given a priority on the basis of :

1. depth of the target formation in the well;

2. arilling fluid to be used;

3. depth of coal beds present;

4. operator;

5. drilling schedule;

6. anticipated drilling problems.

Leaseholder/operators listed are all cooperative and counties listed indicate areas scheduled for drilling during the June to nrtoher perion. 
Table 15. Recommended Testing Sites

\section{Area}

Northern Appalachian

Middle Appalachian

Southern Appalachian

(Warrior Basin)

Oklahoma

(Western Interior)

$\underline{w}$

Illinois

Green River

Powder River

Raton
Priority

1

\section{Leaseholder/Operator:}

Kinloch Deveiopment Corp. Waynesberg collog.

Kentucky-West Virginia Gas Columbia Gas Transmission Weaver Oil and Gas

\section{Pruet and Hughes}

Cleary Petroleum

Arkla Exploration

Hudson-Ohio Oil

Reserve Oil

W. C. Payne

Texas Oil and Gas

C. E. Brehm

Ram Oil

Colorado Interstate

Pacific Transmission

Belco Oil

Davis Petroleum

Anschutz

Phelps Dodge

U.S.G.S.

CF\&I Steel

Phelps Dodge

\section{County/State}

Greene County, Pennsylvania Greene County, Pennsylvania

Letcher County, Kentucky

Pike County, Kentucky

Pike County, Kentucky

Lowndes. County, Mississippi Clay County, Mississippi

Pittsburgh County, Pennsylvania

Latimer County, Oklahoma LeFlore County, Oklahoma coal County, Oklahoma LeFlore County, Oklahoma

Jefferson County, Illinois

Besey County, Indiana

Curban County, Wyoming Sublette County, Wyoming Sublette county, Wyoming Sweetwater County, Wyoming

Campbell County, Wyoming Sheridan County, wyoming

Las Animas County, Colorado Las Animas County, Colorado Colfax County, New Mexico 
Table 15, continued

Area

San Juan Basin

Wind River

Piceance
Priori-y

1

3

1

2

3

1

1
Leaseholder/Operato=

Dome Petroleum

Supron Energy

Western Coal

Pacific Transmission

Mapco

Eelco

Done

Fuelco

Petro Lewis

\section{County/State}

Rio Arriba County, New Mexico Rio Arriba County, New Mexico San Juan County, New Mexico

Uintah County, Utah Uintah County, Utah

Uintah County, Utah

Fremont county, wyoming

Rio Blanco County, Colorado Delta County, Colorado 
FIGURES 
CGMPARISON ON MOST, MINERAL-MATTER-FREE BASIS OF HEA- VALUES AND PROXIMATE ANALYSES OF COAL OF DIFFERENT RANK.

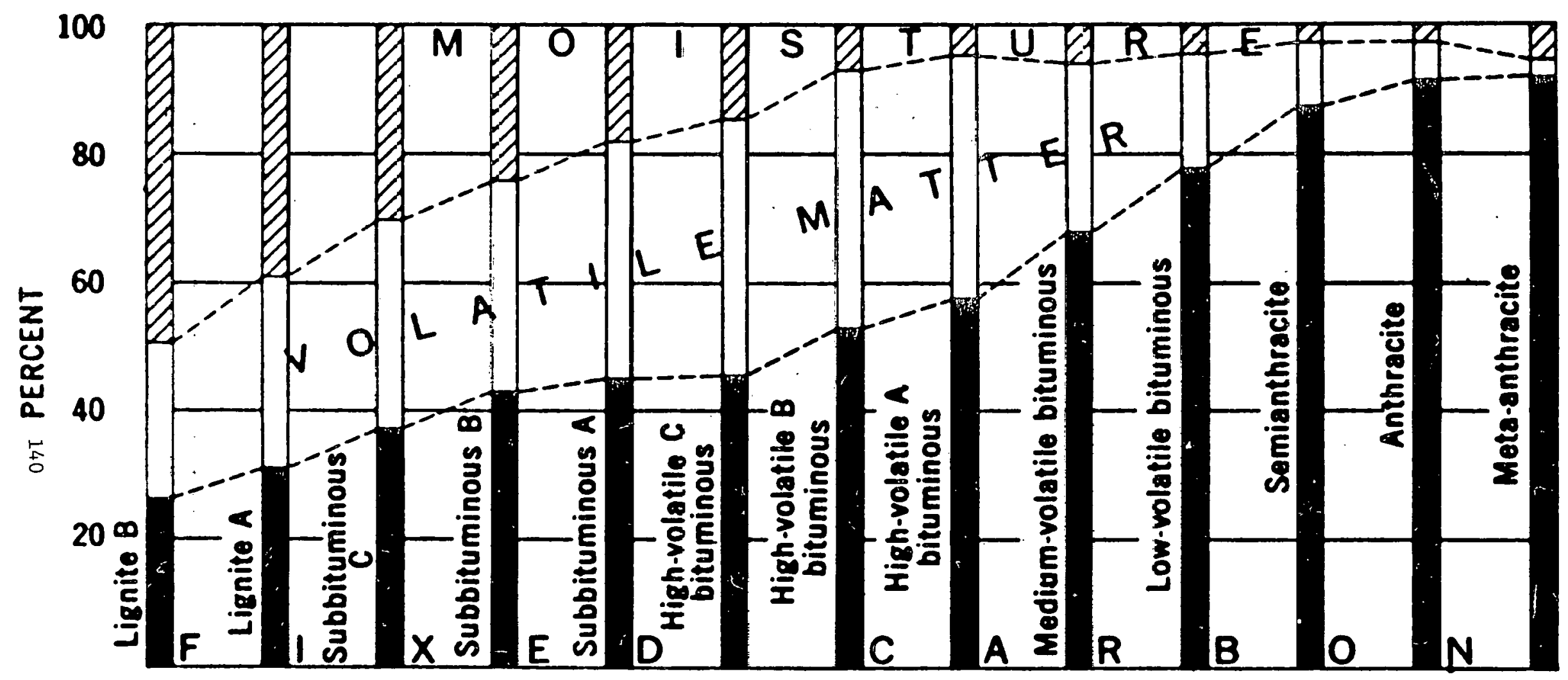

FIGURE 1 
ESTIMATED METHANE CONTENT

WITH DEPTH AND RANK

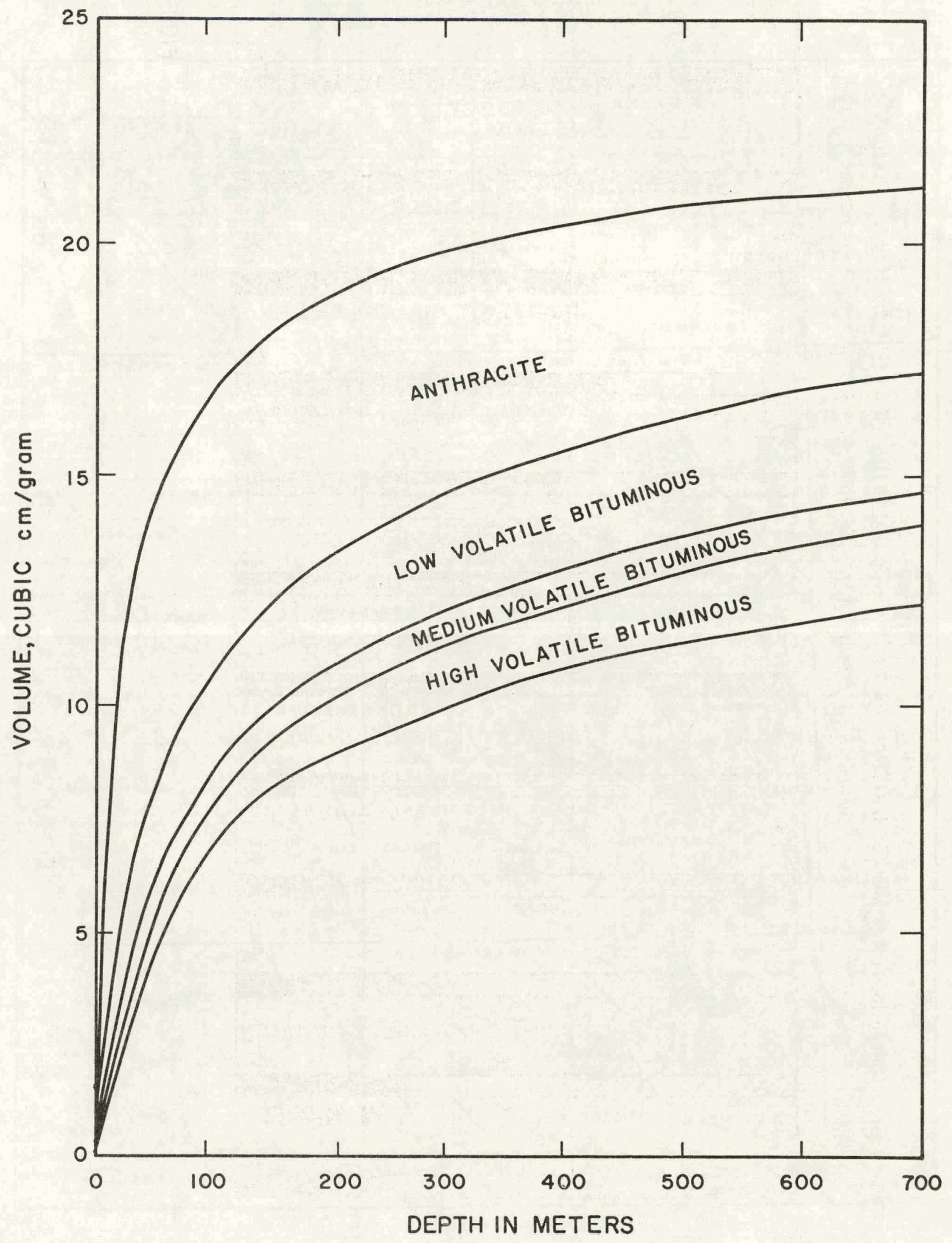

FIGURE 2 


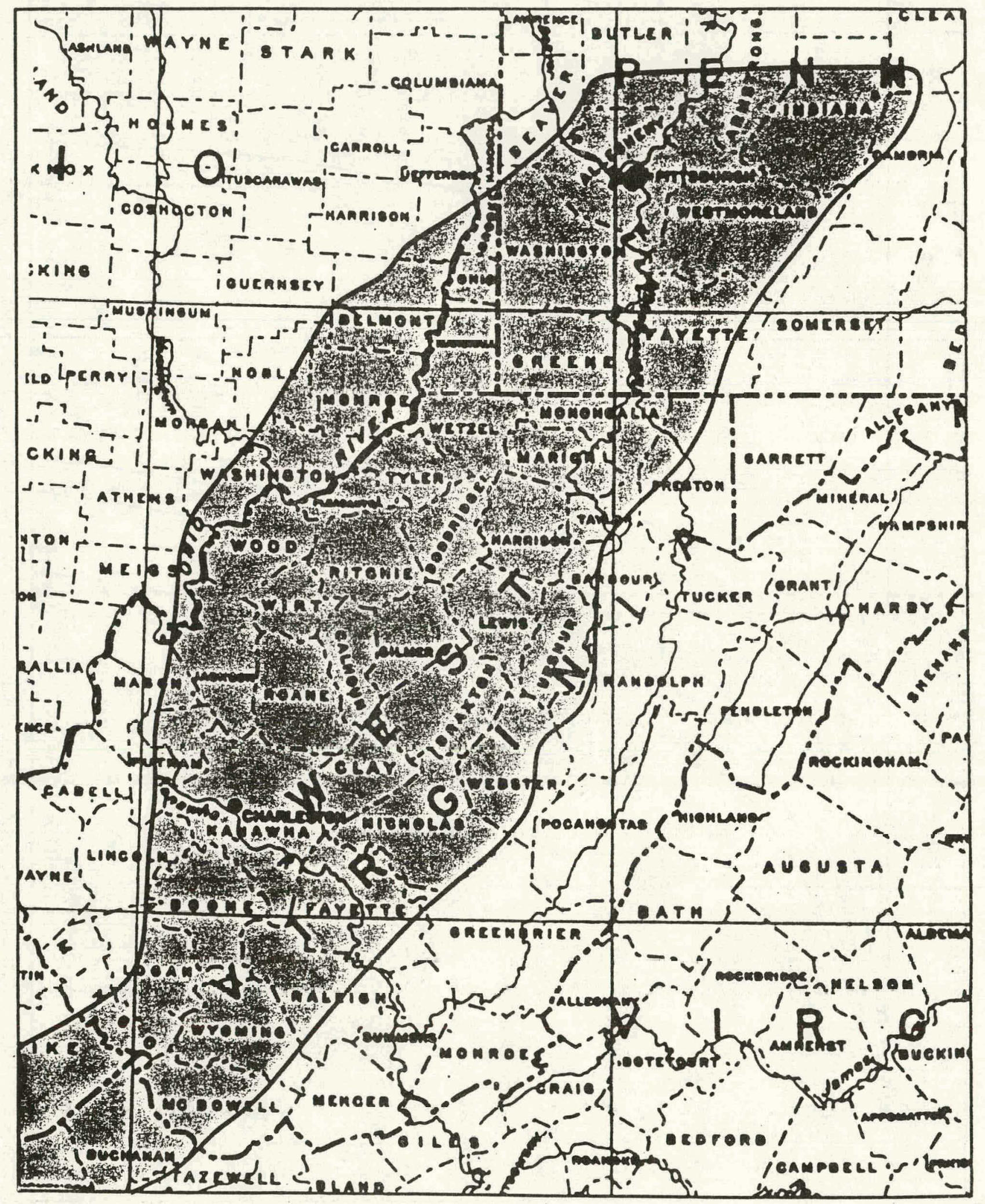

FIGURE 3 - NORTHERN APPALACHIAN 


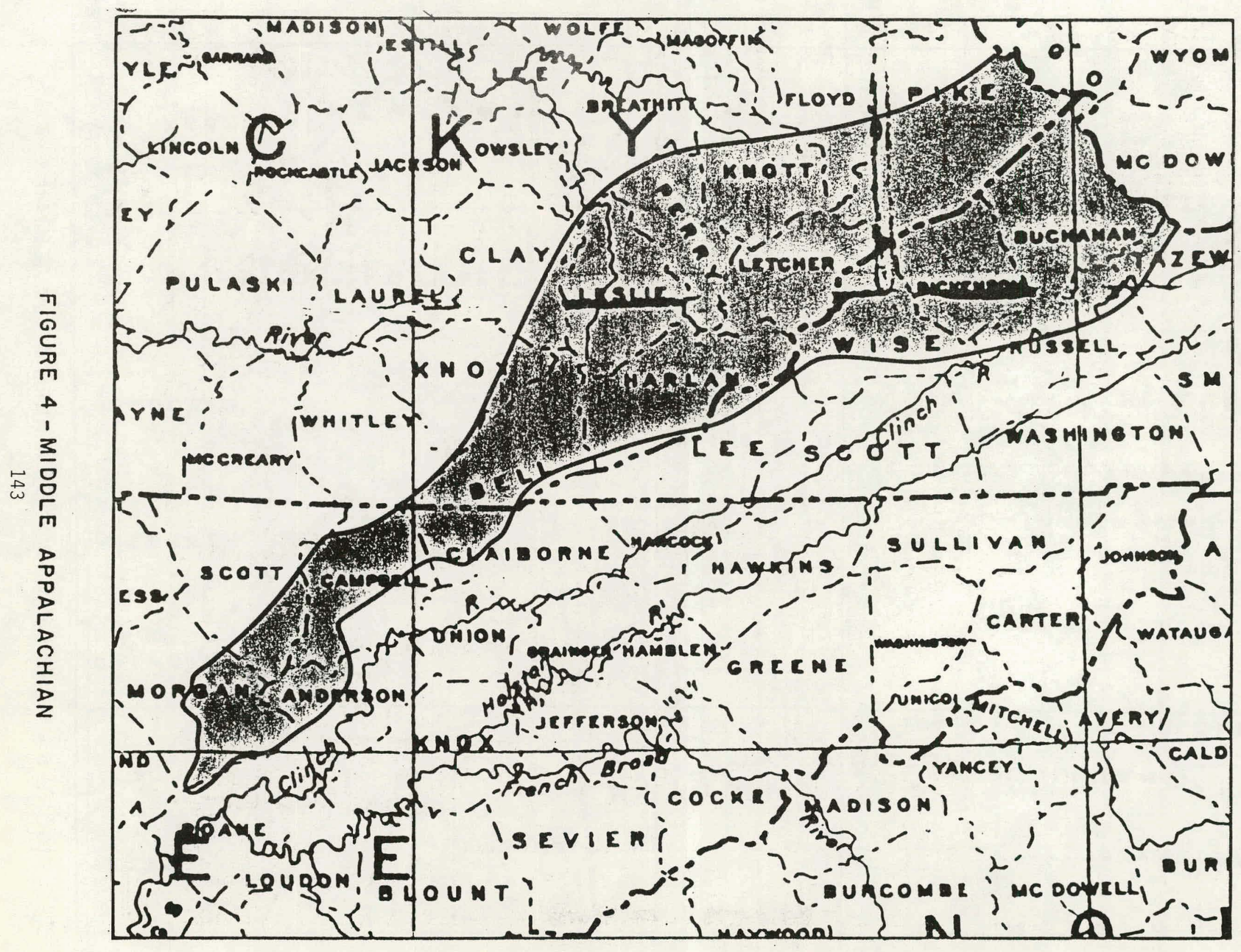




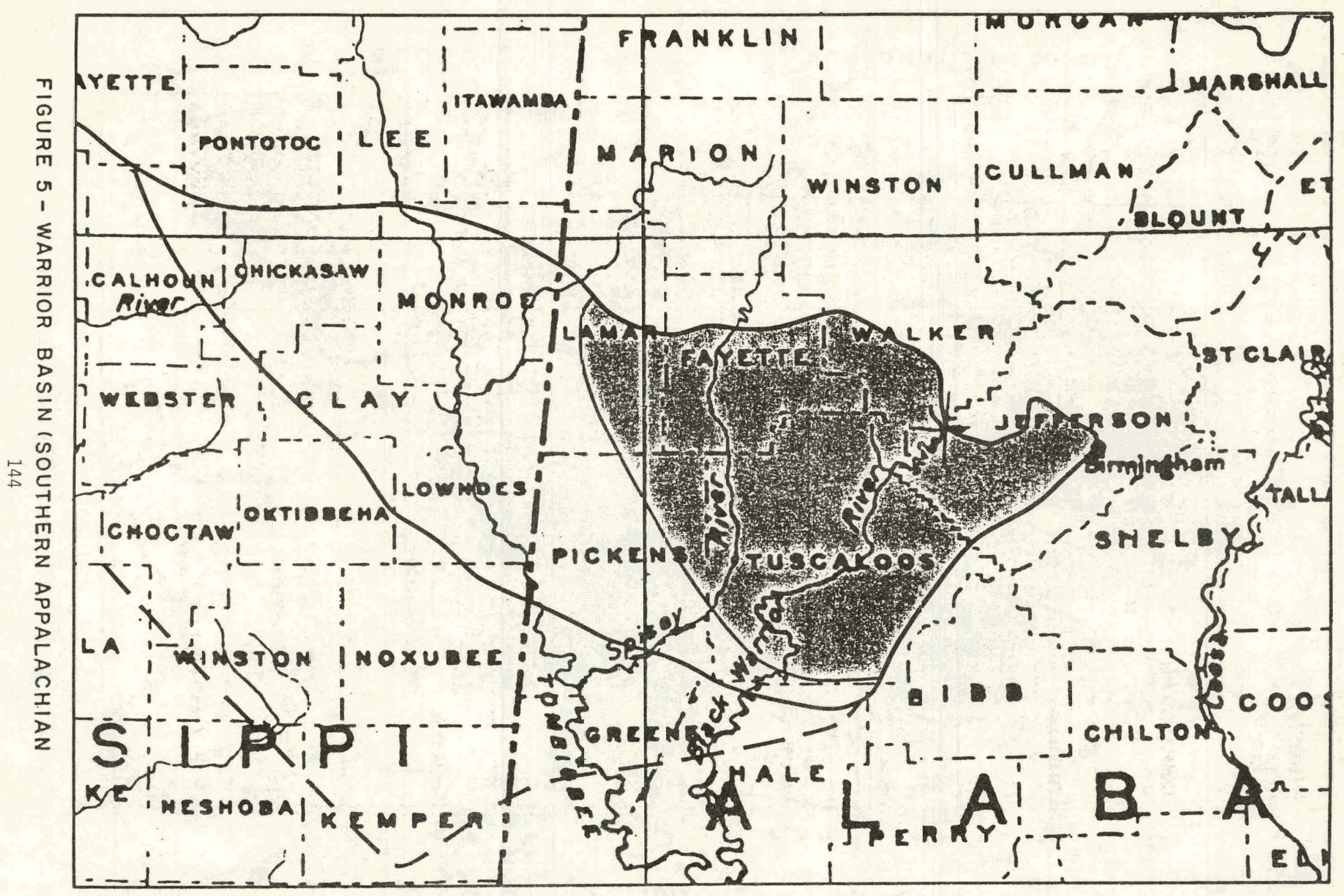




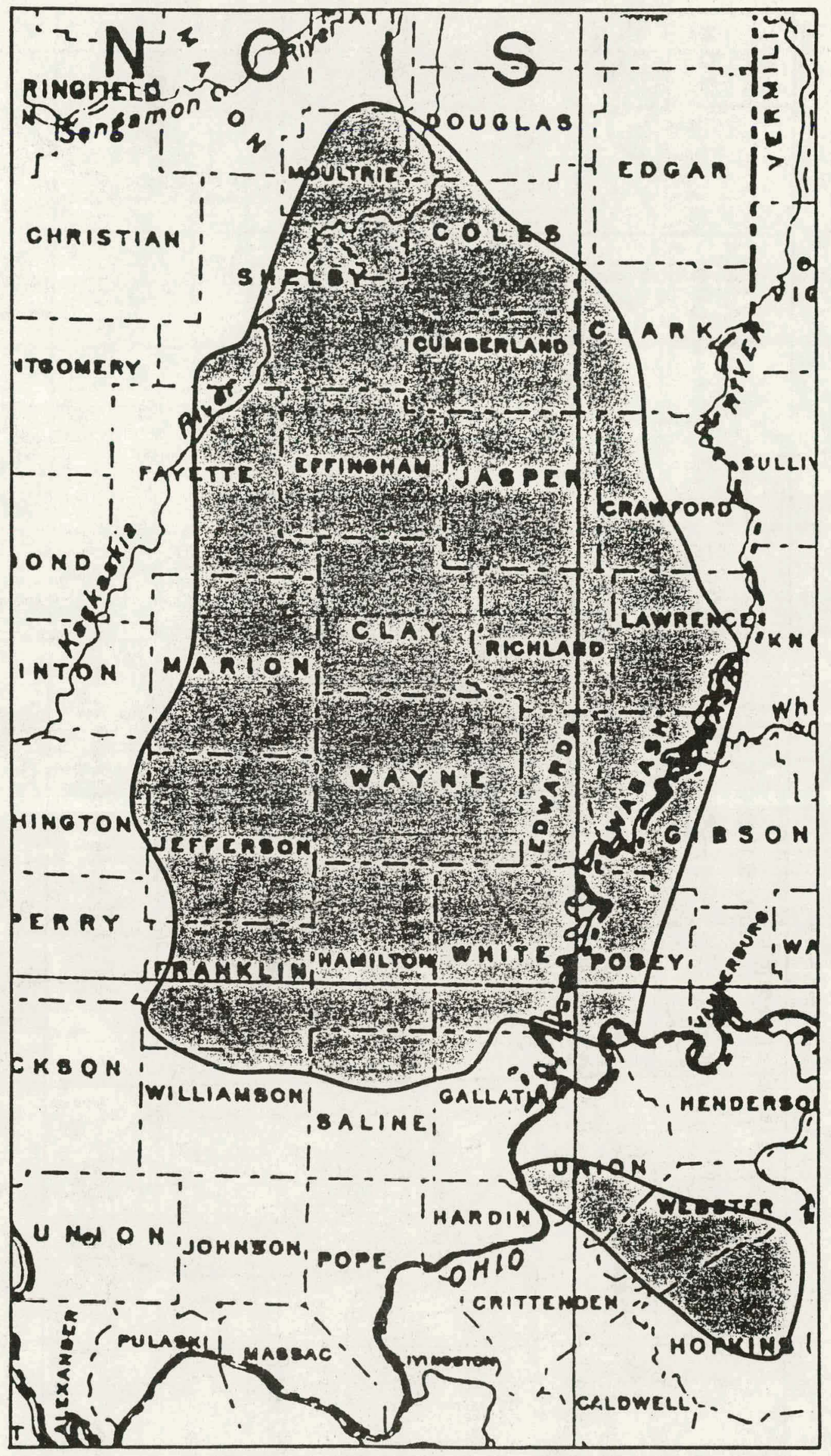

FIGURE 6 - ILLINOIS BASIN 


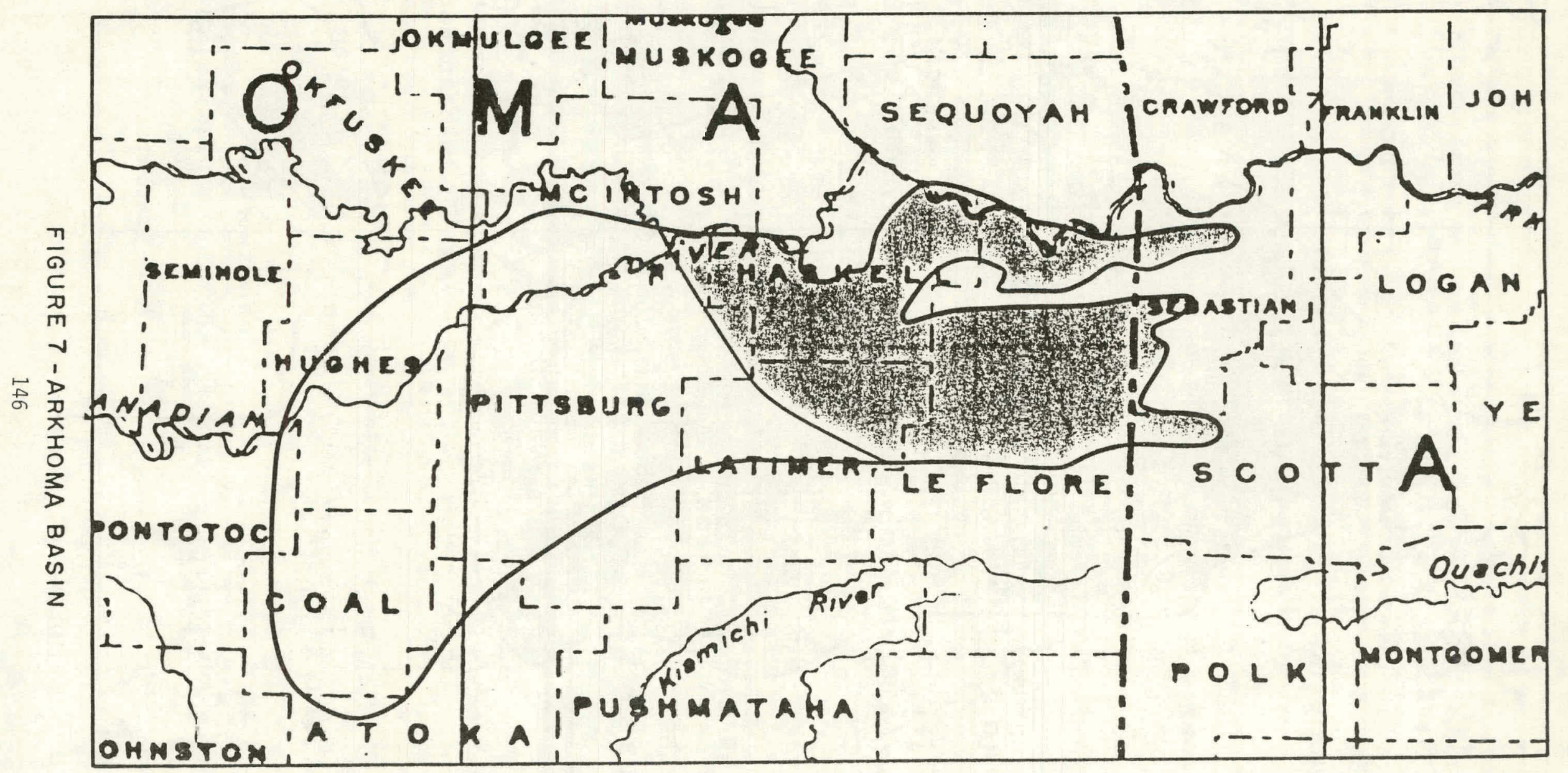




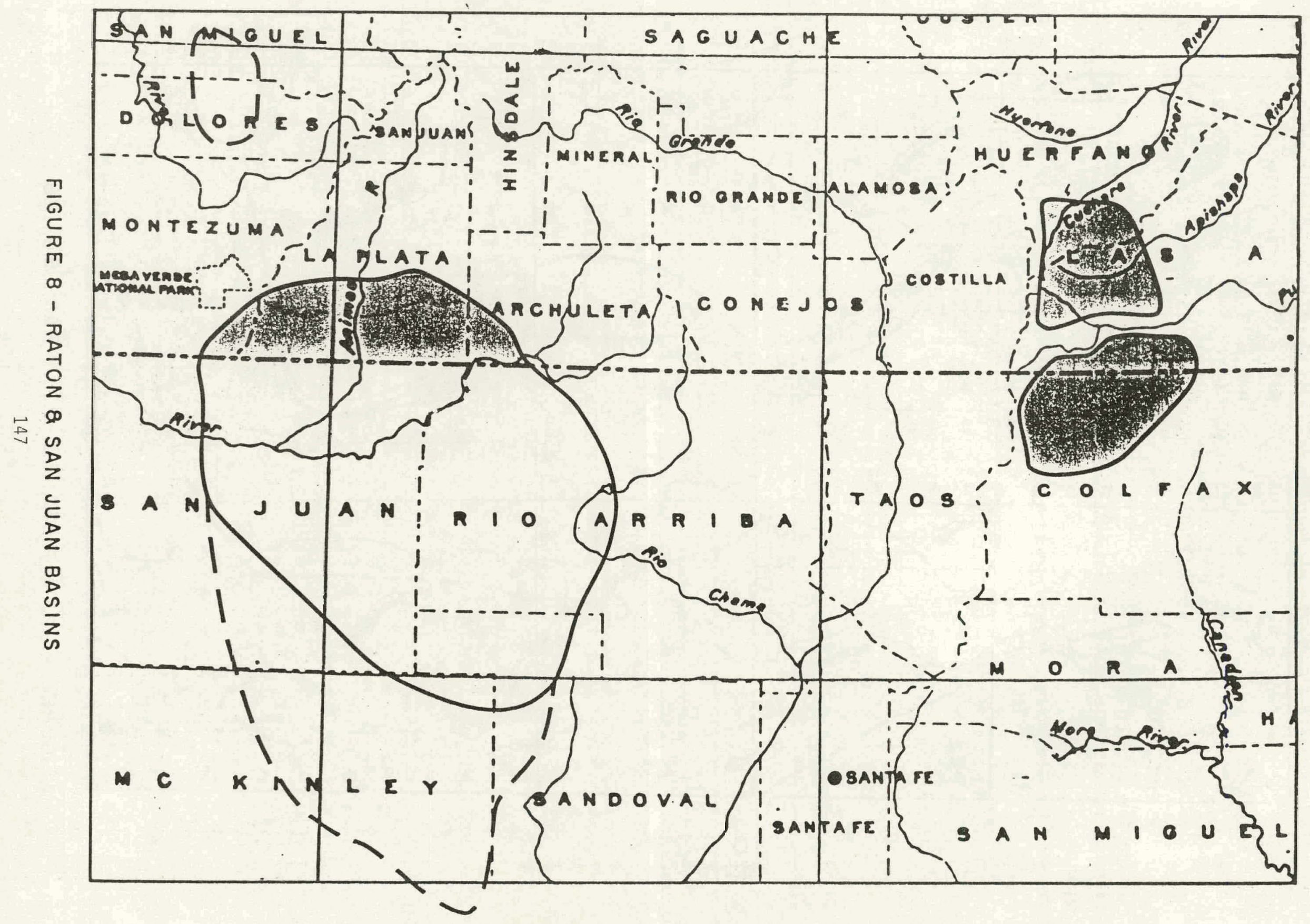




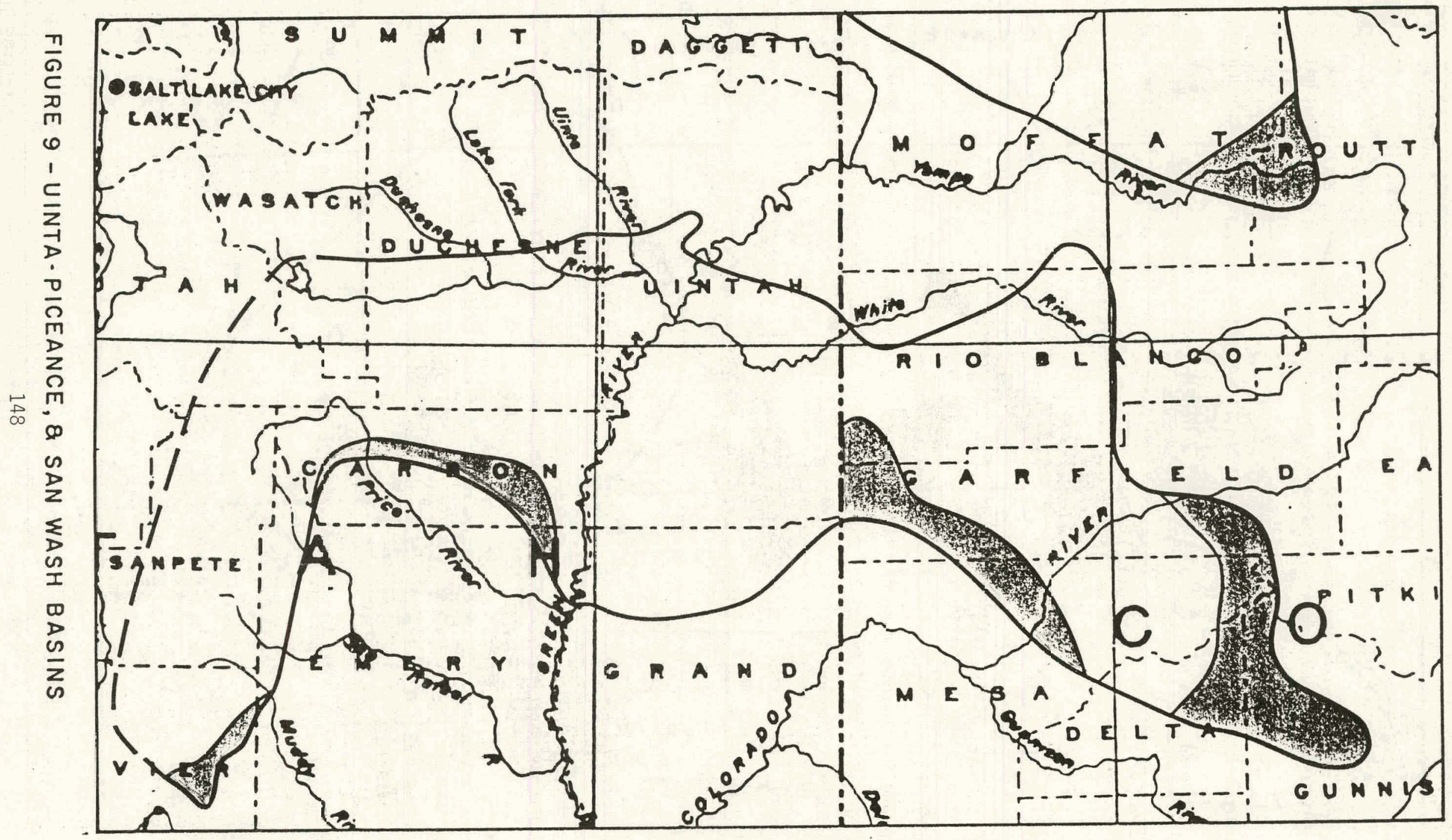




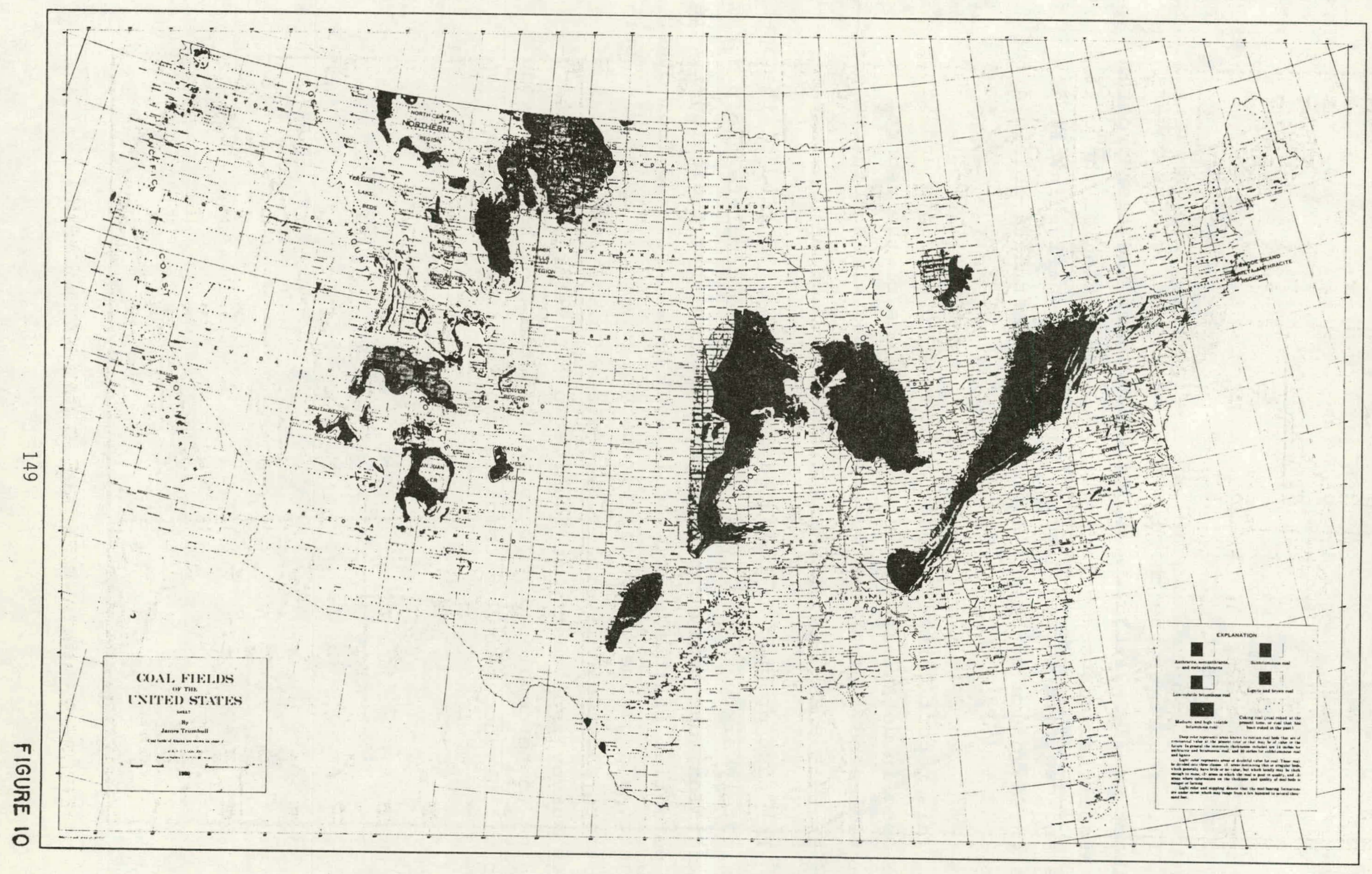




\section{SECTION 111}

\section{INTRODUCTION}

This report is the third volume of reporting that covers Contract EW-78-C-21-8352. Volume I describes the test program and associated costs. Volume II is a compilation of the coal data and geologic information on the several basins involved. This third volume is an evaluation of the test data obtained in 1978.

This report makes frequent reference to concepts and ideas developed in detail in the other two volumes of the report. It is anticipated that as the work is continued through future contracts, this evaluation procedure will be repeated.

The test program as executed in 1978 yielded five of the approximately sixty survey type tests needed to complete the program. In addition, one deliverability test was run that indicated little gas potential at that site. Additional data developed from other projects and gleaned from the literature may yield about five survey tests and two deliverability tests. This leaves a total of fifty survey type tests and twenty-two deliverability tests remaining to be developed. It is anticipated that more than one year will be necessary to complete the test program. 


\section{TEST SITE ANALYSIS}

This section discusses the analysis of various test sites for which data has been found. These sites vary greatly in amount and quality of data. Each site is evaluated individually and ranges of deliverability are made. The ranges were determined by the range used in development of the test program. For those cases where all important variables have been determined except for fracture length, a range of hydraulic stimulation parameters are shown. For those cases that have several missing parameters, the fracture length of 1000. ft was used and fracture conductivity of $50000 \mathrm{md}$-in was used and the variability was determined from the other parameters.

\section{A..: Test Site A - Sublette county, Wyoming}

This site was made available by Belco Petroleum and the well was drilled as a development well in an existing gas field.

1. Location and Geology

The site is located in section 28 - rownship 30 north range 113 west, sublette county, Wyoming. The well is in the western portion of the Green River Basin. The coals found are all in the Mesaverde of cretaceous age.

\section{Tests and Results}

The well was logged with Duel Induction, Compensated Neutron-Formation Density, and Borehole Compensated Sonic Logs. This suite of logs allows the identification of the coalbeds encountered and an estimate of total thickness of the beds. Five coalbeds were encountered with a total thickness of $14 \mathrm{ft}$. The five beds were distributed between 
3436 and 3514 Density Log depth. The thickest bed was from 3444 to 3449 for a gross thickness of $5 \mathrm{ft}$.

Both conventional and sidewall cores were taken for desorbtion. Table 1 shows the results of these desorbtion tests.

These tests show significant gas content with up to 420 cuft/ton. These values are certainly, significant in that they are the highest recorded in the program to date and are verified by two differcnt methods.

A drill-stem test was planned for the site but it was not run because of potential problems with the well caving. since the well was thought to be a producer in an existing. field the operator was understandably cautious.

3. Gas-In-Place and Deliverability Estimates

Using average gas content numbers and the thickness evaluation of $14 \mathrm{ft}$, the gas-in-place calculates to be 6.1 BCf per 640 acre section. Since the only parameters measured were depth, thickness, and gas content; the variability in deliverability is very large. The range is demonstrated on f'igure 1 . The cases shown are for 1.0 and 10.0 md permeability and the maximum and minimum relative permeability curves. Fracture length and conductivity are estimated to be $1000 \mathrm{ft}$ and $50000 \mathrm{md}-\mathrm{in}$, respectively. Pressure was estimated at hydrostatic. The estimated value for the deliverability parameter $\phi$ is between 25000 . and guUUu MCE.

4. Comments

The data set at. this location is far from. complete, but a significant amount of positive information was.obtained. First, the presence of high gas content coals was 
found in the Rocky Mountain Cretaceous Age coals. This, in itself, is a very significant discovery. Further, the high content was verified by two methods of coring. The sidewall cores give estimates comparable to the conventional cores.

B. Test Site B - Confidential Location

This site was made available by an operator who wished to keep the location and identity confidential.

\section{Location}

The location of this site is confidential. The only identifying characteristics are that the coals are in the Mesaverde Formation in the colorado area.

2. Tests Run and Results

The tests run on this well include logs, conventional cores, sidewall cores, and drill-stem tests. The logs included Compensated Neutron-Formation Density, Borehole Compensated Sonic, and Dual Induction Logs: These logs delineated the coalseams that exist from 3694-4980. A total of 95 feet of coal was identified in 16 individual beds.

Both conventional cores and sidewall cores were taken to determine gas content. Not nearly every coalbed was sampled but a significant number were. The gas content results are summarized in Table 2. The log depths are taken from Density Log. Two coalseams had both sidewall and conventional core samples. The gas content of the conventional cores is somewhat higher than that of the smaller sidewall samples.

Two drill-stem tests were taken. The upper interval tested was from 3700-3800 ft. This interval contains three coalbeds that contain a total of $12 \mathrm{ft}$ of coal. The test 
flowed gas to surface with a small blow. The recovery was 256 ft of water. Pressure extrapolated to 1642 psia, a gradient of $0.44 \mathrm{psi} / \mathrm{ft}$. Using the water recovery and the volume of the drill pipe, the analysis of the flow and pressure buildup data indicates a $\mathrm{kh}$ of $10 \mathrm{md}-\mathrm{ft}$. This would yield a permeability of 0.8 md if all twelve feet contributed to the flow. Further, the buildup indicated severe wellbore damage. This undoubtedly could be resolved with a stimulation treatment.

The second interval tested was from 4634-4714 ft. 'l'hese depths are driller's depths and correlate with the density $\log$ at 4646-4726. This interval contains two coalbeds which total 22 ft of thickness. Recovery was $4433 \mathrm{ft}$ of water. The recovery was fresh with chloride content of $700 \mathrm{ppm}$. There is a water sand just below the lower coal zone that could have contributed to the flow. This sand calculated $12 \%$ porosity and $100 \%$ water saturation with a considerable clay or shale content. These characteristics are thought to be such that this sand would not contribute to the flow significantly. Using the recovery to compute a flow rate and the pressure measurements a permeability thickness product, $k h$, of 21933 md-ft is calculated. $\Lambda \varepsilon-$ suming a thickness of $22 \mathrm{ft}$, the permeability calculates to be $1000 \mathrm{md}$. No wellbore damage was present. Initial pressure was 2043.4 psia.

This is the highest permeability ever assessed for a coalbed of any thickness. Further, the highest gas contents found in this well are in these same two coalbeds.

\section{Gas-In-Place and Deliverability}

The upper zone drill-stem test interval that demonstrated an initial pressure of 1642 psia unfortunately was not sampled for gas content. Some of the samples from the 
well fell approximately on the low adsorbtion isotherm and some on the medium isotherm. This would result in between 1.8 and $4.0 \mathrm{Bcf} / 640$ acres. These parameters would result in a range of deliverability as shown on Figure 2 . These give ranges of discounted gas deliverability, $\phi$, of 65000 Mcf to 16000 Mcf. Keep in mind this includes only the twelve foot interval covered by the drill-stem test.

Samples from the second DST interval fall close to the medium isotherm curve and calculate to contain $6.6 \mathrm{Bcf} / 640$ acres. The permeability falls outside the range of those investigated in the test program design. Simulations of this data set show that when permeability gets as high as $1000 \mathrm{md}$, the atmospheric pressure wellbore boundary condition is no longer realistic in terms of the water production rate necessary to maintain that pressure. Figure 3 is a plot of the deliverability projected for two relatively high water removal rates. Again, the external boundary is an infinite acting reservoir. A pattern of these wells would result in an elevated deliverability curve.

\section{Comments}

This well has the largest potential of all the wells found in the project. The high water production rates present both a production problem and a disposal problem. The key to making such a project work is to drill a large number of wells so that a sufficient water rate can be maintained. Careful planning must be done before attempting to complete the high permeability zones in this well.

C. Test Site C - Pittsburg County, Oklahoma

This site was made available by Arkla Exploration Company. The location of the site is section 2 - Township 6N - Range 13E, Pittsburg county, Oklahoma. 
1. Location and Geology

The well contains several coalbeds, most of them very thin. Through correlation with the information in "Geological Survey Bulletin 874", a coalbed at a depth of 2725 ft fits the description of the Upper Hartshorn Coalbed. The Lower Hartshorn coalbed is apparently missing. The upper coals at depths of 2127 and 1903 are probably those described as thin local coals scattered throughout the McAlester Shale.

The well itself is located in the Arkoma basin and was intended to penetrate the Hartshorn coals.

2. Tests and Results

The well was logged with a Dual Induction, Compensated Neutron-Formation Density, and Compensated Sonic Logs. The logs are of good quality and serve to identify the coalbeds. A total of $11 \mathrm{ft}$ of coal in four separate beds was identified.

Sidewall cores were taken and desorbed by Geochem Research, Inc. Three coalbeds were sampled at 1903, 2129, and 2725. The gas contents of the beds are estimated to be $4.09,6.6$, and $2.27 \mathrm{cc} / \mathrm{g}$ respectively. It is indeed unusual that the deepest coalbed has the lowest gas content. One problem was the method of sample containment. Several coal samples were contaminated with shale samples. Later procedures rectified this problem on other wells. .

One drill-stem test was run. The interval from 2700$2740 \mathrm{ft}$ was tested. This zone covers the coal called earlier as the Upper Hartshorn coalbed. The Hartshorn sandstone, a $45 \mathrm{ft}$ highly porous sandstone aquifer exists at $2754 \mathrm{ft}$. The DST interval was designed to prevent this sandstone member from contributing to the flow. Mechanically, the test was only a partial success. The upper inflatable packer failed to seat properly and mud flowing around the packer masked all 
reservoir flow. Attempts to reseat the packer were successful, but all quantitative calculations for permeability were rendered useless. The shut-in pressure does appear reliable. This pressure extrapolates to 735 . pisia, a gradient of only $0.26 \mathrm{psi} / \mathrm{ft}$.

Plans for a second DST were aborted because the hole was beginning to cave. This was monitored by excessive fill in the bottom of the hole with each trip into the hole.

3. Gas-In-Place and Deliverability Estimates

Using weighted average values for gas content the gasin-place is $1.4 \mathrm{BCf} / 640$ acres: Figure 4 represents the range of expected deliverability. The upper curve computes a discounted gas production, $\phi$, of 40000 Mcf and the lower curve computes a $\phi$ of. 3500 Mcf. This range was established using a maximum permeabjlity of 1.0 md and maximum relative permeability curve and the 0.1 md and minimum relative permeability curve.

\section{Comments}

Because of the relatively thin coalbeds and low gas contents, this site must be considered marginal at best. of all the parameters the thickness of only ll ft of coal scattered in four different beds has to be the most disappointing

D. Test Site D-Rio Blanco County, Colorado

This site consists of tests taken on three wells located in Sections 13, 14, and 28, T35, R101W, Rio Blanco County, Colorado. These three wells.were made available by Twin Arrow and Fuel Resources Development Company (Fuelco). 
1. Site Location and Geology

The site is located in the Piceance creek Basin and the coals are Cretaceous Age located in the Mesaverde Formation. The site is located in terrain that is very rough with steep canyons incised into the rock formations.

\section{Tests Run and Results}

Two wells were conventionally cored and a total of 11 coal samples were taken for desorbtion. The coals were all thin and widely scattered. For example, in the Twin Arrow \#2 Well a total of $7.9 \mathrm{ft}$ of coal was cored in a total of four seams over an interval of $192 \mathrm{ft}$. Nine samples were taken for desorbtion. The Fuelco well cored $4.5 \mathrm{ft}$ of coal in four seams in an interval of $143 \mathrm{ft}$. Two samples were taken for desorbtion.

Gas content is shown on rable 3 for the nine samples taken. Gas content is disappointing with all gas content less than one cubic centimeter per gram.

The Twin Arrow \#I Wcll was a Type II well and five intervals were perforated, acidized and flow tested. The intervals tested were the same as were cored in the Twin Arrow \#2. The flow test results were entirely negative with no flow reported, either gas or water.

\section{Gas-In-Place and Deliverability Estimates}

The gas-in-place can be computed using an average coal thickness of $6.2 \mathrm{ft}$ and an average gas content of $0.68 \mathrm{~cm}^{3} / \mathrm{g}\left(22 \mathrm{ft}^{3} / \mathrm{ton}\right)$. This yields a low gas content of 157 MMcf/640 acres. This, coupled with no flow from the Twin Arrow \#I yields a deliverability estimate of zero. 


\section{Comments}

The extremely negative data from this area may be due to the topography. If the coalseams are cut frequently by the canyons, the coal could have been degasified by natural means. Some anomaly must account. for these negative results because the Mesaverde coals have been shown to contain gas and have other characteristics that are favorable for significant gas production (see Test site $B$ ).

\section{E. Test Site E - Clay County, Illinois}

This site was made available by Hagen Oil Company and was drilled as a development well in an existing field.

\section{Location and Geology}

The site is located in the Illinois or Eastern Interior Basin near the deepest portion in Clay County. The series of coals penetrated consisted of the seelyville, No. 5 (Harrisburg), No. 5 a (Briar Hill), No. 6 (Herrin) and No. 7 (Danville). The lowest coal was at $1352 \mathrm{ft}$. The seams were very thin with only eight ft total thickness in five seams.

\section{Tests and Results}

The well was logged with Dual Induction-Laterolog, Compensated Neutron, Compensated Density, and Compensated Sonic. Four conventional cores were taken and a total of seven coal samples were recovered for desorbtion. Sidewall cores were attempted with very low recovery. Only one sample was recovered from the No. 6 (Herrin) seam. The desorbtion results are shown on Table 4 .

Three drill-stem tests were attempted. One test, the deepest at 1342 to 1354 did yield some recovery and pressures. This interval tested the seelyville coal. The test 
analysis yields questionable results because of the very small flowrates but it can be concluded that the perme-. ability is low, less than 2 md. Initial pressure is computed to be 569 psia which calculates to be almost a hydrostatic gradient. Further, the well appears to have little wellbore damage.

The second interval tested, 1071-1083, covered the No. 5a (Briar Hill) Seam. The results of this test were no recovery and little pressure buildup indicating no permeability. The third interval tested, 1026-1038, No. 6 (Herrin) seam showed that the packers did not seat causing the test to be useless.

3. Gas-In-Place and Deliverability Estimates

The gas content of the coal samples is very low with an average of about $0.7 \mathrm{~cm}^{3} / \mathrm{g}$ or $22 \mathrm{cuft} / \mathrm{ton}$. This content at 569 psia is much lower than any of the isotherms used in the sensitivity study. Based on eight feet of thirkness, the gas-in-place is only 200 MMcf/640 acres. Recognizing, the low permeability of the two seams tested, the deliverability has to be less than $10 \mathrm{Mcf} / \mathrm{d}$ making the potential of this site very low. A realistic value of $\phi$ is in the range of 1000 to 2000 Mcf.

\section{Comments}

The data set for this site is quite negative with very low gas content, permeability and thickness. Pressure ie cloce to normal with ncarly a hydrostatic gradienL. These parameters yield low estimates of deliverability. These same results were indicated in earlier publications by the U. S. Bureau of Mines (USBM RI 8043). 
One result was obtained that is of note. The single sidewall sample recovered did give nearly the same gas content that was obtained from the conventional core sample.

\section{F. Data From Other Locations}

Other data in the form of drill-stem tests and gas content measurements have been gleaned from outside knowledge and published literature. Most of these sites were known at the time the test program was developed; however, they are shown here as Table 5 for completeness.

Additional data on gas content measurements are available from the U. S. Bureau of Mines, Colorado Geological survey, and possibly the Illinois Geological survey. This data would include only the gas content measurements at random locations.

The data presented in Table 5 illustrates the ranges of the various parameters. These tend to substantiate the distributions assumed in the earlier report. 
III. TEST PROCEDURES

The test procedures utilized to date are the survey type tests that are basically the Module $I-1$ as described in the earlier report. The only exception is a Module II-2 test that had negative results.

\section{A. Gas Content Tests}

The gas content tests fall into two categories: conventional core samples and sidewall samples. The conventional cores have all been desorbed using the U. S. Bureau of Mines "direct method" (USBM RI 8043). The sidewall samples have been desorbed by a commercial Laboratory using a procedure developed to test drilling cuttings.

The problems with the conventional. cores have been primarily with time and cost. The process of cutting a core is slow and costly. Several days of time may be required to cut 100-150 ft' of core and rig costs may be in the range of $\$ 4,000$ per day.

'l'he sidewall cores are, on the other hand, very fast. The total job lasts only a few hours and samples from a several thousand foot interval can be taken. However, this method is not without problems: Poor coal recovery has been a severe problem plus mechanical problems with the coring tools themselves. From the experience to date, it appears that the best results occur in large diameter holes. The best mechanical recovery was at the Arkla Well (Site C) where the hole size was 10 inches. The Belco Well (Site $A$ ) where the hole size was 8 inches experienced considerably lower recovery. Experience outside the program in 6 inch holes has shown very poor recovery.

The second major problem is related to recovering coal as opposed to shale. Getting the sampler located adjacent to a one 
or two foot thick coalseam is not a simple matter. As the test engineers become more experienced, this will improve. Further, the tests are being run in localities where the service companies are not accustomed to running the sidewall samplers.

Comparisons of gas content measurements were discussed in the individual site discussions. It appears that both methods give reasonable gas content values and either method should be suitable.

\section{B. Drill-stem Tests}

Several drill-stem tests have been run with varying degrees of success. The problems encountered are not unique to the coal program. The most severe of these is zone isolation. This involves choosing a proper packer and placing the packers in the proper spot. Unfortunately, at two of the sites the coalbed to be tested was located in close proximity to an aquifer. In one case (Site C) it meant setting a packer in a very short interval. At another site (Site B) the aquifer was partially penetrated during the test which may mean that the aquifer was tested and not the coalbed.

Results of these tests have given good values of initial pressures and in some instances reasonable estimates of permeability. Unfortunately, there is no known substitute for this test. Costs are closely tied to rig time charges.

\section{Other Tests}

Only one other test was conducted and that was perforating, acidizing, and flow testing a well ready to be abandoned. The result was no flow. This may have been a problem with the test procedure, but more likely, there is little potential from the cual al that site (site D).

Several other tests are scheduled to be run such as isotherms and coal analyses, but these are not available at this point in time. 
Basically there have been three of the important parameters measured. These are gas content, pressure and permeability. While these are definitely the most important, some future information must be gathered about the others as well.

A. Gas Gentent

The expected ranges of gas content were developed using known data at that time. The resulting measurements are shown on Figgure 5. This chart shows the three isotherms assumed to develop the test program and the individual points that have been measured. If each. isotherm can be used to represent the groups indicated by the shaded areas, the assumption of equal probability appears reasonable. The points fall almost equally among the groups.

Again, correlation of gas content with rank cannot be completed because the coal analyses are not yet available.

B. Pressure

All pressure measurements have fallen in the ranges assumed for the test program with one exception. That exception was only 13\% higher than the highest pressure used.

Probably more important than the pressure measurement itself is the pressurc gradient which relates the pressure to the depth: The gradients calculated are all less than or equal to hydrostatic. These vary from 0.26 at site $C$ to .43 at Sites $B$ and $\mathrm{E}$ : No change in the pressure range is needed at this time. 


\section{Permeability}

The distribution of permeability used to develop the test program was assumed to be log normal with a log mean equivalent to about $5 \mathrm{md}$. The log mean of the permeability numbers is equivalent to about $13 \mathrm{md}$ for all measurements and about $9 \mathrm{md}$ if the one extremely large number for site $B$ is left out of the average: "Further, the problem with computing permeability from drill-stem tests is the measurement of flow rate. Since several tests were run that had flow rates too small to measure, the sampling of the permeability is biased toward the higher permeability sites.

For those reasons it is premature to attempt to revise the permeability distribution.

D. Other Parameters

Since no flow tests or hydraulic stimulations have been obtained in the program to date, these parameters must remain as developed in Volume $I$. 


\section{CONCLUSIONS AND RECOMMENDATIONS}

The conclusions that can be drawn from the testing in the 1978 program are listed below.

A. It is feasible to test the coals using wells being drilled for other purposes.

B. The test methods developed in work in the field and additional procedure refinements and operator experience will yield improved results.

C. The values of the parameters obtained are generally well within the ranges estimated. No reassessment of parameter distributions are necessary at this time.

D. No changes in the overall test program are needed at Lhis lime.

The recommendation is to proceed to accomplish the test program as developed in Volume I of this report. Some emphasis on tests in the basins not tested in 1978 is needed. These are the Powder River Basin and the Raton Basin.

The ongoing evaluation must be kept reasonably current with the test activities so that any "mid course correction" can be implemented in a timely manner. 
TABLES 
TABLE 1

GAS CONTENT MEASUREMENTS

SUBLETTE COUNTY, WYOMING

Log Depth ft

$3480-3483$ $3498-3501$ $3512-3511$
Gas content, $\mathrm{cm}^{3} / \mathrm{g}$ Conventional

10.5

13.1

11.9
Sidewall

$9.9-10.9$ 
TABLE 2

\section{GAS CONTENT MEASUREMENTS}

CONFIDENTIAL WELL

Log Depth. ft

$3928-3932$

$4658-4672$

$4716-4724$

$4804-4818$

$4860-4874$

$4972-4982$
Gas content, $\mathrm{cm}^{3} / \mathrm{g}^{*}$ : Conventional

Sidewall

$1.6 \quad(2)$

$7.2(6)$

$8.7(2)$
5.6 (1)

4.2. (1)

5.8 (1)

5.7 (3)

$4.6(6)$

* Average values, numbers in parenthesis indicate number of samples in the average. 
TABLE 3

GAS CONTENT MEASUREMENTS

TEST SITE D

RIO BLANCO COUNTY, COLORADO

Well

Twin Arrow \#2

Twin Ārow \#2

Twin Arrow \#2

Twin Arrow \#2

Twin Arrow \#2

Twin Arrow \#2

Twin Arrow \#2

Twin Arrow \#2

Fuelco

Fuelco
Location

S-T-R

$14-3 \mathrm{~S}-101 \mathrm{~W}$

$14-3 \mathrm{~s}-101 \mathrm{~W}$

$14-3 S-101 \mathrm{~W}$

$14-3 S-101 \mathrm{~W}$

$14-3 \mathrm{~S}-101 \mathrm{~W}$

$14-3 S-101 \mathrm{~W}$

$14-3 S-101 \mathrm{~W}$

$14-3 \mathrm{~S}-101 \mathrm{~W}$

$28-3 \mathrm{~S}-101 \mathrm{~W}$

28-3S-101W
Depth

ft

685

698

759

791

774

802

805

827

1585

1603
Gas Content $\mathrm{cm}^{3} / \mathrm{g}$

0.97

0.61

0.79

0.45

0.78

0.71

0.62

0.86

0.56

0.49 
'I'ABLE' 4

GAS CONTENT OF COAL SAMPLES

SITE E, CLAY COUNTYY, ILLINOIS

Sample
Depth

992

993

994

994

1034

1035

1075

1090

1352
Gas content, $\mathrm{cm}^{3} / \mathrm{g}$ Conventional Sidewall

0.71

0.87

0.88

0.51

0.57

0.26

0.45

0.81

1.25
Seam Name

No. 7 (Danville)

No. 7 (Danville)

No. 7 (Danville)

No. 7 (Danville)

No. 6 (Herrin)

No. 6 (Herrin)

No. $5 a$ (Briar Hill)

No. 5 (Harrisburg)

No. 4 (Seelyville) 
TABL.E 5

MITTINANE FROB:- CONI, PROUECT OATA FROM OUTSIJE: LUGATIONS
Site locistion

County, State

Munnngolia, w. Va.

Carbon, Utah

Alegheny, ra.

Alleghersy, Pa.

Alleglieny, Pa.

Allegheny, Pis.

Jefferson, Ala.

Marion, W. Va.

Buchanun, h. Va.

Tuscaluosa, Ala.

Washingeton, ra.

Green, Pa.

Green, Pa.

Green, Pa.

Green, Pa.

Green, Pa.

Green, Pa.

Westmorland, Pa.

\section{Coalbed}

$P 1$ : tsburgh

Castlegate $\|=$

U. Freeport

M. Klttanning

Clarion

Mezcer

Blue Creck.

P1rtsburgh

Pocohontas

Mary Lec/Bluz Ereek

Pittsburgh

Wa:nesburgh

Plttshurgh

Bakerstown
U. Freeport
M. Kittanning

L. Kittanning

Varlous

\begin{tabular}{|c|c|c|c|c|}
\hline $\begin{array}{l}\text { Depth } \\
\mathrm{ft}\end{array}$ & $\begin{array}{c}\text { Gas } \\
\text { Content } \\
\mathrm{cm}^{3} / \mathrm{g}\end{array}$ & $\begin{array}{c}\text { Pressince } \\
\text { lesid }\end{array}$ & $\begin{array}{c}\text { Permeab: } 1 \text { ity } \\
\text { md }\end{array}$ & $\begin{array}{l}\text { Fracture } \\
\text { Length }\end{array}$ \\
\hline $800 \pm$ & -- & 293.4 & 1.7 & --- \\
\hline $1000 \pm$ & 4.69 & $458 . .4$ & 0.1 & -- \\
\hline 730 & 1.80 & --- & --- & --- \\
\hline 8.30 & 5.10 & 296.4 & 69 & --- \\
\hline 980 & 2.90 & 336.4 & 39 & $\cdots$ \\
\hline 1150 & 1.60 & 489.4 & 42 & --- \\
\hline 1075 & 13.50 & 410.4 & -- & --- \\
\hline $900 \pm$ & 6.40 & 182.4 & 21 & --- \\
\hline 1380 & 13.60 & 598.4 & 7 & -- \\
\hline 1985 & 14.80 & 834.4 & 35 & $\cdots$ \\
\hline 429 & 4.40 & $160 . \dot{4}$ & 5 & 330 \\
\hline 329 & 1.04 & --- & -- & \\
\hline 422 & 1.95 & --- & -- & \\
\hline 825 & 7.60 & $-\cdots$ & --- & \\
\hline 1003 & 8. 30 & -- & +- & \\
\hline 1155 & 6.70 & -- & --- & \\
\hline 1201 & 13.20 & 409.8 & $0.5-1.0$ & -- \\
\hline $192-640$ & 1.160 (Avg) & 234.4 & $10(A \nabla g)$ & 1000 \\
\hline
\end{tabular}

USBYA Drill-Sten Tesit - No Rroord of Gas contcilt

USBil Drill-stem Tese - Full core, Direct Method Gas Centent

USB:A Drill-Sten Test - Full Core, Direct Method Cas Colitent

UISB: Drillwaren Test - Full Core,

Direct Mothod Cas Content

USBSI Drdl1-Sten Test - Full core,

Direct Nethod Gas Centent

USBi Dr1ll-Sten Test - Full core,

Direct. Method Gas Content

USB:y Drill-sten Test - Pressure

Uninterpreted for Permeability

USRYI Drill-St t:ra Test - Full Core,

Direct Mothoj Cas Content

USBM Drill-Stem Test - Full Core, Direct Method cas Cintent

full core blrect lethod has con-

tent, Injer. Te'st, Press. \& Perm.

llistory sackh of Dat.l in USBit

RI 8047

Sidewall Cores Desorbt in

Sidewall Cores Desorbt.Inn

Siduwall Cores Desorbtion

Sidewall Cores Desorbtion

Sidewall Cores Bẹsorbeion

Sidwall Cores Desorletion Injection Test

Average lialues for 12 cinajheds, Actual Flow Rates of $45 \mathrm{Mcf} / \mathrm{d})$ (Type III liell) 
FIGURES 
FIGURE 1

RANGE OF GAS DELIVERABILITY-SITE A

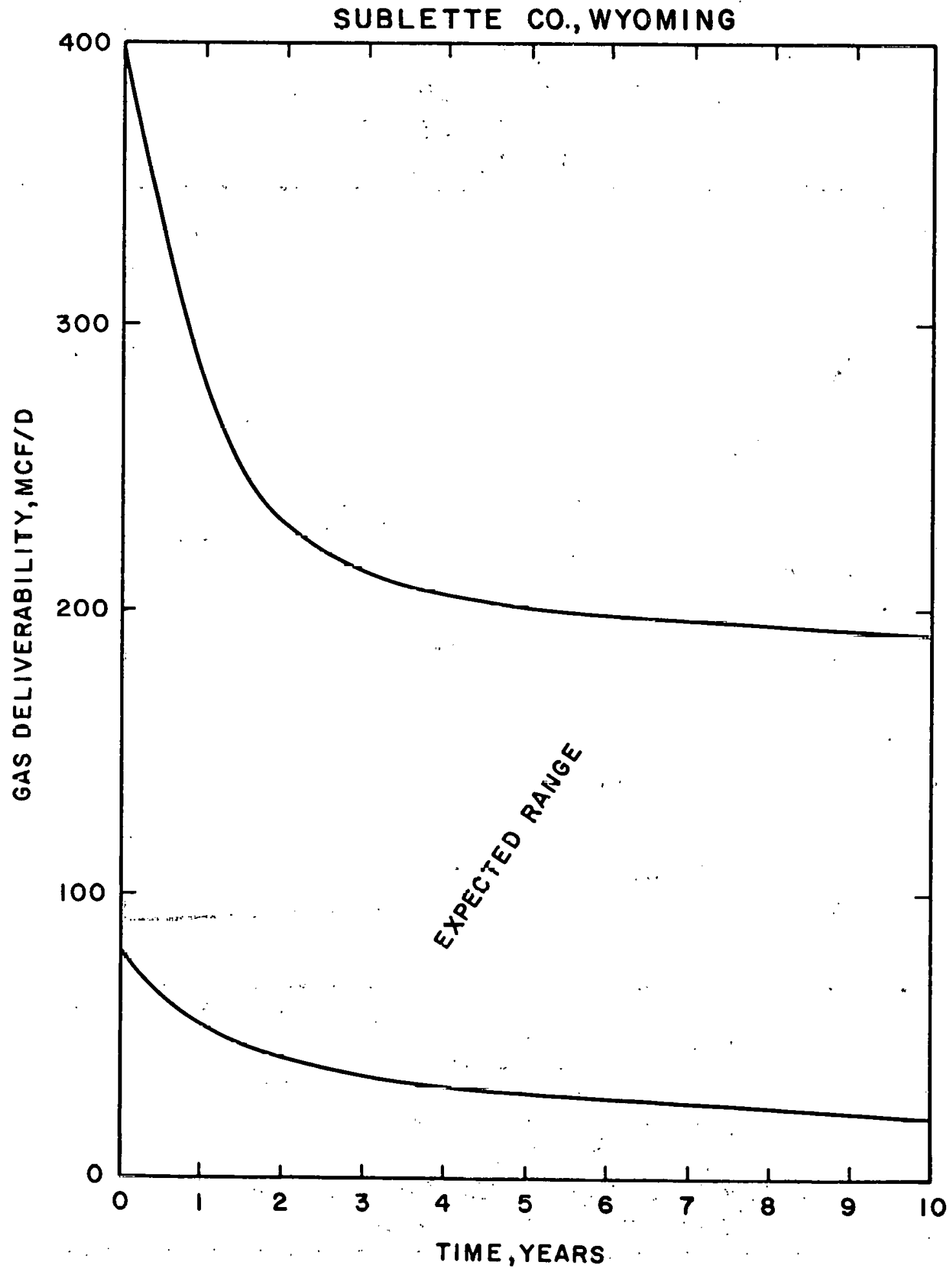


FIGURE 2

RANGE OF GAS DELIVERABILITY

TEST SITE B - UPPER ZONE

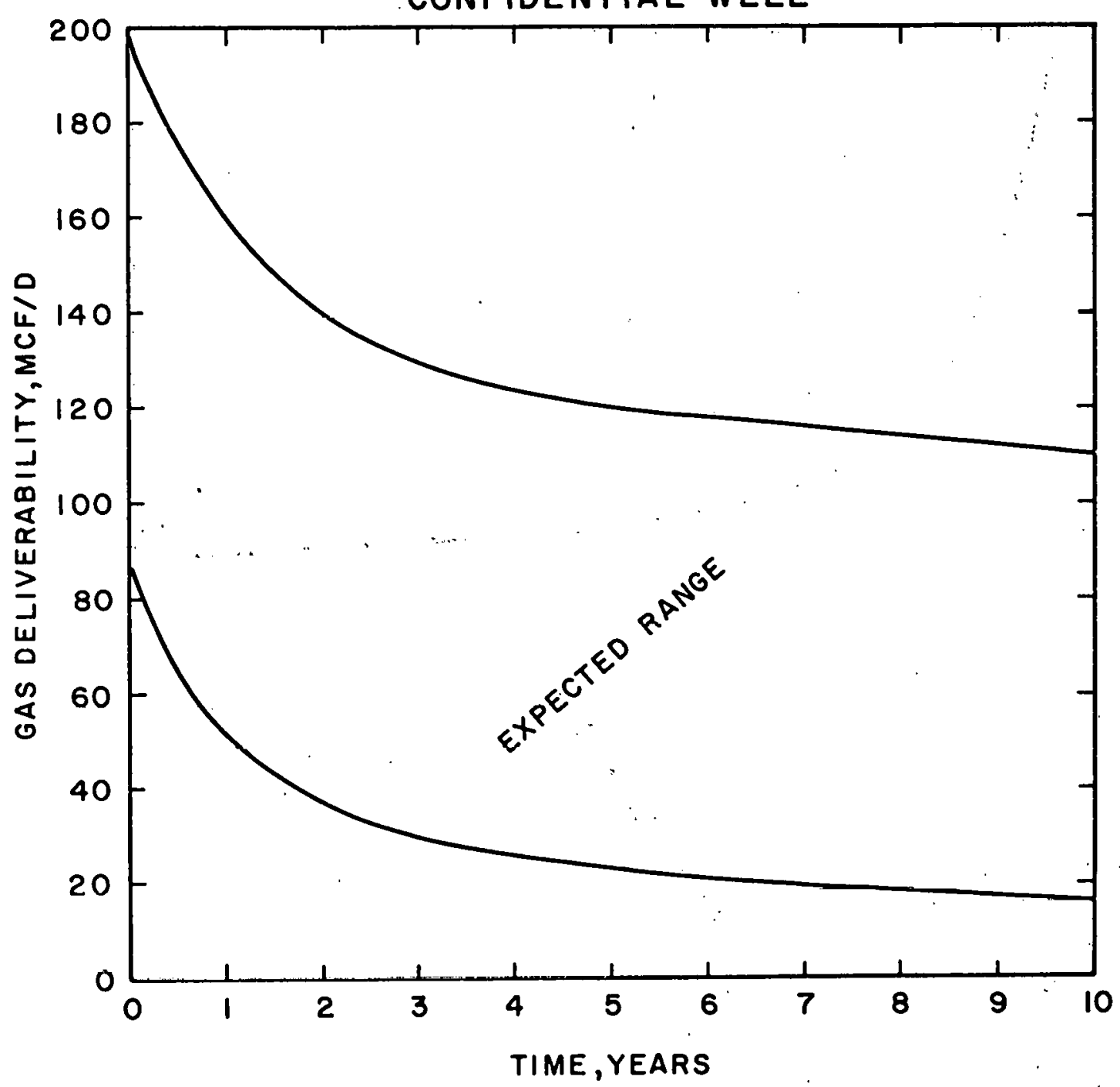


FIGURE 3

RANGE OF GAS DELIVERABILITY

TEST SITE B - LOWER ZONE

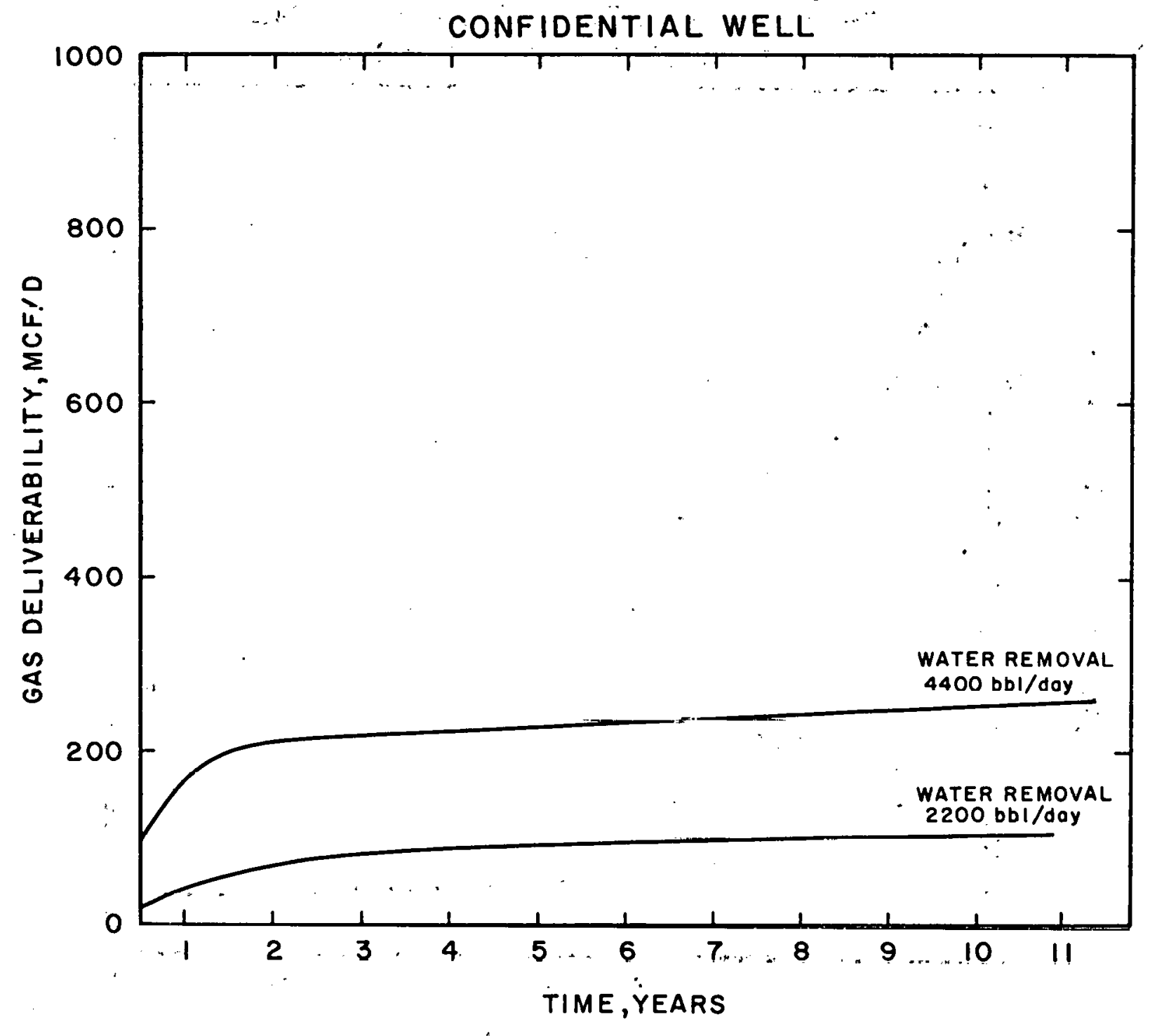


FIGURE 4

RANGE OF GAS DELIVERABILITY - SITE C PITTSBURGH CO., OKLAHOMA

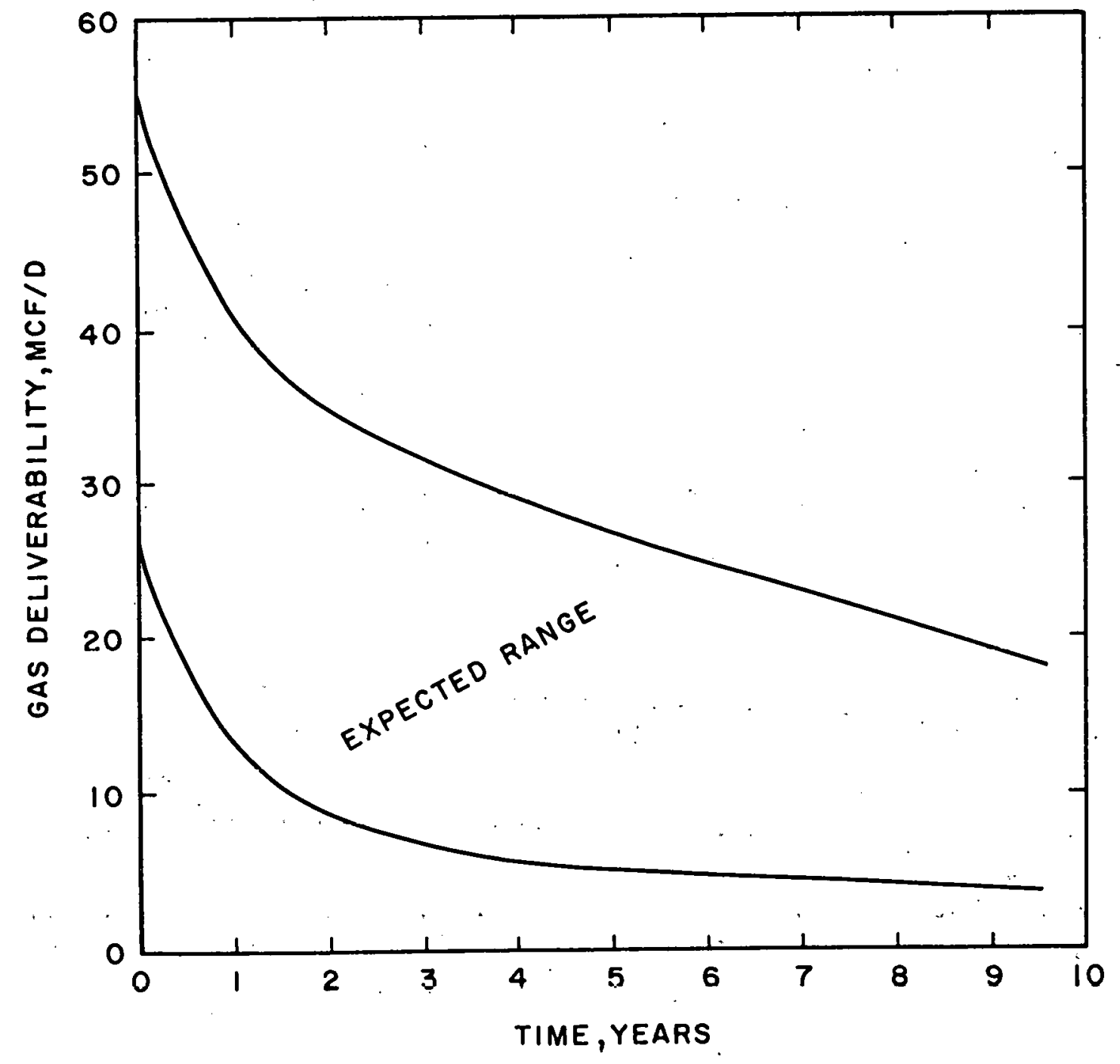




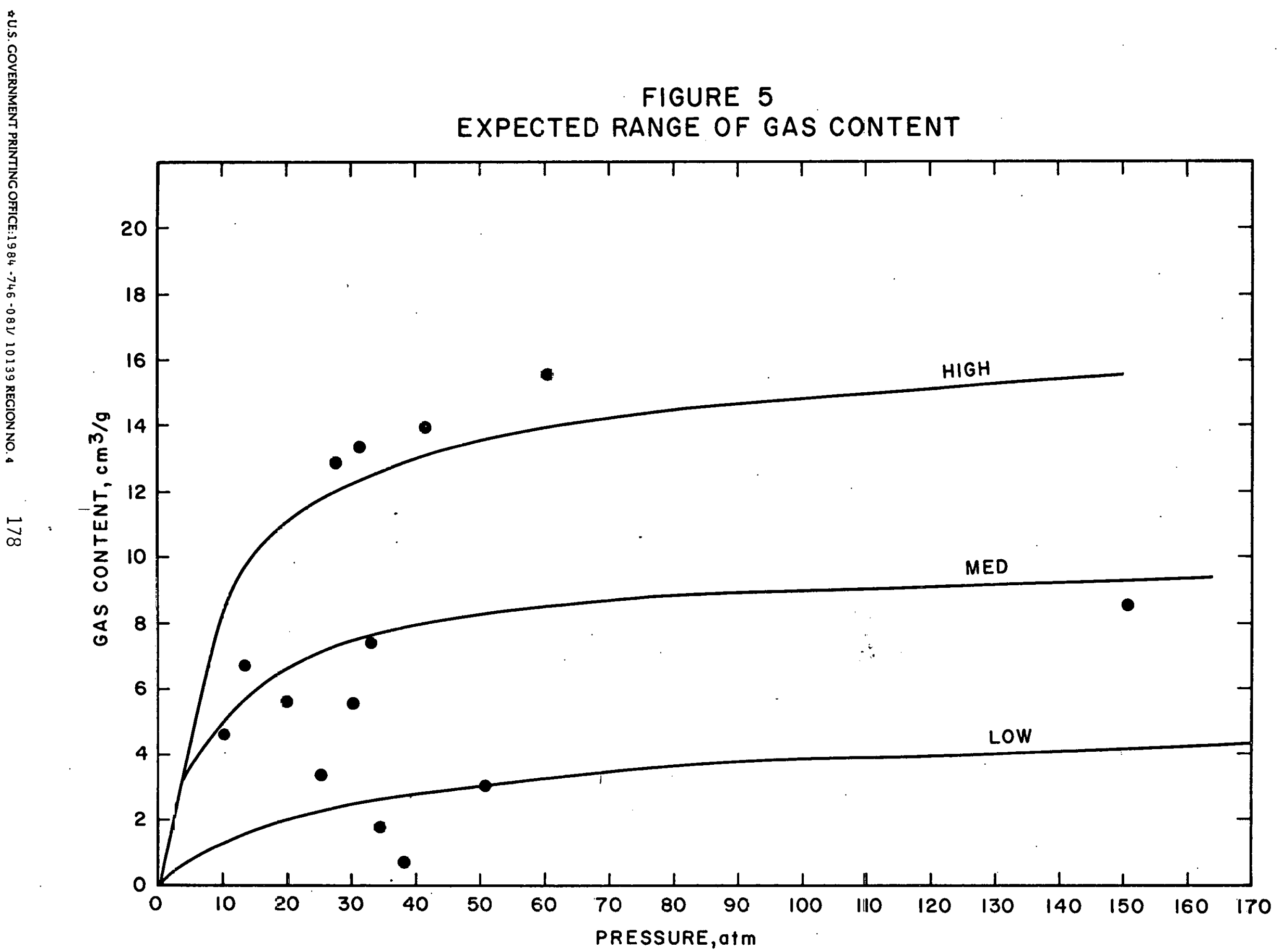

